\title{
Investigating the heterogeneity of violent crimes: A descriptive analysis of offence characteristics
}

\author{
By \\ Emma Leigh
}

\begin{abstract}
A thesis
submitted to Victoria University, Wellington in fulfilment of the requirements for the degree of Master of Science

in Forensic Psychology
\end{abstract}

Victoria University, Wellington

April 2014 


\begin{abstract}
Informed by theories on offending behaviour, violent offender rehabilitation programmes aim to provide treatment to a group of individuals who have committed a diverse range of offences, from assault to aggravated robbery to murder. Yet despite progress with specific offence types (e.g., homicide, robbery, assault), there is no research describing the offence chain characteristics of such a heterogeneous sample of violent offences. This exploratory study uses the structured approach of the Pathways Model of Assault (PMA; Chambers, 2006) to code and catalogue similarities and differences in the offence characteristics of an archival heterogeneous sample of violent offences. Cluster analysis was also utilised to investigate whether it was possible to construct a parsimonious series of pathways to represent the offence process for this diverse sample. The resultant model, the Pathways Model of Violent Offences (PMVO) was constructed and 12 pathways were revealed. The results suggest that upon initial investigation, there appear to be common, shared characteristics among a heterogeneous sample of violent offences.
\end{abstract}




\section{Acknowledgements}

I would like to thank the New Zealand Department of Corrections for permission to access the archival offence chains that made this study possible, and the staff at Wellington Psychological Services who welcomed me into their offices during the coding stage.

Special thanks go to my supervisor’s. Dr. Devon Polaschek thanks for your awesome support, guidance and flexibility, and Dr. Marc Wilson, for your much needed assistance with the stats. Thanks also to Victoria University, Wellington Scholarships.

Cheers to everyone in the Forensic Lab, your feedback and support was much appreciated. In particular, Morgan who spent hours talking me through cluster analysis, among other things.

Also to Jane, our entertaining procrastination breaks kept me sane.

Thanks to Sue, Wayne, Gus and Gethin who shared their home with me and looked after me over those last few months.

Most of all, thanks to Tony, for his constant support and unwavering belief in me. 


\section{Table of Contents}

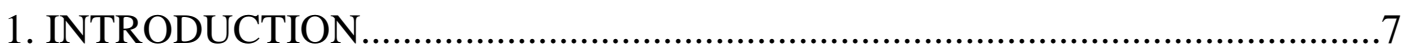

1.1 The Instrumental-Reactive Violence Dichotomy...................................9

1.2 Characteristics Associated with the Instrumental-Reactive Dichotomy..13

1.3 Descriptive Research on Violent Offences..............................................16

1.3.1 Relapse Prevention theory....................................................16

1.3.2 Offence process models.........................................................21

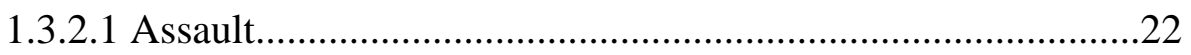

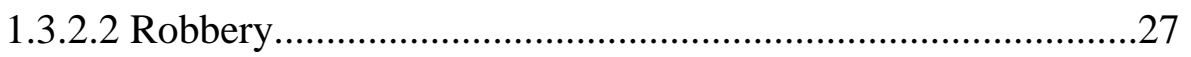

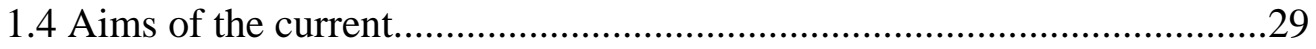

\section{STUDY 1}

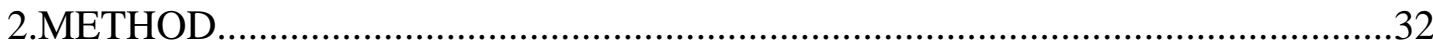

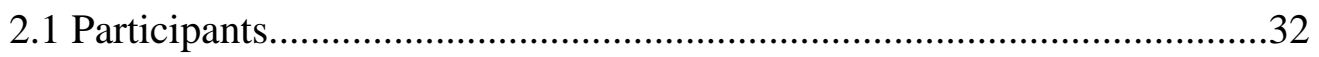

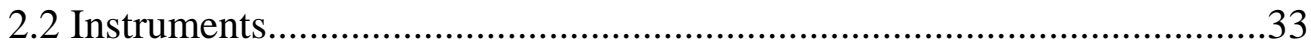

2.2.1 The coding scheme................................................................33

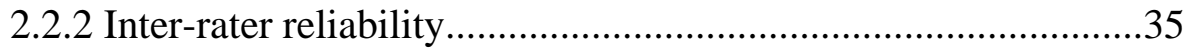

2.2.3 Coding scheme categories and variable definitions...................35

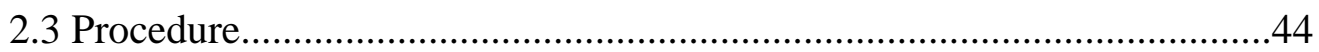

2.4 Data Preparation and Planned Analyses................................................45

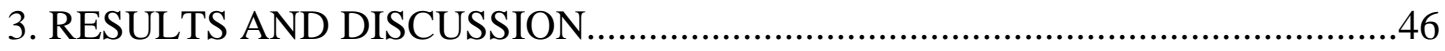

\section{STUDY 2}

4. METHOD. .67

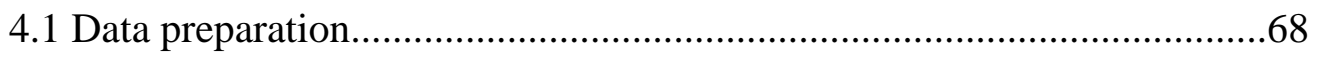

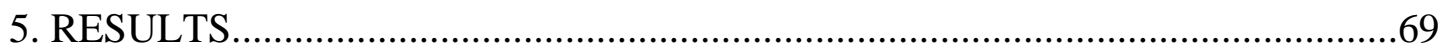

5.1 Cluster Characteristics for each Phase of the PMVO...............................73

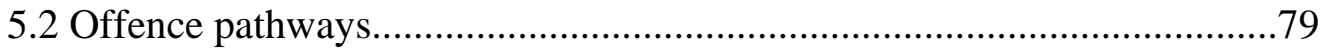




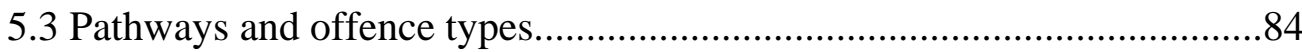

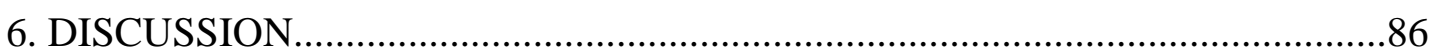

6.1 Expected and Unexpected Pathways.................................................87

6.2 Comparison of PMVO Pathways with the ARM and PMA....................92

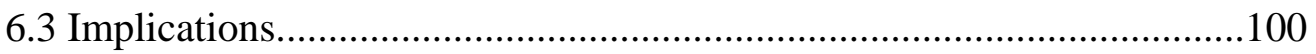

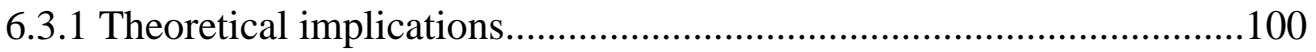

6.3.2 Treatment implications...................................................................102

6.4 Limitations and Future Research......................................................104

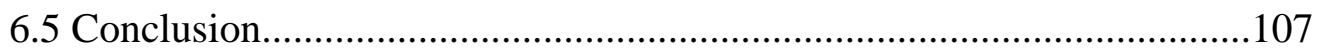

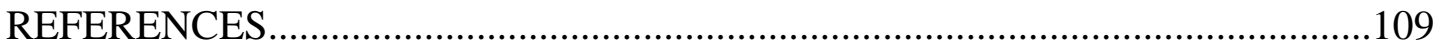

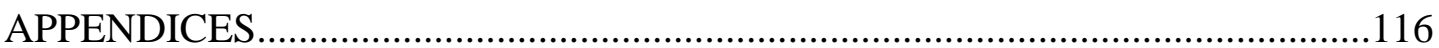

Appendix A-Ross-Oxnam Coding Scheme................................................116

Appendix B-Coding crib sheet for current study.....................................127

Appendix C-Full definitions of coding variables.......................................135

Appendix D-Breakdown of qualitative emotion data................................... 141

Appendix E-Coding crib sheet for cluster analysis......................................143

Appendix F-SPSS cluster analysis solutions..............................................152

\section{LIST OF TABLES}

Table 1. Offence Characteristics listed in Cornell’s (1996) Coding Guide for Violent

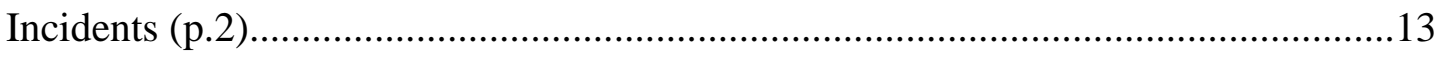

Table 2. Five Primary Routes through the Pathways Model of Assault (Chambers et al., 2009,

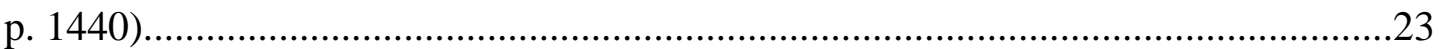

Table 3. Definitions of Variables Categorised under Lifestyle Characteristics...........36

Table 4.Definitions of Variables Categorised under Coping Strategies......................38

Table 5.Definitions of Variables Categorised under Precipitating Events..................39 
Table 6. Definitions of Goal Setting Variables.....................................................40

Table 7. Definitions of variables categorised under planning.................................41

Table 8. Definitions of Variables Categorised under Violence Enactments..............43

Table 9. Definitions of Variables Categorised under Evaluations............................44

Table 10. Pre-offence Lifestyle Characteristics.....................................................47

Table 11. Pre-offence Drug Use Information.........................................................49

Table 12. Pre-offence Coping Strategies.............................................................51

Table 13. Pre-offence Precipitating Events............................................................53

Table 14. Pre and During Offence Goal Setting....................................................54

Table 15. Pre and During Offence Planning Characteristics.....................................57

Table16. During the Offence Violence Enactments................................................60

Table 17. Offenders’ Emotions Noted Before, During and After the Offence..........63

Table 18. Post-offence Evaluation Characteristics................................................65

Table 19. Variables Included in Cluster Analyses...............................................70

Table 20. Six Main Routes through the Pathways Model of Violent Offences.........82

Table 21. Sub-pathway routes through the Pathways Model of Violent Offences....83

Table 22. Main Pathways by Offence Type............................................................84

\section{LIST OF FIGURES}

Figure 1. The Pathways Model of Assault (Chambers et al., 2009, p.1438)............23

Figure 2. A visual representation of the Pathways Model of Violent Offences.......72

Figure 3. The lifestyle and coping strategies phase..............................................73

Figure 4. The precipitating events and goal setting phase.....................................75

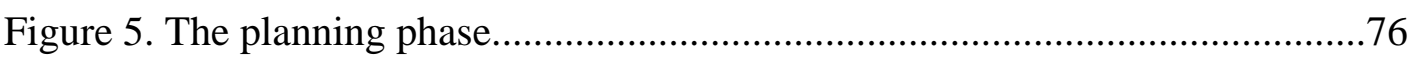

Figure 6. The violence enactments phase......................................................77

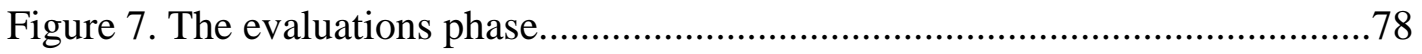




\section{Introduction}

Interpersonal violence is a pervasive phenomenon, which a brief look at both historical and present day media stories will attest. As a result of its consequences violence is also an important societal issue, highlighted by prison, crime and victim statistics. According to official statistics for 2011 the following number of offences were recorded by New Zealand Police; 83 homicide and related offences (e.g. attempted murder, murder, manslaughter), 42,278 assaults and other acts intended to cause injury, and finally 2,340 robberies (New Zealand Police, 2012).

It is also widely acknowledged that official reported offence figures such as these represent only the 'tip of the iceberg' of actual crimes committed (Walters \& Bradley, 2005). The true number of offence occurrences, the so-called 'dark figure' of violent crime is likely to be significantly higher than the official figure (Walters \& Bradley). The 'dark figure' is evidenced in the results of the latest New Zealand Crime and Safety Survey 2009 (NZCASS), a tri-annual survey of approximately 6000 New Zealand residents aged 15 or over. The survey asks participants about their experiences of victimisation and aims to capture information about crimes not reported to the police. The results of the NZCASS estimated the occurrence of 699,000 assault and threat incidents, and 58,000 robberies in 2009 (Morrison, Smith, \& Gregg, 2010). These figures are substantially higher than the 42,375 assault incidents and 2,507 robberies reported to the Police in 2009 (New Zealand Police, 2010).

An examination of the New Zealand prison population also reiterates the relevance of violence research. As of March 2012 the New Zealand prison population stood at 8698 offenders either sentenced or on remand (8187 of them were male). Of all convicted prisoners 40.5\% were convicted of violence offences (Department of Corrections, 2012).

In recent years considerable descriptive research has been conducted on violent offences. A popular approach to descriptive research has involved constructing models of the 
offence process from written narratives of an offender's index offence. The models use the offence characteristics to provide a detailed breakdown of the offence process. However, the vast majority of this type of research focuses on specific offence types, for example rape (Polaschek, Hudson, Ward \& Siegert, 2001), murder (Cassar, Ward \& Thakker, 2003), assault (Chambers, 2006; Chambers, Ward, Eccleston, \& Brown, 2009) and robbery (Nightingale, 2002).

One downside to the focus on specific offence types (e.g., robbery or assault) is that it has potentially led to the perpetuation of an urban myth that offenders are specialists; that is, that offenders tend to commit the same type of offence repeatedly. Yet previous research suggests that a 'specialised' offender is actually a rare phenomenon, (Polaschek, Wilson, Townsend, Daly, 2005; Simon, 1997), and the majority of offenders are actually criminally versatile (Simon). Furthermore, rehabilitation programmes in New Zealand often treat a group of offenders who have committed a diverse range of violent index offences, from assault to murder to robbery. Therefore, in addition to the focus on single offence types it would also be of benefit to gain a better understanding of the offence characteristics of a heterogeneous sample of violent offences.

In summary, violent crime will touch the lives of many New Zealanders. Research that aids the understanding of violence is of theoretical and practical relevance, particularly when that increased knowledge is applied to the effective rehabilitation of violent offenders (Murdoch, Vess, \& Ward, 2010). Yet despite progress in specific areas of violent offending such as homicide (Cassar, Ward \& Thakker, 2003), robbery (Nightingale, 2002) or assault (Chambers, 2006; Chambers et al., 2009), there is very little research that specifically describes the offence chain characteristics of a diverse sample of violent offences.

The current exploratory study examines the characteristics of violent offences using offenders' accounts of the incident. The aim is to provide a descriptive analysis of a 
heterogeneous sample of violent offences. Before progressing further it is worth addressing the definitions of aggression and violence relevant to this thesis.

Aggression and violence are words that have a tendency to be used interchangeably within the literature, but there are differences. There are various definitions but broadly speaking, aggression may be thought of as behaviours committed with the immediate (proximate) goal of inflicting physical or psychological harm on another person, where that person is motivated to avoid the harm (Bandura, 1973; Berkowitz, 1993; Bushman \& Anderson, 2001). Violence on the other hand, is commonly referred to as an extreme form of aggression (Bushman \& Anderson). Therefore all violent acts are aggressive, but not all aggressive acts (e.g., gossiping, yelling) are violent (Tapscott, Hancock, \& Hoaken, 2012).

The legality of the behaviour is also commonly used to clarify the difference between aggression and violence, with behaviours punishable by law referred to as violence (Patrick \& Zempolich, 1998). Given that the focus of the current study is on the violent offences of convicted offenders, the term violence, rather than aggression will be used in this thesis other than during the review of existing literature, where the original terminology will be used. Beyond simply defining violence and aggression, the sheer diversity of violence also presents a fundamental challenge to researchers. In order to make sense of this diversity a popular method of conceptualising violence has been to develop different typologies. The instrumental-reactive violence dichotomy is one such typology and this is outlined in the following sections.

\section{Overview of the Instrumental-Reactive Violence Dichotomy}

The manner in which violent behaviour is, and has been conceptualised over the years is an ongoing debate. Over the years a variety of different typologies have been posed, a discussion of which is well beyond the scope of this thesis (for a brief overview of the typologies see Ramirez, Rodriguez, \& Manuel, 2003). However, for the purposes of the 
current research the distinction between instrumental and reactive violence is a useful conceptualisation. The instrumental-reactive dichotomy also remains a popular and pervasive method of categorisation (Bushman \& Anderson, 2001), and there is some support for this distinction (e.g., Cornell, 1996). The next section briefly outlines the instrumental- reactive violence dichotomy, its criticisms and some suggestions for improvement.

Reactive aggression has generally been described as impulsive, unplanned and angry aggression occurring in response to perceived provocation. Reactive aggression is also sometimes referred to as hostile, impulsive or affective aggression; the ultimate goal of this type of aggression is to inflict harm on another person (Anderson \& Bushman, 2002). In research, reactive aggression has been operationalised as occurring in an interpersonal conflict involving an absence of planning or goals (Cornell, Warren, Hawk, Stafford, Oram, \& Pine, 1996). In contrast, instrumental aggression is generally described as planned, premeditated aggression used to achieve some other goal beyond that of harm (Berkowitz, 1993). In research, instrumental violence has been operationalised as planned, goal-driven violence with an absence of provocation (Cornell, et al.).

Whilst there is still support for the usefulness of the reactive-instrumental dichotomy (e.g., Fontaine, 2007), there are also those who argue against it (e.g., Anderson \& Bushman, 2001). The arguments against the dichotomy generally relate to the fact that it "may oversimplify a highly complex behaviour with multiple motivations and manifestations” (Woodworth \& Porter, 2002, p. 437). For example, robbery where the primary goal is material gain has been described as "perhaps the prototype of instrumental violence" (Campbell \& Muncer, 1994, p. 338). However, we need to remember that such things are seldom so straightforward. In particular, Campbell and Muncer refer to the potential secondary gains of robbery, such as victim humiliation, power, or a hedonistic lifestyle, which are more commonly perceived as goals of reactive violence. 
In addition, a number of studies have also found that violent behaviour often consists of a mixture of instrumental and reactive elements. For example, in a study by Barrett and Felthous (2003) 40\% of an offender sample committed either mostly impulsive or mostly premeditated acts while the remaining $60 \%$, the majority, committed acts that were a mixture of both. Similarly Cornell et al. (1996) found that a review of offenders’ offence histories indicated that most, if not all offenders with a history of instrumental offences also had a history of reactive offences, and that some crimes had an element of both types of aggression. Cornell suggested that this mixed aggression history was consistent with the views of Anderson and Bushman (2001) who posit that reactive violence is a broader more heterogeneous phenomenon than instrumental violence.

Meloy (1997) suggests an offence that presents a mixture of instrumental and reactive elements may occur as a result of physical proximity of the offender and victims. For instance, a primarily instrumental violent offence such as robbery may evolve into a reactive offence if some unplanned event occurs which invokes a response to feelings of fear or anger felt by the offender (e.g., a bank robber demands money from a teller who resists the demand, this leads the offender to shoot the teller).

Conversely, a reactive offence such as assault may evolve into an instrumental offence when the offender wishes to further punish the victim (e.g., during a unplanned assault the offender goes on to steal the victim's wallet) (Meloy, 1997). Thus there are situations where offenders will commit offences, which demonstrate mixed elements of instrumental and reactive violence (Weinshenker \& Siegel, 2002).

As a result of this complexity and the diversity of violent offending, an inflexible approach to the instrumental-reactive violence dichotomy could indeed present categorisation problems. One proposed solution to this problem is to consider instrumental and reactive aggression together as a single dimension, with each type of aggression located at opposite 
ends of a continuum. Arguably this would help accommodate those violent events that appear to demonstrate elements of each type of aggression (Chambers, 2006; Woodworth \& Porter, 2002).

Bushman and Anderson (2001) also propose a refinement. They suggest distinguishing aggression by the proximate and ultimate goal of the violence. Using assault as an example of reactive violence and robbery as an example of instrumental violence, Bushman and Anderson state that both offences are acts of aggression because in both offences the victim is harmed. That is, they both have the proximate goal of harm, yet they differ in ultimate goals. The ultimate goal of robbery is often material gain, yet both the proximate and ultimate goal of assault is generally to cause harm (Bushman \& Anderson). Bushman and Anderson therefore suggest that use of proximate and ultimate goals still allows for discussion of instrumental and reactive aggression, but it also has the capacity to accommodate incidents where there are elements of both.

Alternatively, studies that developed self-report instruments to rate aggressive behaviours have highlighted that perhaps the two types of aggression should be considered as two separate dimensions. For example, Stanford, Houston, Villemarette-Pitman, and Greve, (2003) used a 30-item self-report instrument to rate aggressive behaviours in a male community sample $(n=93)$ over a 6 month period. Behaviours were rated on two separate dimensions, predominantly impulsive or predominantly premeditated. Essentially, the results revealed that whilst both types of aggression could be differentiated on certain correlates, they also shared many correlates.

In summary, despite the on-going debate surrounding the reactive-instrumental dichotomy, it still provides a useful conceptualisation of violence for the purposes of the current study. In order to decide whether the use of violence is instrumental or reactive, along with considering the offence as a whole, relevant characteristics of the offence are often 
examined. The following section provides a brief overview of the offence characteristics often associated with, or used to distinguish between reactive and instrumental violence. Characteristics Commonly Associated with Reactive and Instrumental Violence

A positive aspect of the on-going instrumental-reactive violence dichotomy debate is the volume of research it generates. As a result there is a substantial body of literature on this subject, but in keeping with the aims of the current study the focus will remain on characteristics more proximate to the offence (e.g., planning, provocation, violence severity).

Cornell et al. (1996) conducted a study that aimed to test the hypothesis that offence characteristics and psychopathy measures can differentiate between offenders who commit instrumentally violent offences versus reactively violent offences. In order to explore the offence characteristics element of the research Cornell (1996) developed a coding guide based on eight offence characteristics with a view to clarifying the distinction between instrumental and reactive violence. According to Cornell (1996), of the eight characteristics listed in Table 1 below the first four proved particularly useful in differentiating between the two types of violence.

Table 1.

Offence Characteristics listed in Cornell's (1996) Coding Guide for Violent Incidents (p.2)

Offence characteristics and description

Planning

Goal-directedness

Provocation

Arousal

Severity of violence
Degree of premeditation or preparation for aggression

Degree to which aggression is motivated by some external gain or incentive such as money

Degree of provocation, frustration or threat from victim

Degree of anger experienced by aggressor

Degree of injury to victim 
Relationship to victim Closeness of relationship between victim and aggressor

Intoxication

Intoxication on drugs or alcohol during incident

Psychosis

Presence of psychotic symptoms during incident

This coding guide, and therefore the offence characteristics listed above now appear to provide a basis for numerous studies examining instrumental and reactive violence (e.g., Broomhall 2005; Tapscott, Hancock, \& Hoaken, 2012; Woodworth \& Porter, 2002). The original study by Cornell et al. (1996) that led to the development of the coding guide is reviewed below.

In a two-part study Cornell et al. (1996) aimed to test the hypothesis that offence characteristics and psychopathy measures can differentiate between offenders who commit instrumentally violent offences versus reactively violent offences. In Study 1 the 106 male offenders convicted of a diverse range of offences (e.g., murder, assault, robbery, fraud) were divided into 3 groups, instrumental, reactive or nonviolent. Of the violent offenders, 32 offenders were selected for the instrumental violence group as they had a history of at least one instrumentally violent offence. Thirty-six offenders were selected for the reactive violence group on the basis they had no previous history of instrumental violence within their offending history.

Ultimately this means that this study compared a reactive-only violence group with a group of offenders who likely utilise both instrumental and reactive violence. Cornell et al. found reactive violence to be so pervasive across the sample that the presence of instrumental violence was considered as a different, more advanced form of aggression. For relevance to the current study the focus will remain on their findings in relation to offence characteristics.

To clarify the distinction between reactive and instrumental violence, raters used file information to code each offender's most recent offence on six offence characteristics: planning, goal-directedness, provocation, anger, victim injury, and victim relationship. 
Chi-square analyses on the violence classification (i.e., reactive, instrumental or nonviolent) and the six offence characteristics were carried out on a subsample of 50 offenders chosen because a detailed offence narrative was available for their most recent offence. The results revealed that instrumental offenders were more likely to plan their offence and have an identifiable goal. In contrast, reactive-only offenders were more likely to know their victim, to have felt provoked and to have acted in anger.

Study 2 used a further sample of 50 violent offenders referred for pre-trial evaluation. On this occasion offenders were classified as instrumentally or reactively violent offenders and once again their most recent offence was coded on the six characteristics. Instead of using file information, data on the offenders was gathered during a process of extensive interviewing and testing of the offenders, as well as corroboration from other collateral sources where possible.

As in Study 1, chi-square analyses were conducted to evaluate the association between reactive and violent overall classification and the six offence characteristics. The results in this case indicated instrumental offenders were more likely to have an identifiable goal (e.g., robbery) but were not more likely to plan their offence. Reactive offenders were more likely to have a close relationship with the victim, to have felt provoked and act in anger.

With this study Cornell et al. (1996) tried to illuminate the differences of the oftdiscussed distinction between instrumental and reactive violence. Instead, what they did find was that "the distinction between instrumental and reactive violence is not absolute" (p. 788). They found offenders classified as either reactive or instrumental sometimes committed offences that began as reactive or instrumental but evolved into the other type of violence during the offence process. However, they did report that instrumental offences were overall 
best differentiated from reactive offences by the presence of an identifiable goal. In addition, reactive offenders were more likely to know their victims, feel angry and provoked.

Although the Cornell et al. (1996) study has been reviewed in greater detail, among the wider literature there is support for the association of a number of characteristics with the two types of violence. In summary, the following offence characteristics are commonly associated with instrumental violence in the literature: goal-directedness (Berkowitz, 1993; Cornell et al., 1996; Weinshenker \& Siegel, 2002), premeditation or a level of planning (e.g., Cornell et al., 1996), a lack of emotional arousal (e.g., Stanford et al., 2003) and an absence of perceived provocation (e.g., Meloy, 1997).

In contrast, characteristics commonly associated with reactive violence include emotional arousal, a lack of planning, a level of perceived provocation and a main goal of causing harm to the victim (e.g., Broomhall, 2005; Cornell et al., 1996). In addition, in response to Berkowitz (1993) suggestion that instrumental offenders are more likely to use

only as much force as necessary to achieve their goal, Tapscott, Hancock and Hoaken (2012) hypothesised that reactive offences would be more serious in terms of victim injury than instrumental offences. Using information from 188 offences obtained from 71 medium-risk offenders Tapscott, Hancock and Hoaken found support for Berkowitz (1993) hypothesis. Reactive offences did demonstrate a greater severity of violence than instrumental offences. Having considered the instrumental-reactive violence dichotomy and the relevant associated offence characteristics, the following section reviews the descriptive research on violent offences.

\section{Descriptive Research on Violent Offences}

Relapse Prevention theory. Before covering the existing literature on violent offences it is worthwhile commenting on relapse prevention theory and the relapse prevention model, herein referred to as RP theory or the RP model. The RP approach of the 1980's 
inspired a wave of the more recent research into offence processes, and made a very important contribution to sex offender treatment. Over time this contribution generalised to treatment and research with violent offenders.

RP theory and the subsequent model was originally developed from, and used with success, in the substance abuse arena. The RP model was based on research on the antecedents of a relapse (Marlatt \& Gordon, 1985). Essentially, in the addiction arena the sequence of events leading up to a relapse is studied in a bid to isolate critical points and identify high-risk situations. The aim is to provide education and insight into an individual's behaviour so they can understand and recognise the warning signs indicating a relapse (Zamble \& Quinsey, 1997). An RP treatment approach aims to increase self-efficacy, coping skills and motivation to maintain behavioural change (Zamble \& Quinsey, 1997). Pithers, Marques, Gibat, and Marlatt (1983) were then responsible for the theory being transferred to the criminal-offending arena when they adapted it for use with sexual offenders. The use of the RP approach soon spread and it became a popular framework for sexual and non-sexual offender treatment programmes (Polaschek, 2003).

However, there were a number of problems in those early days. The underlying issue revolved around the RP model being derived from work on substance abuse. As a result, the RP model was based on a set of substance abuse focused assumptions that research eventually revealed was not always relevant in the criminal-offending arena (Polaschek, 2003). For example, the RP model assumes the client is committed to avoiding the problem behaviour, yet sex offender researchers discovered that some sex offenders found offending a positive process and as such fully intended to commit further offences (Ward, Louden, Hudson \& Marshall, 1995).

The need for better refinement of the RP approach for use with offenders of a variety of offence types has significantly contributed to the literature by inspiring a wave of research. 
In particular, much descriptive research that focuses on specific offences has been conducted, such as rape, (Polaschek, 2001), homicide, (Cassar et al., 2003) and assault (Chambers, 2006; Chambers et al., 2009). Ultimately, the RP approach highlighted the importance of breaking down the offence process to provide a detailed temporal sequence of the behavioural, emotional and cognitive elements of the offence from pre-offence to postoffence (Polaschek, 2003).

In summary, use of the RP approach in the criminal-offending arena, acknowledges the differences between addiction and criminal offending but still utilises the original principles. The breaking down of an offence process can still be usefully applied to guide investigation into the process of violent offence recidivism and help identify individual treatment needs (Zamble \& Quinsey, 1997). The following section outlines some of the relevant descriptive literature inspired to some degree by use of the RP approach in the violent offending domain.

There is actually a dearth of research that seeks to document common processes across different types of violent offending. This lack of research is both surprising and of relevance since research suggests it is uncommon to find an offender who specialises in one type of offence (Simon, 1997). Furthermore, New Zealand based rehabilitation programmes often provide treatment to a group of offenders who have individually and collectively committed a variety of index offences,

However, there is one significant contribution to this literature, provided by Zamble and Quinsey (1997) in a study on the criminal recidivism process. The majority of the remaining literature tends to be offence specific, and a popular approach to this type of descriptive research is from the RP inspired construction of offence process models. The following paragraphs firstly outline the work done by Zamble and Quinsey on the criminal recidivism process, and follow with examples of relevant specific offence process models. 
Zamble and Quinsey (1997) conducted a Canadian based study on recent recidivists ( $n=311)$. They included participants who had committed a new serious offence (determined by a sentence length of at least 2 years) and as such returned to prison within a year of their last release. The focus of the research was gaining information about an offender's most recent offence, the new offence. The researchers used a heterogeneous sample consisting of approximately one third of offenders convicted of assault, one third convicted of robbery and one third convicted of property offences. With difficulty, a small comparison group of nonrecidivists was also recruited $(n=36)$.

The retrospective study focused mainly on the antecedents of the new offence and included numerous measures: for example, age, previous convictions, and lifestyle measures such as relationships, living arrangements, employment, and substance use. Information on a limited number of more proximate aspects of the offence process itself was also investigated: for example, planning, consideration of outcomes, and thoughts about the victim. The researchers were also interested in recidivists' thoughts, emotions and goals, and they collected the data from a number of different sources such as structured interviews with participants, questionnaires and file information.

The descriptive results of the study were reported for the whole sample, with the researchers concluding that for the majority of the participants, life out of prison was difficult. The participants had all the usual hassles of daily life in addition to specific problems associated with release from prison; such as reintegration and limited employment opportunities. Still using the information reported about an offender's most recent offence Zamble and Quinsey went on to make a number of comparisons. They found there were substantial differences between recidivists and non-recidivists in almost all areas they examined: for example, personal background, coping, emotional reactions, and problems experienced. 
Using the same data, further comparisons were made between subtypes within each offender group (e.g., violent vs. non-violent theft offenders, and among assault offenders i.e., rapists vs. others). The results indicated that to some extent it is possible to identify distinct precursors to related types of offending, but due to issues with sample size and missing data the researchers were unable to form strong conclusions. A final set of comparisons was made between offence types.

In line with previous research on offender heterogeneity (e.g., Simon, 1997), Zamble and Quinsey found the majority of offenders had committed all the different offence types (assault, property and robbery) at some point in their criminal careers. Despite this fact they separated participants by most recent offence type (i.e., the offence that they are in prison for at time of recruitment for study). Three offender groups were identified; assault, property offences and robbery.

Comparisons of the three offender groups revealed the groups could be differentiated on both their antecedents and during-the-offence process variables: particularly the robbery and assault groups. This differentiation between offence types led Zamble and Quinsey (1997) to argue that there are distinct pathways that lead up to the commission of different types of offence. In other words, an offender who ends up committing a robbery will follow a different pathway to that robbery than an offender who ends up committing an assault, even if historically they have committed both types of offence.

It does make some intuitive sense that perhaps a particular combination of psychological and environmental events influences the commission of one type of crime over another (which in turn influences the during-the-offence process variables). Whilst it is clear the offenders within Zamble and Quinsey’s sample demonstrated different pathways as a function of offence type, this is still only based on a single offence per offender. We cannot know for sure what pathways those offender's may follow next time they offend. A 
longitudinal study collecting data from an offender group who each commit a variety of crimes is really needed to take Zamble and Quinsey’s argument beyond a hypothesis.

Having said that, the Zamble and Quinsey study is an exploratory study and by studying the sample as a whole it contributes important knowledge about the offence process of a diverse sample of violent offenders and offences. In addition, the later separation of the data by both offence type and offence sub-type also contributes to the specific offence literature. There are however some methodological considerations and limitations to be aware of in this study, beyond the already mentioned need for a longitudinal study.

Firstly, whilst the use of self-report data from the perspective of the offender shouldn’t be underestimated (Camp, Skeem, Barchard, Lilienfeld, \& Poythress, 2013), selfreport data carries with it the possibility of poor recall, as well as biased and/or untrue recollection of events (Wright \& Bennett, 1990). Secondly, there was no non-criminal control group. For comparison, perhaps a non-criminal control group matched on age and where possible reflecting a representative mix of background characteristics (e.g., education levels, employment levels, substance use) could have been scored on antecedent variables. In addition, due to difficulties with recruitment the sample size of the non-recidivist comparison group was small $(n=36)$. Thus, any comparisons between recidivists and non-recidivists should be interpreted with caution.

Offence process models. The utility of the offence process model was originally realised in the context of addiction with the development of the RP approach (Marlatt \& Gordon, 1985). Offence process models aim to provide a knowledge and understanding of the stages and processes that lead to offending, and as a result allow treatment and interventions to be better targeted and also sensitive to individual needs (Chambers, 2006). The offence process model approach has been used to focus on specific offence types, such as sex offending (e.g., Laws, 1989; Pithers, 1990; Ward et al., 1995), rape (Polaschek et al., 2001), 
homicide (Cassar et al., 2003), assault (Chambers, 2006; Chambers et al., 2009) and robbery (Nightingale, 2002).

Offence process models are descriptive models created using a bottom up approach. That is, they are constructed from the data collected from offenders using grounded theory, a systematic method that builds theory about a phenomenon from the data itself (see method for further detail on grounded theory). The models are constructed from offender narratives of the offence and they represent a model of the offence as a temporal process (Chambers, 2006). Essentially, an offence process model dissects the offence via sequential stages that incorporates the development of violent behaviour, lifestyle preceding the offence, behaviours during the offence, as well as post-offence behaviours. Offences are then traced through the model according to their characteristics, and the final route each offence follows is commonly referred to as a pathway (e.g., Chambers, 2006; Nightingale, 2002). As a result there may be multiple different pathways associated with a descriptive offence process model.

Two offence process models of particular relevance to the violent offence literature and the current study are outlined below. The first, the Pathways Model of Assault (PMA; Chambers, 2006; Chambers et al., 2009) focuses on assault offences. The PMA is of particular interest as it was also used as a framework to guide the development of the current research. The second offence process model focuses on robbery offences.

Assault. The PMA (Chambers, 2006) was constructed using offence transcripts obtained from 35 male offenders residing in two maximum-security prisons in Victoria, Australia. All offenders had been convicted of one of three offences: assault causing injury, assault causing serious injury, or assault other. Offenders were selected to participate in the study only if the main goal of the assault was to harm the victim (if the assault occurred during another offence the offender was excluded). 
The PMA represents a "sequential model of the offence of assault” (Chambers, 2006, p. 75), and consists of 14 categories, which are displayed, in Figure 1 below.

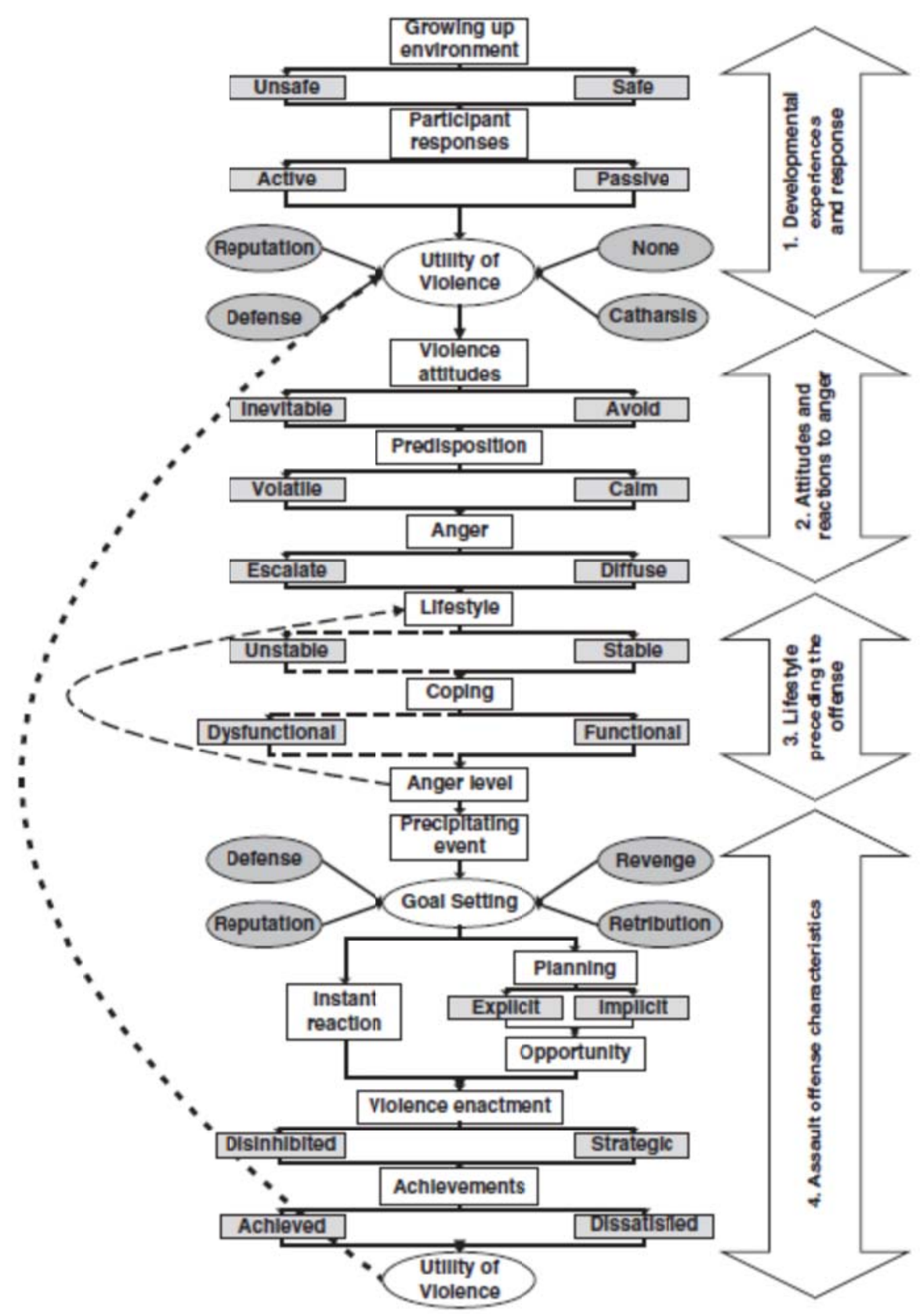

Figure 1. The Pathways Model of Assault (Chambers et al., 2009, p.1438)

Chambers found five major pathways through the PMA, the routes of which are displayed in Table 2 below. 
Table 2.

Five Primary Routes through the Pathways Model of Assault (Chambers et al., 2009, p. 1440)

\begin{tabular}{|c|c|c|c|c|c|}
\hline \multirow[b]{2}{*}{ Category } & \multicolumn{5}{|c|}{ Pathway } \\
\hline & 1 & 2 & 3 & 4 & 5 \\
\hline $\begin{array}{l}\text { Growing up } \\
\text { environment }\end{array}$ & Unsafe & Unsafe & Unsafe & Safe & Safe \\
\hline $\begin{array}{l}\text { Participant } \\
\text { responses }\end{array}$ & Active & Active & Active & Passive & Passive \\
\hline $\begin{array}{l}\text { Violence } \\
\text { attitudes }\end{array}$ & Inevitable & Inevitable & Inevitable & Avoid & Avoid \\
\hline Predisposition & Volatile & Volatile & Volatile & Calm & Calm \\
\hline Anger & Escalate & Escalate & Escalate & Diffuse & Diffuse \\
\hline Lifestyle & Unstable & Unstable & Unstable & Stable & Unstable \\
\hline Coping & Dysfunctional & Dysfunctional & Dysfunctional & Dysfunctional & Dysfunctional \\
\hline Planning & Instant reaction & Explicit & Implicit & Explicit & Implicit \\
\hline $\begin{array}{l}\text { Violence } \\
\text { enactment }\end{array}$ & Disinhibited & Strategic & Disinhibited & Strategic & Disinhibited \\
\hline Achievements & Achieved & Achieved & Dissatisfied & Achieved & Dissatisfied \\
\hline
\end{tabular}

Pathway 1 represented about $40 \%$ of the sample, and essentially reflected that violence was a normal, effective and appropriate response to conflict (Chambers et al., 2009). Pathway 2 represented about $26 \%$ of the sample and was very similar to Pathway 1 . The main difference was planning, with Pathway 1 participants demonstrating an instant reaction to a perceived provocation, as opposed to Pathway 2 offenders whose offending behaviour demonstrated some explicit planning (Chambers et al.). Pathway 3 represented about 9\% of the sample, with these offenders lacking conscious awareness of their violent intentions. Offending behaviour demonstrated aspects of implicit planning, and offenders were generally dissatisfied with the outcome as their violent behaviour was against their ideals (Chambers et al.). 
Pathway 4 represented about $14 \%$ of the sample; the offending of individuals in this pathway appeared uncharacteristically violent. Background history of offenders following Pathways 4 and 5 reflected a non-violent approach to conflict resolution and developed problem-solving skills. In terms of their violent offending, it seems that after long-term rumination (up to a year) on the perceived infraction by the victim, resorting to violence was deemed the only way to resolve the situation. Participants were generally satisfied with the outcome (Chambers et al., 2009). Pathway 5 represented about 6\% of the sample, with their uncharacteristically violent behaviour marked by acute mental instability and a reduction in coping abilities. Offending was generally preceded by a significant or emotional event (e.g. relationship breakdown) and post-offence the offenders were dissatisfied (Chambers et al.).

In order to interpret and make sense of her results Chambers (2006) utilised Megargee’s (1966) theory of under-controlled and over-controlled offender types. Megargee $(1966,1979)$ developed a theory of aggression where he distinguished between two types of violent offender using the Minnesota Multiphasic Personality Inventory (MMPI): overcontrolled and under-controlled personality types. He developed this theory in an effort to explain the phenomenon where a generally non-violent individual commits an extremely violent offence. Megargee explains the difference between the two types of offender in terms of their anger regulation.

Under-controlled individuals have low levels of tolerance in provoking situations, and little self-control and they are likely to act violently more often but less severely (Megargee, 1966). In contrast, the over-controlled individuals normally inhibit violence. In order for these individuals to behave violently they need to be intensely or repeatedly provoked. Violence in over-controlled individuals is rare but when it does occur it is extreme (Megargee, 1979). Blackburn (1986) also found support for Megargee’s over-controlled and undercontrolled personality types, although in his research Blackburn found four groups. Two of 
the groups were variations of an over-controlled personality type and had lower scores on measures of hostility and aggression. The remaining two groups were variations of an undercontrolled personality type and had higher scores on measures of hostility and aggression.

Megargee went on to predict that over-controlled individuals will be uncommon among offenders who have committed frequent assaults in their criminal histories, and this prediction has been supported (Megargee, 1966; Blackburn, 1986).

Using Megargee’s (1966) typology Chambers concluded that Pathways 1, 2 and 3 represented the offences of under-controlled offender types, and Pathways 4 and 5 represented the offences of over-controlled offender types. Chambers (2006) isolated level of planning as the main difference between under-controlled and over-controlled offender types in her study. More specifically Chambers identified that over-controlled offender pathways (Pathways 4 \& 5) lacked any instant reaction to provocation, instead they were characterised by some level of planning, either explicitly or implicitly. Perhaps because over-controlled offenders did not believe violence was the best way to solve problems. As a consequence offences committed by over-controlled offenders generally demonstrated due consideration to the use of violence, with violence often considered a last resort.

In contrast, offenders committing the under-controlled Pathway 1 offences appeared to instantly react to perceived threats using violence as an immediate and valid tool for problem solving (Chambers, 2006). In the Pathway 2 offences, under-controlled offenders were unable to react instantly, simply because the victim was not present at the time the offender learned or perceived something negative about them. Therefore these offenders had to wait for an available opportunity to assault the victim; hence the offence became an explicitly planned offence. The final under-controlled offender pathway is Pathway 3. In Pathway 3 offences the offenders were trying to lead a non-violent life and did not intend to 
use violence. As a result their subsequent offences were implicitly planned with offenders utilising previously learned violent habits, especially when intoxicated.

A particular strength of Chambers (2006) research is the description of assault offence patterns based upon the offender perspective. The descriptions are in the form of five different offence pathways, three of which are associated with the more common undercontrolled offender type and two with less common and uncharacteristically violent overcontrolled offender types. The identification of two types of offender represents an important contribution to the violence literature. The existence of two fundamentally different offender types potentially highlights a rehabilitation challenge, in that each offender type is likely to require different treatment approaches. The differentiation between over-controlled and under-controlled offenders in Chambers study replicates previous research on other specific offence types, such as homicide (Cassar et al., 2003) and sex offending (Ward et al., 1995) where similar differentiation has been found.

Whilst the PMA (Chambers, 2006; Chambers et al., 2009) clearly contributes to the violence literature its central limitation is its offence sample and therefore the models generalisability. Even though a small sample is generally necessary for labour intensive qualitative techniques such as grounded theory, it still needs to be remembered that this study is based on only 35 individual offence narratives. Not only does 35 represent a small sample size, the results tend to imply the offence narrative used is representative of all other offences committed by the offender. Whilst developmental history and background factors are considered and as such add some validity to the two offender type results, a longitudinal study sampling offences for each offender over time is required to provide more solid evidence.

Robbery. Nightingale (2002) developed a descriptive model of aggravated robbery offences, the Aggravated Robbery Model (ARM). The ARM aims to cover multiple domains 
including situational, behavioural and cognitive aspects. After developing the model, Nightingale (2002) found the offences used to create it followed two main pathways through the model: the Negative Affect Pathway and the more common Positive Affect Pathway. According to Nightingale (2002) offences following the Positive Affect Pathway were characterised by younger offenders (mean age 18 years) who felt positive in the lead up to offending. The offences were committed as an integral part of a valued criminal lifestyle, with robbery the "go-to" event in response to a presented opportunity or a lack of money. Offences following this pathway also tended to display more serious violence when victims did not co-operate.

In contrast, Nightingale (2002) reports offences following the Negative Affect Pathway were characterised by significantly older offenders (mean age 24 years). These offenders tended to view their lives negatively, and offences were generally in response to an increasing desperation for money or drugs. Although, like the Positive Affect Pathway, Negative Affect Pathway offenders also offended when opportunity arose. In contrast to the Positive Affect Pathway offences, offences following the Negative Affect Pathway were less likely to report physical violence during the offence.

Interestingly, the ARM appears to present a fresh perspective to the generally accepted concept of robbery. The generally accepted concept presents robbery as the result of a failure to cope with external stressors and it is strongly associated with negative affect (e.g., Walsh, 1986; Wright \& Decker, 1997). Nightingale suggests that, particularly for younger offenders, positive rather than negative affect appears more closely associated with robbery offending. Nightingale (2002) suggested the association of positive affect with offending reflects the central goal of counteracting or avoiding aversive moods by providing pleasure and excitement. Nightingale went on to speculate whether mood management is a fundamental feature of the robbery offence process. 
Nightingale (2002) further tested the ARM with a wider selection of robbery offences and found the model did not successfully encapsulate revenge-based robberies, but did demonstrate some promise with assault-based robberies. That is, robberies that were more reactive or dispute related offences as compared to the more 'traditional' predatory, instrumental robberies.

One of the main strengths of the ARM (Nightingale, 2002) is the identification of the Positive Affect Pathway, which challenges the existing concept that robbery is associated with negative affect. This finding underlines the utility of descriptive models for investigating the heterogeneity of specific offence types from the offender perspective, and providing a good foundation for future research.

As with the PMA (Chambers, 2006; Chambers et al., 2009) in the strength also lays the weakness. For the same reasons listed above for the PMA the necessarily small sample size of the ARM ( $n=25)$ somewhat undermines the validity of anything other than speculations regarding the generalisability of the model. In addition, Nightingale constructed the model using a sample of mainly traditional (main goal of material gain) offences, with one assault-based robbery offence. Further testing of the ARM with archival offence chains revealed it did not accommodate assault-based or revenge-based robberies particularly well. This finding effectively highlights the diversity of offence patterns even within an offence type. Since the original sample size was small, the finding also raises the question of whether the inclusion of a non-traditional robbery offence in the construction of the ARM has any impact upon the models use with traditional robberies?

\section{Aims of the Current Study}

As previously noted there is a knowledge gap in the violence literature, with very few studies considering a range of types of violent offences. As a result, the current study comprised two parts. Based on self-report accounts, the first part, Study 1, aimed to produce a 
descriptive analysis of the offence chain characteristics of a diverse sample of violent offences. The offences examined include a variety of assaults (including murders) and robberies, with offences describing the use of violence across a broad spectrum from low level (e.g. verbal threats), right through to fatal.

The second part, Study 2, aimed to utilise the descriptive analysis of Study 1 to investigate the violent offence process further by developing a pathways style model loosely based on Chambers (2006) PMA. Study 2 aimed to explore the temporal process of violent offences including pre-offence, during offence and post-offence characteristics, and to identify and examine any shared pathways to offending.

Ward and Hudson (1998) describe a meta-theoretical framework that differentiates between three different levels of theories. Beginning with level I theories, described as multifactorial, comprehensive frameworks that aim to explain offending behaviour. Level II theories are described as single factor theories that attempt to explain important single factors in the bigger picture of the offence. Finally there are Level III, or micro-theories that aim to provide a detailed description of an offence viewed as a temporal process and considers personological and situational factors. In sum, the current study represents a micro-theory and such a description of the violent offence process should provide the touchstone or the basis for future research (Canter, 2000). As Ward and Hudson (1998) note, micro-theories "serve to identify possible clinical phenomena and therefore describe the puzzles that subsequent theory sets out to explain” (p. 65).

The need for Study 2 relates to offender rehabilitation. Examining offence characteristics as part of a temporal process and identifying common pathways to offending should aid a better understanding of the heterogeneity of violent offenders. Increased knowledge and understanding has substantial implications for informing development of treatment interventions and increasing responsivity. Investigating the offence process both in 
general, and on an individual basis should prove useful for identifying relevant treatment targets (McMurran \& Howard, 2009). This information can be used to tailor individual treatment interventions, but also provides a sufficient breadth of information for when offenders who have committed a variety of violent offences are treated together. All of which follows the principles of effective correctional treatment of risk, need and responsivity (Andrews \& Bonta, 2010).

Violent offenders are unlikely to be specialised offenders (Simon, 1997), and researching only the more extreme (e.g., murder, see Cassar et al., 2003) or specific violent offences (e.g., robbery, see Nightingale, 2002) could mean we miss intervention opportunities at earlier stages of offending careers or we are not seeing the full picture for that individual. For instance, specific offence research using single offence narratives per offender may only be capturing atypical offence patterns for that offender, and more typical patterns may exist with their own associated treatment needs. For example, according to some studies the use of violence diminishes with age (e.g., see Pallone \& Hennessy, 1993).

Furthermore, research with a focus on a diverse sample of violent offences is also arguably more representative of what actually occurs in reality and therefore may better reflect the offender population under treatment (Chambers, 2006). This may help address the often 'one size fits all’ approach to correctional rehabilitation (Howells and Day, 2002), where the effectiveness of providing a single treatment to all offenders of a variety of crimes remains uncertain (Tapscott, Hancock, \& Hoaken, 2012).

In sum, this research aimed to provide a descriptive analysis of a heterogeneous sample of violent offences. Using this analysis the study aimed to answer the question: Are there distinct patterns of offending characteristics within such a heterogeneous sample? In addition, Zamble and Quinsey (1997) suggest there are psychological, and importantly for this study, offence differences associated with different types of current offence. Therefore a 
secondary aim is to see if there are differences in offence characteristics between offence types (e.g. assault vs. robbery).

\section{Method Study 1}

\section{Participants}

This study examined 150 violent offence chains, each from a separate offender. An offence chain is an offence narrative either written by, or recorded in the offender's own words. It provides a detailed description of an offence from the offender perspective, including pre, during, and post-offence characteristics (e.g., use of alcohol/drugs, relationship to the victim, whether a weapon was used). The offence narratives were recorded during the assessment phase of an intensive, prison-based violence rehabilitation programme run by New Zealand Department of Corrections between 1998 and 2007.

Selection for the current study was dependent upon the existence of a sufficiently detailed offence chain to permit data coding. The final sample size for this study totalled 150 offence narratives, all of which were obtained from high-risk violent offenders. Of the total sample $62 \%$ of the offences were assault-based (including murder) and 38\% of the offences were robbery-based. The offence types presented in the sample were diverse. Offences included a variety of assault offences (victim injuries ranging from minor through to severe), murders, and robberies. The robberies ranged from street robberies (e.g., bag snatch), through to planned bank robberies and also involved a range of victim injuries ranging from minor right through to fatal.

Demographic information was available for 149 participants. Ethnicity was recorded as 54.4\% Maori, 27.5\% European/Pakeha, and 17.4\% other ethnicity. The mean age at the start of the rehabilitation programme was 30.99 years $(S D=8.11$, range $18-60)$. The mean age at first conviction was 16.53 years $(S D=2.38$, range $13-27$ years). The mean number of 
previous convictions was $42.93(S D=34.28$, range $1-170)$, and $7.44(S D=5.90$, range $1-34)$ for violent convictions.

\section{Instruments}

The coding scheme. As a means of cataloguing the data contained within the offence chains, a coding scheme was developed. This section begins with an outline of how the coding scheme was developed followed by a description, and definitions of the categories and variables that make up that coding scheme.

The bulk of the items contained within the coding scheme have been extracted, refined and occasionally amalgamated from two existing resources; the Ross-Oxnam Violence Prevention Unit Offence Coding Scheme (ROCS: Polaschek, 2006), and information gained using grounded theory methodology by Chambers (2006; Chambers et al., 2009) during her development of the Pathways Model of Assault (PMA).

The ROCS (see Appendix A) consists of 47 items separated into three categories; preoffence variables, during offence variables and post offence variables. The items cover a wide range of personological and situational variables, for example from 'quality of relationships' (a pre-offence variable), to ‘weapon use' (a during offence variable) to 'thoughts about the offence' (a post-offence variable). The ROCS was the result of research undertaken to identify the type and scope of information generally contained within offenders' written offence chains (Polaschek, 2006). The majority of the variables from the ROCS were included in the coding scheme of the current study.

In Chambers (2006) research, grounded theory methodology (GTM) was employed to analyse the transcribed semi-structured interviews of offenders participating in her study. Grounded Theory is a bottom-up process, which allows theory to be constructed from the data (Chambers). Chambers constructed categories (e.g. Lifestyle preceding the offence) and subcategories (e.g. stable vs. unstable lifestyle) from concepts within the data (Chambers). 
To assist with the development of a coding scheme for the current study Chambers (personal communication, March $23^{\text {rd }}$, 2012) provided a list of basic meaning units she extracted from her interviews using GTM. A basic meaning unit refers to the minimum amount of information drawn from the data that expresses an individual idea (Strauss \& Corbin, 1998). Chambers used these basic meaning units to construct the categories within her model and therefore develop the PMA. To illustrate, the 'lifestyle preceding the offence' category was constructed from, among others, meaning units such as: 'employed', 'unemployed', and 'relationship problems'. The current study used Chambers list of basic meaning units (Chambers, personal communication) and PMA category headings (Chambers, 2006; Chamber et al., 2009) as a framework to organise the variables obtained from the ROCS and to guide the coding and reporting procedure in general. The categories are outlined in more detail below.

In summary, the coding scheme of the current study represents a refined and amalgamated version of the two previously described sources. The ROCS provided the majority of the variables, and the PMA, provided the structure and category headings under which the variables were organised.

The coding scheme for the current study consisted of 59 variables organised under the following 7 categories: 1) lifestyle preceding the offence, 2) coping strategies, 3) precipitating events, 4) goal setting, 5) planning, 6) violence enactments and 7) evaluations. The variables were designed to catalogue pre, during and post offence personological and situational offending characteristics detailed in the sample of offence chains. The range of variables was broad in order to satisfy the exploratory nature of the current study. Each of the 7 categories and their associated variables are described in more detail below.

The first draft of the coding scheme was used to code five offence chains. The pilot coding highlighted a number of issues with the coding scheme that were mostly to do with 
ambiguous response options. Loose definitions for some of the variables on the coding scheme made it unclear what information the variable was designed to capture. As a result of the pilot coding, definitions for each variable were clarified. An additional five offence chains were then coded, leading to increased refinement of the coding scheme. In this case most issues highlighted were related to variables that were appearing only very infrequently within the offence chains (e.g. level of physiological arousal) and so were removed. This was a constraint born of using archival self-report data; only variables for which sufficient detail was present in the offence chains were included in the coding scheme (see Appendix B for coding sheet).

Inter-rater reliability. Using the refined coding scheme the researcher coded a further 10 offence chains for use in a test of inter-rater reliability. An assistant suitably trained in the use of the coding scheme independently coded the same 10 offence chains. Cohen’s kappa was used to assess inter-rater reliability for categorical items, and weighted kappa was used for items with scaled response options. Kappa is generally thought to be a more robust measure than simple percent agreement calculation since it takes into account the agreement occurring by chance (Bakeman \& Quera, 2011). A kappa score of .6 and above was considered acceptable (Bakeman \& Quera). The kappa results indicated that 11 items of the 59 items on the coding scheme were unreliable, requiring further clarification. The researcher clarified the relevant definitions and a further 18 offence chains were coded by both researcher and assistant. Kappa values ranged from .61 to .94 indicating a good to excellent inter-rater reliability.

Coding scheme categories and variable definitions. The 59 variables in the coding scheme were divided unevenly into 7 categories. For example, variables categorised as preoffence lifestyle aimed to gather information about an offender's lifestyle leading up to the offence, including: relationships, finances, health, drug use, housing. The following sections 
outline the type of information the study aimed to record under each category and brief definitions of the variables are included (see Appendix C for full definitions). It is acknowledged that some variables (e.g., weapon use) could reasonably be placed in a number of categories (e.g. planning or violence enactments). The decision to place a variable under a particular category was guided to some degree by Chambers (2006) approach to constructing the PMA, although ultimately it was a subjective decision.

1) Pre-offence lifestyle characteristics. The pre-offence lifestyle category records information relating to the offender's lifestyle in the lead up to the offence. The variables categorised under the lifestyle phase cover a broad range of domains: from relationships to health, finances, social life and substance use. It should also be noted that the information recorded with these variables might either reflect an enduring way of life or a lifestyle shaped by more recent life-changing events (Chambers, 2009). For each category in the following section a complete list of variables and their brief definitions are displayed in a table directly below the relevant text.

Table 3.

Definitions of Variables Categorised under Lifestyle Characteristics

Variable Definition

Relationship status Marital/relationship status of offender

Quality of

relationship

Quality of offenders relationship with partner

Mental health

Status of emotional/mental health

problems

Employment/source

of income

Source of income (e.g. illegal, legitimate) 
Reliability of

income

Financial stressors

Social life/family

support

Criminal

lifestyle/associates

Substance abuse

Type of drug

Living arrangement

Quality/stability of

living arrangement

Physical health

problems

Gang activity
Degree to which the offender appears to have a regular and

reliable income

Indication that offender is under extra financial pressure (e.g. debt, job uncertainty, got a loan out). May include a specific desire for an item or lifestyle beyond current financial means Spends time with friends and or family - not socially isolated. Consider both quality and quantity of family support and/or social life. Social contact does not need to be pro-social. Extent to which current lifestyle revolves around crime and/or criminal associates

Extent of substance use (e.g. occasional, excessive) List of drugs used by offender (including alcohol)

Who with/where was offender living in lead up to offence Stability and quality of offenders living arrangement (e.g. homeless or stable accommodation)

Evidence of physical health problems (e.g. illness, disability or prescribed medication

Offender is a gang member, or is he involved with, or associates with gang members. This is about lifestyle so it does not necessarily need to relate to the index offence.

2) Pre-offence coping strategies. The coping strategies category aimed to record offenders' use of coping techniques, and the included variables that have been previously associated with offenders' coping strategies prior to the offence (e.g., Chambers, 2006; Zamble \& Quinsey, 1997). The variables cover both functional (e.g., help seeking) and dysfunctional (e.g., increased substance use) methods of coping with stressors. 
Table 4.

Definitions of Variables Categorised under Coping Strategies

\section{Variable Definition}

Increased

Evidence of increased substance use in lead up to offence. More usage

substance

than 'normal' for that individual or appears to be using drugs as a use

coping mechanism (e.g. "The drink and drugs was the best way for me

to blackout so I didn't have to think")

Any rumination in lead up to offence. Rumination refers to thinking

Rumination about anger provoking incidents after they have been suppressed

over

(Linden et al., 2003). May involve: angry afterthoughts, angry

grievances

memories, or revenge fantasies (Sukhodolsky, Golub, \& Cromwell, 2001)

Help

Any indication offender sought pro-social help to cope with stressors in lead up to offence, or realised he had an issue and made efforts to seeking address it (e.g. seeking rehab for substance abuse problems) Any indication offender attempted to resolve conflict in non-violent

Attempts manner. Employs pro-social/constructive problem solving techniques conflict resolution (e.g. asking a family member of victim to mediate and help resolve differences)

Conflict avoidance Evidence to suggest offender attempted to avoid conflict in lead up strategies offence (e.g. leave area or avoid intoxicants)

3) Pre-offence precipitating events. The precipitating events category aimed to record events or situations that occurred in the lead up to the offence; they may have contributed directly (e.g., the victim provoked the offender by threatening him) or indirectly 
(e.g., a family argument earlier in the day) to the commission of the offence (Chambers, 2009).

Table 5.

Definitions of Variables Categorised under Precipitating Events

\begin{tabular}{|c|c|}
\hline Variable & Definition \\
\hline Intoxication & $\begin{array}{l}\text { Level of intoxication at time of offence } \\
\text { Incidents, events, situations that could be considered provoking but }\end{array}$ \\
\hline $\begin{array}{l}\text { Indirect victim } \\
\text { provocation }\end{array}$ & $\begin{array}{l}\text { were not directly addressed, or happening to the offender himself } \\
\text { (e.g. members of offender's family or friends threatened by victim) }\end{array}$ \\
\hline $\begin{array}{l}\text { Direct victim } \\
\text { provocation }\end{array}$ & $\begin{array}{l}\text { Incidents, events, situations that could be considered provoking and } \\
\text { were directed at/towards the offender himself (e.g. victim actively } \\
\text { assaults or tries to assault offender) }\end{array}$ \\
\hline $\begin{array}{l}\text { Family } \\
\text { argument }\end{array}$ & $\begin{array}{l}\text { Was offender involved in any arguments with family members in } \\
\text { lead up to offence? The argument need not be related to index } \\
\text { offence. }\end{array}$ \\
\hline $\begin{array}{l}\text { Intimate } \\
\text { partner }\end{array}$ & $\begin{array}{l}\text { Was the offender involved in any arguments with romantic partner in } \\
\text { the lead up to the offence? The argument need not be related to the }\end{array}$ \\
\hline argument & index offence. \\
\hline $\begin{array}{l}\text { Opportunity for } \\
\text { material benefit }\end{array}$ & $\begin{array}{l}\text { The offence appears to result from offender taking advantage of } \\
\text { recently acquired knowledge (e.g. passes a shop and sees large sum } \\
\text { of money placed in till which initiates idea for a robbery) }\end{array}$ \\
\hline $\begin{array}{l}\text { Gang related } \\
\text { conflict }\end{array}$ & Conflict arising within or between gangs \\
\hline Proximal mood & $\begin{array}{l}\text { In the few hours preceding the offence what was the offenders } \\
\text { predominant mood theme (i.e. generally positive, neutral, generally }\end{array}$ \\
\hline
\end{tabular}


negative)

4) Pre-and during-offence goal setting. The goal-setting category aimed to record what an offender wished to achieve by committing the offence (Chambers, 2009). Goal setting covers both pre-offence and during-offence to ensure that multiple goals can be coded where appropriate, and to accommodate situations where goals change as the offence progressed. For example, pre-offence an offender had an initial goal of revenge and assaulted the victim. However, during the assault the offender noticed the victims watch and decided to steal it, thus adding a goal of material gain.

Table 6.

Definitions of Goal Setting Variables

\begin{tabular}{ll}
\hline Variable & Definition \\
\hline No apparent & No apparent motivation for the use of violence, or asserted harm \\
goal/accidental & was accidental \\
Violence utilised because offender or his family/friends are \\
Currently under threat/attack - as opposed to using violence as a \\
preventative measure from as yet unidentified threats \\
Violence or criminal behaviour used for gaining power, respect, or \\
Reputation & control through development of a reputation or for bolstering an \\
& existing reputation \\
Revenge & violence or criminal behaviour as a punishment for perceived \\
Retribution & hitting a woman) \\
& Violence or criminal behaviour as a punishment for perceived \\
\hline
\end{tabular}


infidelity)

Material gain

Violence or criminal behaviour utilised for material gain, as a means to obtain tangible goods

Sadism Inflicting pain for personal pleasure/gratification

Thrill/sensation Violence or criminal behaviour used to counteract feelings of

seeking boredom or to provide feelings of excitement

Violence or criminal behaviour erupts as a means to release a build

Catharsis up of anger or frustration. Use of violence or commission of crime leads to a feeling of relief (may be temporary).

5) Pre- and during-offence planning. The planning category aimed to record the degree to which the offender planned and prepared to carry out the offence. The variables categorised under planning were designed to highlight differences not only between planned versus unplanned offences; but also, where sufficient detail in the offence chain exists, to differentiate between implicit (e.g., planned opportunism or no conscious awareness of intentions) versus explicit planning (e.g., at least a basic level of planning, full conscious awareness of intentions).

Table 7.

Definitions of variables categorised under planning

\begin{tabular}{ll}
\hline Variable & Definition \\
\hline Consideration of & Degree to which offender considered the potential negative \\
impact of committing this offence upon himself, victim, family \\
(e.g. losing job, prison recall, child access)
\end{tabular}


Degree of planning

\section{Conscious}

awareness of

intentions

Planned

opportunism

Weapon use

Source of weapon

Type of weapon

Co-offenders

Role of offender

Number of victims

Victim/offender

relationship

Emotional arousal
Level of planning and preparation offender undertook in relation to offence, from no planning to elaborate planning Degree to which offender appeared consciously aware of intention to commit offence at outset of the offence. This is not the same as 'degree of planning' as there need not be any planning of 'how' the offence was going to be carried out Evidence to suggest that offender had rehearsed/considered how he might conduct a similar type of crime prior to this offence, and go on to offend if opportunity arises. There should be a cognitive element (awareness) in the rehearsal for this offence

Did offender possess a weapon, and was it used in commission of offence Where did the offender source the weapon List the type of weapon(s) used Did offender commit the crime alone or with co-offenders Did the offender undertake a 'main' role or a 'secondary' role during the offence How many victims were involved in the index offence How well, if at all did the offender know the victim What was the arousal level of the offender immediately before and during the offence, from low arousal to high arousal 
6) During offence violence enactments. The violence enactments category contains variables that aimed to record violence-related characteristics that occurred during the commission of the offence. For example, the level of injury the offender inflicted on the victim, or the level of resistance proffered by the victim during the offence. For simplicity, all emotion data is recorded in this category even if the emotion was recorded as occurring before or after the offence.

Table 8.

Definitions of Variables Categorised under Violence Enactments

\begin{tabular}{ll}
\hline Variable & Definition \\
\hline Level of & Level of victim injury starting from no injury, and ending with fatal \\
violence/injury & injury \\
Victim &
\end{tabular}

Describes how the victim reacted during the offence, from compliant reaction (level to strong reaction

of resistance)

Level of self-

control (during To what extent could the offender control his use of violence during infliction of the offence, from lost control to maintaining full control violence)

Emotions identified Offender emotions identified before, during, and after the offence

Offence duration Duration of offence, from short (<30 mins) to long ( $>30$ mins)

7) Post-offence evaluations. The post-offence evaluations category consists of variables designed to record how the offender feels about the offence, both soon after commission and sometime later. For example, was the offender generally satisfied or 
dissatisfied with outcome? The variables also cover more specific feelings associated with the offence, such as remorse for the victim or regret for the offender's own outcome.

Table 9.

Definitions of Variables Categorised under Evaluations

\begin{tabular}{|c|c|}
\hline Variable & Definition \\
\hline $\begin{array}{l}\text { Feelings towards } \\
\text { outcome (soon } \\
\text { after offence) }\end{array}$ & $\begin{array}{l}\text { How did offender appear to feel about the offence soon after it } \\
\text { occurred, from generally dissatisfied to generally satisfied }\end{array}$ \\
\hline $\begin{array}{l}\text { Feelings towards } \\
\text { outcome (at a } \\
\text { later date) }\end{array}$ & $\begin{array}{l}\text { How did offender appear to feel about the offence at some later } \\
\text { date, from generally dissatisfied to generally satisfied }\end{array}$ \\
\hline $\begin{array}{l}\text { Regret (own } \\
\text { outcome) }\end{array}$ & $\begin{array}{l}\text { To what degree does offender regret how offence affected his own } \\
\text { circumstances (including how his family may have been affected) }\end{array}$ \\
\hline $\begin{array}{l}\text { Guilt/remorse } \\
\text { (for victim) }\end{array}$ & $\begin{array}{l}\text { Level of remorse the offender demonstrates for victim (and/or } \\
\text { victim’s family) }\end{array}$ \\
\hline $\begin{array}{l}\text { Thoughts about } \\
\text { offence (after } \\
\text { commission) }\end{array}$ & $\begin{array}{l}\text { Offender's thoughts about the offence between commission and } \\
\text { apprehension. To what degree has the offender been preoccupied } \\
\text { with the offence or how has the offence affected the offenders } \\
\text { general functioning or concentration. }\end{array}$ \\
\hline Circumstances of & Did the offender voluntarily handed himself in to the authorities or \\
\hline capture & not \\
\hline
\end{tabular}

\section{Procedure}

The data archive from which offence chains were drawn consists of a file for each man created at the time that he attended the rehabilitation programme. The information was 
retained for use in further research projects with permission granted at that time by both New Zealand Department of Corrections and the offender. After extracting the individual offence chains from the archive, the researcher read and coded each one using the coding scheme designed and described above.

The researcher aimed to code all 59 variables where sufficient detail in the offence chain allowed. Due to the nature of the data (archival self report) it was difficult to code all responses to the same level of detail; the researcher was only able to code the information existing within each offence chain, the detail of which varied considerably. For example, the variable relationship status located within the lifestyle category has six response options: single; in a relationship; married; defacto; divorced/separated; and unknown. Sometimes the coder had the information that indicated the offender was involved in a relationship, and in what capacity (e.g. married or defacto). On these occasions the specific response was coded. With other offence chains it was only possible to code that the offender was in a relationship, not the specific standing of that relationship. Thus on these occasions only the response 'in a relationship’ could be coded.

\section{Data Preparation and Planned Analyses}

After all data were coded and entered into a spreadsheet, a number of changes were made to the data set to improve ease of analysis and interpretation. The response options to all variables were adjusted where necessary to read low to high. For example, the response options for the variable 'gang related conflict' were originally inputted in the high to low order of yes followed by no. The options were reordered so the results read no followed by yes. For Study 1 all analyses were descriptive. 


\section{Results and Discussion Study 1}

Using offender self-report data in the form of a detailed written offence chain the following section presents a descriptive account of the offence characteristics for the whole sample. The results for each of the seven categories with their associated variables are presented individually in a tabular format, starting with lifestyle, followed by coping strategies, precipitating events, goal setting, planning, violence enactments and evaluations. The discussion is incorporated with the results for Study 1, although this section will remain predominantly descriptive.

\section{Pre-offence Lifestyle Characteristics}

Table 10 below displays characteristics of the offenders' lifestyles prior to the offence. Over two thirds of offenders were either in a relationship (in a relationship with unspecified marital status, married or defacto), and just under a third were single. Of those offenders in a relationship and with information recorded on their relationship quality (almost $50 \%$ of the sample), only $6 \%$ reported a strong, stable relationship. The remainder reported at least some level of relationship conflict. Nearly a quarter of offenders suffered financial stress in the lead up to offending. In terms of relationship conflict and financial stress these findings are consistent with Zamble and Quinsey (1997) who found two of the three most common problems reported by offenders included interpersonal conflict (mainly with partners) and financial stress (substance abuse was also ranked but this is discussed in the next section). About a third of offenders in the current study reported some level of gang activity or affiliation, with roughly three quarters of offenders engaging in a criminal lifestyle to varying degrees. Only a third of offenders indicated some degree of legitimate employment. 
Table 10.

Pre-offence Lifestyle Characteristics

\begin{tabular}{|c|c|c|}
\hline Variables & Percentage & Frequency $(n=150)$ \\
\hline \multicolumn{3}{|l|}{ Relationship status } \\
\hline Single & $23.3 \%$ & 35 \\
\hline In a relationship & $50 \%$ & 75 \\
\hline Married & $6.7 \%$ & 10 \\
\hline Defacto & $7.3 \%$ & 11 \\
\hline Divorced/separated & $1.3 \%$ & 2 \\
\hline Unknown & $11.3 \%$ & 17 \\
\hline \multicolumn{3}{|l|}{ Relationship quality } \\
\hline Strong/stable & $6 \%$ & 9 \\
\hline Satisfactory, some conflict & $6.7 \%$ & 10 \\
\hline Strained, quite conflictual & $14.7 \%$ & 22 \\
\hline Significant conflict, presence of abuse & $23.3 \%$ & 35 \\
\hline N/A (single or separated) & $24.6 \%$ & 37 \\
\hline Unknown & $25.3 \%$ & 37 \\
\hline \multicolumn{3}{|l|}{ Mental health problems } \\
\hline None stated / apparent & $87.3 \%$ & 131 \\
\hline Some & $12 \%$ & 18 \\
\hline Extensive & $0.7 \%$ & 1 \\
\hline \multicolumn{3}{|l|}{ Financial stressors } \\
\hline No/none apparent & $76 \%$ & 114 \\
\hline Yes & $24 \%$ & 36 \\
\hline \multicolumn{3}{|l|}{ Social life/family support } \\
\hline None stated/apparent & $8.7 \%$ & 13 \\
\hline Some & $68 \%$ & 102 \\
\hline Extensive & $23.3 \%$ & 35 \\
\hline \multicolumn{3}{|l|}{ Physical health problems } \\
\hline No/none apparent & $96 \%$ & 144 \\
\hline Yes & $4 \%$ & 6 \\
\hline \multicolumn{3}{|l|}{ Gang activity } \\
\hline No/none apparent & $67.3 \%$ & 101 \\
\hline
\end{tabular}


Yes

$32.7 \%$

49

\section{Criminal lifestyle/associates}

None stated / apparent

$21.3 \%$

32

Some

$34.7 \%$

52

Extensive

$44 \%$

66

\section{Reliable income}

Unreliable

$32.7 \%$

49

Reliable

$67.3 \%$

101

\section{Employment/source of income}

Unemployed/on benefits

$32.7 \%$

49

Illegal income (crime)

$24.7 \%$

37

Employed (cash in hand - no income tax)

$8 \%$

12

Legitimate

$33.3 \%$

50

Unknown

$1.3 \%$

2

\section{Living Arrangement}

No fixed address

$8 \%$

12

Prison

$4.7 \%$

7

Flatting/lodging

$10 \%$

15

With family

$30 \%$

45

Alone (with/without children)

$8 \%$

12

With partner ( $\&$ children)

$29.3 \%$

44

Unknown

$10 \%$

15

\section{Quality/stability of living arrangement}

Poor

$14.7 \%$

22

Adequate

$78.7 \%$

118

Unknown

$6.6 \%$

10

Substance abuse was a common theme in the current sample of offence chains, with nearly $80 \%$ of offenders using drugs regularly or excessively. Table 11 below summarises the findings. Whilst high, these figures are unsurprising since a high level of substance use is often a memorable feature of the pre-offence characteristics of many offender populations (Zamble \& Quinsey, 1997). In the current study offenders most frequently admitted to using 
both alcohol and cannabis (28.7\%), followed by other poly-drug use (when a person uses two or more different drugs). Offenders engaging in poly-drug use reported using between two and five different drugs.

In sum, the offence chains appear to depict a general pre-offence lifestyle in which offenders suffer a variety of issues and problems, such as relationship trouble, substance abuse, unemployment and financial stress. Overall, these findings are consistent with previous research on serious offender populations (Chambers, 2006; Chambers et al., 2009; Nightingale, 2002; Zamble \& Quinsey, 1997). However, as Zamble and Quinsey point out, members of the general population also face some of these everyday challenges, and they go on to suggest the difference between offending and not offending may lie in a person's ability to cope. Characteristics commonly associated with coping are discussed in the next section.

Table 11.

Pre-offence Drug Use Information

\begin{tabular}{lcc}
\hline Variables & Percentage & Frequency \\
& $(n=150)$
\end{tabular}

\section{Substance use}

None-Occasional

$21.3 \%$ 32

Regular/Moderate

$37.3 \%$ 56

Frequently-Excessively

$41.3 \%$

\section{Type of drug}

Alcohol only

Cannabis only

$15.3 \%$

Alcohol \& Cannabis only

$28.7 \%$

Methamphetamine

$4 \%$

Poly-drug use (other than alcohol \& cannabis only)

$24 \%$

Breakdown of poly-drug use in order of descending frequency* 


$\begin{array}{llc}\text { Stimulants (Methamphetamine, amphetamine, } & 12.6 \% & 18 \\ \text { ecstasy, cocaine, Ritalin) + } & & 16 \\ \text { Cannabis + } & 11.2 \% & 12 \\ \text { Hallucinogens (LSD, mushrooms) + } & 8.4 \% & 11 \\ \text { Unspecified drugs \& pills + } & 7.7 \% & 10 \\ \text { Benzodiazepines (valium, halcion, rivotril, } & 7 \% & 7 \\ \text { rohypnol) + } & & 2 \\ \text { Opioids (morphine, heroin) + } & 4.9 \% & 1\end{array}$

+ Denotes other drugs were used as well as the listed drug.

*Total percentage of the listed drugs is over $24 \%$ due to use of multiple drugs by these participants

\section{Pre-offence Coping Strategies}

Table 12 below presents characteristics that have been previously associated with offender coping strategies prior to the offence (e.g., Chambers, 2006; Zamble \& Quinsey, 1997). In about a third of cases, substance abuse increased in the months, weeks or days leading up to the offence. About one-fifth of offenders reported some degree of rumination, and positive strategies of coping such as help-seeking, non-violent conflict resolution and conflict avoidance were rare.

Previous research suggests maladaptive ways of coping with problems is a common feature among convicted offenders (Zamble \& Porporino, 1988; Zamble \& Quinsey, 1997). Based on previous research by Zamble and Quinsey (1997) who found ineffective coping in response to problems in a similar offender population, it seems plausible the results of the current study, particular in terms of substance use, also suggest a level of ineffective coping. 
In the current study it was not always easy to determine the role played by substance abuse in the bigger picture of the offence process. Zamble and Quinsey (1997) also reported that sometimes the offence appeared to be one of the consequences of substance abuse, whereas at other times substance use appeared to represent the start of a coping failure.

Interestingly, Zamble and Quinsey also followed up their results on coping strategies with a self-efficacy questionnaire. The results of the questionnaire indicated that offenders were unaware of any deficiencies with their coping ability. The limitations of the archival data used in the current study prevents more than mere speculation on an offender's coping ability, but since self-efficacy is such a salient issue in the rehabilitation of violent offenders this is an area for future research with this type of offender population.

Table 12.

Pre-offence Coping Strategies

\begin{tabular}{lll}
\hline Variables & Percentage & Frequency $(\boldsymbol{n}=150)$ \\
\hline Increased substance use & & \\
No/none apparent & $67.3 \%$ & 101 \\
Yes & $32.7 \%$ & 49 \\
Help seeking & & \\
No/none apparent & $91.3 \%$ & 137 \\
Yes & $8.7 \%$ & 13
\end{tabular}

\section{Rumination}

None apparent

$70.7 \%$

Some

$16.7 \%$

25

Extensive

$12.7 \%$

19

\section{Attempts conflict resolution}

None apparent

Some effort

Considerable effort

\section{Conflict avoidance}

\section{strategies}

None apparent 
Some effort

Considerable effort
$6 \%$

$0.7 \%$
9

1

\section{Pre-offence Precipitating Events}

Table 13 below presents events recorded in the lead up to the offence. In terms of arguments, the most frequently recorded was an argument with an intimate partner (18.7\%), although the partner did not always go on to become the victim of the offence coded for. Over half of all offenders were either moderately or heavily intoxicated immediately prior, and during the offence, and negative mood (e.g. angry, depressed) was evidenced in just under half of cases. There was no evidence of either direct or indirect provocation for the majority, perhaps indicating that for these men, violence is a desirable method for achieving their goals, and not necessarily just a response to a provoking situation (Canter, 2000; Hochstetler, Copes \& Williams, 2010). For clarity, provocation was only recorded if the victim was involved in the provocation. For example, if the offender had an argument with his partner and then a couple of hours later went on to commit an unprovoked assault on a stranger, an intimate partner argument would be recorded but provocation would not. However, if the offender's partner went on to become the victim (and the offender perceived some level of provocation) both an intimate partner argument and provocation would be recorded.

Another possible explanation is that some of the men may reflect Megargee's (1966) under-controlled personality type. The under-controlled personality type is distinguished by low tolerance for provocation and little self-control (Megargee). It is speculated that the use of unprovoked violence by a majority of offenders in the current sample suggests a low tolerance for aversive circumstances and therefore shares some similarity with Megargee's under-controlled types. This speculation makes some intuitive sense when considering Megargee's typology of under-controlled and over-controlled offenders. With the generally 
extensive and varied criminal history of the offenders responsible for the offence chains in the current study, over-controlled offenders are unlikely to be a common phenomenon. Overcontrolled individuals normally inhibit violence, and require intense or repeated provocation to offend (Megargee), which is likely to result in fewer offences. Therefore, we would expect to find a majority of under-controlled offender types in this sample, and this does appear to be the case.

Table 13.

Pre-offence Precipitating Events

\begin{tabular}{lll}
\hline Variables & Percentage & Frequency $(\boldsymbol{n}=150)$ \\
\hline Family argument & & \\
No/none apparent & $94.7 \%$ & 142 \\
Yes & $5.3 \%$ & 8
\end{tabular}

Intimate partner argument

$\begin{array}{lll}\text { No/none apparent } & 81.3 \% & 122 \\ \text { Yes } & 18.7 \% & 28\end{array}$

\section{Opportunity for material}

\section{benefit}

No/none apparent

$98 \%$

Yes

$2 \%$

3

\section{Gang related conflict}

No/none apparent

$94.7 \%$

Yes

$5.3 \%$

8

\section{Intoxication}

None apparent/disclosed

$41.3 \%$

62

Moderate

Heavy

$33.3 \%$

50

\section{Proximal mood}

Neutral/none apparent

Negative

Positive

$16.7 \%$

25

\section{Indirect provocation*}


$\begin{array}{lll}\text { None apparent } & 80.7 \% & 121\end{array}$

$\begin{array}{lll}\text { Gang rival } & 4.7 \% & 6\end{array}$

Threats to family/friends $\quad 13.3 \% \quad 19$

Attention paid to partner/ex $\quad 3.3 \% \quad 5$

\section{Direct provocation}

None apparent

$62.7 \%$

94

Low level

$13.3 \%$

20

Insults offender (infidelity

$10.7 \%$

16

inc)

Threatens offenders

$6.7 \%$

10

Assaults offender

$6.7 \%$

10

*Multiple options were recorded where present

\section{Pre- and During-Offence Goal Setting}

Table 14 presents offender goals identified in the offence chains. The most commonly identified goals were reputation (45.3\%) and material gain (40.7\%), with sadism (0.7\%) the least common.

Table 14.

Pre and During Offence Goal Setting

\begin{tabular}{lll}
\hline Variables & Percentage & Present \\
& $1.3 \%$ & Frequency $(\boldsymbol{n}=\mathbf{1 5 0})$ \\
\hline No apparent goal & $21.3 \%$ & 2 \\
Defence & $45.3 \%$ & 32 \\
Reputation & $7.3 \%$ & 68 \\
Retribution & $28.7 \%$ & 11 \\
Revenge & $40.7 \%$ & 43 \\
Material gain & $0.7 \%$ & 61 \\
Sadism & $6.7 \%$ & 1 \\
Thrill/sensation seeking & $27.3 \%$ & 10 \\
Catharsis & 41 \\
\hline
\end{tabular}

Note. Multiple goals were coded when reported 


\section{Pre and During Offence Planning}

Table 15 below summarises the offence characteristics related to planning or preparing to offend. It is clear from the figures that the vast majority of offenders did not put too much thought into the offence. This is reflected in a number of characteristics. First, the majority of the sample displayed a general lack of consideration for the negative consequences that could occur as a result of the offence. Second, opportunistic offending was most prevalent with almost half the sample offending in this manner, followed by a basic level of planning. Basic planning refers to a vague plan with few details (e.g., let's do a robbery tomorrow at the bank). This again is consistent with the findings of Zamble and Quinsey (1997) who discovered that the majority of their sample barely considered the offence until they were practically committing the crime. Interestingly though, about a third of Zamble and Quinsey’s sample of offenders must have done some thinking on the subject as they reported they had considered the possible negative consequences, but remained undeterred anyway. For clarity, in the current study opportunistic offending is not the same as planned opportunism. Planned opportunism is coded when there is evidence to suggest the offender had considered or rehearsed how he might commit a particular type of offence if and when a suitable opportunity arose.

Zamble and Quinsey proposed one possible explanation for potential negative consequences failing to deter offenders; that the thought of positive outcomes counteracted the negative. Unsurprisingly, Zamble and Quinsey found the main benefit of offending to be material gain, and as a result expected this explanation to apply more commonly to offenders committing property crime. Not only is this focus on positives outweighing negatives in line with rational choice theory, which asserts offenders apply a cost-benefit analysis to the situation (Cornish \& Clarke, 1986), it also shares some similarities to Nightingale’s (2002) research on aggravated robbers. Nightingale discovered that aggravated robbers follow two 
main pathways to offending, of which the Positive Affect Pathway was most prevalent. The Positive Affect Pathway describes offenders who feel positive in the lead up to offending, and offending is an integral part of a valued lifestyle; offences are anticipated to yield largely positive outcomes.

In terms of the current sample, it is possible that due the archival nature of the data the consideration and subsequent dismissal of negative consequences was not accurately captured. A future study with the benefit of semi-structured interviews would be useful to examine this point further. Thus, although offenders in the current sample did not appear to put much thought into the offence, it is possible that a form of cost-benefit analysis did occur but was not detected due to the limited data.

In addition, that half the current sample offended opportunistically adds another possible angle to the apparent lack of thought about offending. Perhaps, the lack of consideration actually reflects a level of expertise or automaticity in offending. For example, it is possible the results in the current study actually reflect a situation where experienced offenders need to give as much thought to the process of offending as to any other act that becomes automatic with mastery, such as driving. The fact that a weapon was used in nearly two thirds of all offences is also a little surprising when almost half of all offences were opportunistic or unplanned. Arguably this adds weight to speculation about automaticity, since it could imply offenders carry both the knowledge and the necessary equipment to take advantage when opportunity arises. Automaticity of offending behaviour could prove an interesting angle for future studies to investigate.

In order to investigate planning characteristics and automaticity future research could consider applying aspects of Ward and Hudson's (1998) self-regulation model. Originally developed to describe the sex offender relapse process, the self-regulation model details two main types of offender goal, approach goals and avoidance goals. Approach goals represent 
situations where the offender is determined to offend, whereas avoidance goals represent situations where the offender wants to avoid offending.

Ward and Hudson describe four goals, two avoidant goals and two approach goals. The avoidant goals: avoidant-passive and avoidant-active both refer to an offender's desire to not offend. The avoidant-passive offender is likely to feel unable to control their intentions and may engage in covert planning. In contrast, the avoidant-active offender directly attempts to control their behaviour or the emotions that are putting them at risk of offending, but the strategies chosen to do so are not effective.

Of the approach goals, approach-automatic refers to offending behaviour that likely occurs without conscious awareness as offenders follow well-learned offending scripts. As a result the offence appears to happen with very little or no planning. The difference between approach-automatic and avoidant-passive lies in the desire to engage in (approach-automatic), or avoid (avoidant-passive) offending. The final goal, approach-explicit refers to a straightforward conscious decision to engage in offending behaviours and as such offenders implement strategies deemed necessary to achieve their goal.

In summary, Ward and Hudson’s (1998) description of sex offender approach and avoidance goals may provide a useful framework with which to examine automaticity in violent offending. Incorporating the detail of approach and avoidance goals into future coding schemes would allow for a more fine-grained examination into the more proximate characteristics of the offence process, particularly the planning process (or lack of it).

Table 15.

Pre and During Offence Planning Characteristics

Variables Percentage Frequency $(n=$

150)

\section{Considers consequences}

No consideration apparent

$80 \% \quad 120$

Some 
Extensive

$2 \%$

3

\section{Degree of planning}

Opportunistic/none apparent or

$46 \%$

69

disclosed

Basic

$35.5 \% \quad 53$

Moderate

$14.7 \% \quad 22$

Elaborate

$4 \%$

6

\section{Conscious awareness of intentions}

None apparent/disclosed

$15.3 \% \quad 23$

Some awareness

$19.3 \% \quad 29$

Full awareness

$65.3 \%$

98

\section{Planned opportunism}

No

$96.7 \% \quad 145$

Yes

$3.3 \%$

5

Weapon use

No

$34.7 \% \quad 52$

Yes

$64.7 \% \quad 97$

Had but didn’t use

$0.7 \%$

1

\section{Source of weapon}

Found at scene

$16.6 \% \quad 25$

Taken from victim

$2.6 \% \quad 4$

Taken to scene by offender

$43 \% \quad 65$

Unknown

$2.7 \%$

4

Type of weapon

Axe

$2 \%$

3

Bat

$2.7 \%$

4

Bladed instrument

$34.7 \% \quad 52$

Firearm

$12.7 \% \quad 19$

Bottle

$3.3 \% \quad 5$

Other

10

15

\section{Co-offenders}

No

$56.7 \%$

85

Yes

$43.3 \%$

65 


\section{Offender role}

Main role

$94.7 \%$

142

Secondary role

$5.3 \%$

8

\section{Number of Victims}

One

$75.3 \%$

113

One or more

$8 \%$

12

Two

$10.7 \%$

16

More than two

$6 \%$

9

Victim/offender relationship

Unknown

Known

Close relationship (e.g., family,

friend, partner)

Emotional arousal

Low or none apparent/disclosed

Moderate

High
$44 \%$

$36 \%$

$20 \%$

$17.3 \%$

$40 \%$

$42.7 \%$
66

54

30

\section{Violence Enactments: During the Offence}

Table 16 below summarises the violence-related characteristics that occur during the offence. It is clear from the table that offenders inflicted a range of injury levels upon victims, but two thirds were at least moderate injuries (larger wounds, severe bruising) or worse, with a quarter proving fatal. During the offence about half the victims were reported to be compliant or unresisting, but a sizable proportion of victims strongly resisted the offender/s (39.3\%). Only a few men reported losing all self-control (e.g., seeing 'red', or unable to stop inflicting harm). In fact, in two thirds of cases there was evidence to suggest the offender was in full control of his actions, in that he was able to cease inflicting violence when he chose to do so.

With so many offenders demonstrating full self-control it is difficult not to consider the implications in terms of the instrumental-reactive violence dichotomy. According to the 
dichotomy, strategic use of violence, that is, using violence only as necessary to achieve your goal is more commonly associated with the use of instrumental aggression (Berkowitz, 1993; Tapscott, Hancock, \& Hoaken, 2012).

Table16.

During the Offence Violence Enactments

\section{Variables}

Level of violence (injury)

No injuries or threats

Threat but no physical assault

Assault, no injury

Minor injury (e.g. bruises, small cuts)

Moderate injury (e.g. larger wounds, severe bruising)

Serious injury (e.g. broken bones, gunshot wounds)

Severe injury (e.g. life-threatening, lasting

impairment)

Fatal

\section{Victim reaction (resistance)}

Compliant/no resistance reported

Overtly compliant, covert reaction (e.g., panic

button)

Overt action (e.g. scream, run away)

Strong reaction (e.g. fighting back, defending others) $\quad 39.3 \%$

\section{Level of self-control}

Lost control

Some control

Full control

Offence duration

Short $(<30$ mins $)$

$90.7 \%$

$9.3 \%$

$2.7 \%$

$16 \%$

$4.7 \%$

$10.7 \%$

$20.7 \%$

$12.7 \%$

$6 \%$

Longer (>30 mins)

$5.3 \%$

$29.3 \%$

$65.3 \%$

\section{Frequency \\ $(n=150)$ \\ Percentage}

4

24

7

16

19

9

8

44

98

15

59

40

$$
\text { Longer (>30 mins) }
$$


Results from the current study indicate high levels of self-control among offenders, which arguably reflects a more strategic, instrumental use of violence for these offenders. Yet this is at odds with other results from the current study, which could indicate more reactive violence, such as the lack of planning, with most offenders planning either minimally or not at all. Level of planning is a characteristic often used as a distinguishing feature of reactive versus instrumental violence. Higher levels of planning are generally associated with instrumentality, and a lack of planning with reactivity (e.g., Cornell et al., 1996).

There are a number of possible explanations for the surprising violence self-control results of the current study. First, hampered by the nature of the archival data the coding definition developed in the current study may not have been detailed enough to capture an accurate picture (see method, or Appendix C for definitions). Second, the entire results may reflect such a heterogeneous sample of offenders and offending characteristics that it is difficult to make sense of all the multiple characteristics together (e.g., self-control and planning). Although on that note, a more dimensional application of the instrumental-reactive dichotomy could also improve clarity. Third, the possibility of automaticity of offending behaviour is again raised. Automaticity may explain why offender's actions were likely to be interpreted as in control and unplanned by coders.

Emotions were recorded as part of violence enactments and are presented in Table X below, along with emotions from before and after the offence. Where there was insufficient detail to associate the emotion with an offence phase (e.g., before, during or after the offence), it was recorded separately as 'no phase'. There is an ongoing debate on whether anger is considered a positive or negative emotion (e.g., Carver \& Harmon-Jones, 2009). However, since the current research is exploratory and descriptive, Watson and Tellegen's (1985) twofactor structure of affect was used as a parsimonious method of condensing a large amount of 
qualitative data from the offence chains into more meaningful emotion categories (see Watson and Tellegen, 1985 and Appendix D for further detail).

Across all recorded phases of the offence there was considerable missing data on emotion. However, of the data available, high negative affect (e.g., anger, fear, anxiety) was the most frequently identified category of emotion across all phases. These results are not entirely surprising given the lifestyle issues some offenders report (e.g., relationship conflict, substance abuse, financial stress), particularly when paired with poor coping ability. Zamble and Quinsey’s (1997) results reflect something similar to those of the current study; offenders in their sample commonly reported feelings of frustration, depression, anxiety and anger in the month leading up to offending, with anger becoming increasingly dominant closer to the time of offending (Zamble \& Quinsey, 1997). In contrast, Nightingale’s (2002) Aggravated Robbery Model (ARM) may present a more complex picture.

Nightingale (2002) found two main affective pathways to aggravated robbery offending: a Negative Affect Pathway and a Positive Affect Pathway. The Negative Affect Pathway appears to share some similarities with the results of both the current study and the findings of Zamble and Quinsey (1997). Offenders following the Negative Affect Pathway tended to view their lives more negatively and offending was a response to an increasing desperation for money or drugs (Nightingale, 2002).

Conversely, and at odds with results of the current study, the more common Positive Affect Pathway to aggravated robbery was characterised by offenders who felt positive in the lead up to offending. Offending for these individuals was a central feature of a valued criminal lifestyle (Nightingale, 2002). Age of offenders is perhaps one salient difference between Nightingale’s two pathways. Younger offenders ( $M=18$ years) are associated with the Positive Affect Pathway, whilst the Negative Affect Pathway is associated with slightly older offenders ( $M=24$ years). The mean age of the offenders in the current study was nearly 
31 years, so closer to the age of Nightingale’s Negative Affect Pathway, which could explain some of the similarities between the ARM Negative Affect Pathway and high levels of negative affect reported by the offenders in the current study.

Unsurprisingly, the discovery of a Positive Affect Pathway in the ARM led Nightingale (2002) to question the validity of the long held view that robbery offending was generally the result of a failure to cope with external stressors and associated with negative affect. Yet superficially the results of the current study lend support for that long held view, although offender age has been raised as an issue worthy of further investigation.

It is also worth remembering that only about a third of the current sample of offences were robbery-based offences, with the remainder being assault-based offences. In addition, Nightingale's (2002) ARM worked well with 'traditional' (main goal of material gain) robberies but did not as successfully encapsulate revenge or assault-based robberies. All three types of robbery were present in the current sample. It would be interesting to see if the ARM differences in offender affect and age extends to the generally violent offenders of the current study. In order to do this a more in depth analysis of the emotions reported in the offence chains of the current study would be required. Likewise, it would also be interesting to see if there are affect differences across offence type.

Table 17.

Offenders' Emotions Noted Before, During and After the Offence

\section{Variables}

Emotions identified Before

High positive affect

Low positive affect

High negative affect

Low negative affect

Pleasantness

Unpleasantness

\section{Percentage}

\section{Frequency}

$(n=150)$

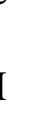


Strong engagement $\quad 0 \quad 0$

Disengagement $\quad 0 \quad 0$

Unknown

$48.7 \%$

\section{Emotions identified During}

High positive affect

$2.7 \% \quad 4$

Low positive affect

0

0

High negative affect

$18.7 \%$

28

Low negative affect

0

Pleasantness

Unpleasantness

Strong engagement

0

0

Disengagement

0

0

Unknown

$76 \%$

\section{Emotions identified After}

High positive affect

$4.7 \% \quad 7$

Low positive affect

$0.7 \% \quad 1$

High negative affect

$17.3 \% \quad 26$

Low negative affect

0

Pleasantness

$10 \%$

15

Unpleasantness

$10.7 \%$

Strong engagement

0

Disengagement

$0.7 \%$

1

Unknown

$56 \%$

\section{Emotions identified No phase detail*}

High positive affect

$4 \%$

6

Low positive affect

0

0

High negative affect

$27.3 \%$

39

Low negative affect

$0.7 \% \quad 1$

Pleasantness

$1.3 \%$

2

Unpleasantness

$6.3 \% \quad 9$

Strong engagement

$0.7 \% \quad 1$

Disengagement

0

Unknown

$71.3 \%$

*For 16 participants multiple emotions were recorded 


\section{Post-offence Evaluations}

Post-offence evaluations were difficult to accurately capture with the archival data used in the current study. There was a large amount of missing data because the detail in many offence chains ceased at the end of the offence process itself. Of those offence chains containing further detail, it was often selective, only implied in the text, and covered only one or two of the variables coded. As a consequence, the results from this phase are reported but should be interpreted with some caution. Ultimately, a future study with more comprehensive data is advisable.

Table 18 provides a summary of post-offence characteristics relating to how the offender felt about different aspects of the offence after commission. Offender feelings about the outcome soon after the offence were divided across all three categories from satisfied, ambivalent/neutral and dissatisfied. Yet, at a later date (ranging from as little as a week to several years later) over half of offence chains reflected a general dissatisfaction with the outcome. Perhaps related to this result, about two thirds of offenders described at least some degree of regret for their personal outcome and roughly a third of offenders felt remorse for the victims.

Table 18.

Post-offence Evaluation Characteristics

\begin{tabular}{lll}
\hline Variables & Percentage & Frequency $(\boldsymbol{n}=\mathbf{1 5 0})$ \\
\hline Feeling towards outcome -soon after & & \\
Generally dissatisfied & $30 \%$ & 55 \\
Ambivalent & $38 \%$ & 31 \\
Generally satisfied & $20.7 \%$ & 17 \\
Unknown & $11.3 \%$ & \\
Feeling towards outcome - later date & & 84 \\
Generally dissatisfied & $56 \%$ & 30 \\
Ambivalent & $20 \%$ & 6
\end{tabular}


Unknown

\section{Regret (own outcome)}

No regret

Some Regret

Considerable regret

Unknown

\section{Remorse/guilt (for victim)}

No remorse

Some remorse

Considerable remorse

Unknown
$20 \%$

30

$15.3 \%$

23

$34.7 \%$

52

$30 \%$

45

$20 \%$

30

$35.3 \%$

53

$38.7 \%$

58

$22.7 \%$

34

$3.3 \%$

5

Thoughts about offence after commission (preoccupation)

No thoughts/unconcerned

$15.3 \%$

23

Slightly preoccupied

$20.7 \%$

31

Preoccupied, can't concentrate

$28.7 \%$

43

Worried, panicky, totally preoccupied

$18 \%$

27

Unknown

$17.3 \%$

26

\section{Circumstances of capture}

Handed self in

$10 \%$

15

Did not hand self in

$31.3 \%$

47

Unknown

$58.7 \%$

88

In summary, although the descriptive results from each category have been reported and discussed individually it is important to remember that offence characteristics do not generally occur in isolation, independently of each other. An offence chain details a series of actions (much like any other) and each category represents a part of that sequence of events (Nightingale, 2002).

These descriptive results now represent a foundation for further research on the offence characteristics of heterogeneous violent offences. Study 2 utilises these results to 
further explore the offence sample, and perhaps reduce the heterogeneity by investigating whether shared pathways to offending exist.

\section{Method Study 2}

Study 1 set out to describe the samples’ violent offences and the associated characteristics organised under seven general headings taken from Chambers’ PMA (Chambers, 2006). Having coded and described the variability in the sample, the next step was to investigate whether it was possible to construct a parsimonious series of pathways to represent the offence process for this diverse sample of violent offences. Although this research aim was derived from Chambers (2006; Chambers et al., 2009) PMA, an analytic goal was to derive the pathways using a more quantitatively based approach than Chambers. Cluster analysis was the statistical technique chosen for this purpose. Cluster analysis is a technique that creates clusters (i.e. subgroups) of cases based on shared characteristics. Ideally in this context, offences in one cluster will share many characteristics, but should have different characteristics to offences not belonging to that cluster (Mooi \& Sarstedt, 2011).

There are a number of cluster analysis techniques available, and the non-hierarchical $k$ - means technique was selected for this study. In order to compare the findings readily with Chambers’ PMA, a two-cluster solution was specified. Therefore, $k$-means is a logical choice as it not only requires a pre-specified number of clusters, but is also a partitioning method that forms clusters with the least within-cluster variation (Mooi \& Sarstedt, 2011). The following section details the preparation of the data for the cluster analyses. 


\section{Data Preparation}

A frequency analysis was conducted on 52 of 59 variables across all the phases coded for in this study. Seven variables were excluded because they were either: (a) a variable with responses that were dependant on another variable (quality of relationship, source of weapon, type of weapon, type of drug); or (b) the variable responses were recorded verbatim (rather than by selecting a response option) and were too varied, with often a substantial amount of missing data across the sample (emotions identified, number of victims, circumstances of capture).

Next, from the remaining 52 variables those with insufficient variability (defined as scoring 95\% or above for any one response option) were removed. These variables were physical health, attempts conflict resolution, opportunity for material benefit, no goal, sadistic goal, and planned opportunism.

Some changes were made to the response options for the remaining 46 variables. These changes generally involved amalgamating variables in two main ways. Firstly, for variables where there was insufficient detail in the offence chain to circle a response other than 'unknown', the response options were amended. For example, using the variable 'mental health problems', the coder was unable to select with confidence one of the 3 options: none, some or extensive, so for cluster analysis purposes the options were amended to: none apparent or disclosed, some or extensive. So now all ‘unknown' responses were coded none apparent/disclosed. Secondly, where the variable had a large selection of possible responses (e.g. relationship status - single, married, separated, defacto etc.) the responses were collapsed into a dichotomous choice (e.g. 'no relationship disclosed' or 'in a relationship). For full details see cluster analysis coding sheet in Appendix E.

This procedure was necessary to minimise any missing data (i.e. 'unknown' or 'insufficient detail') from the data set. If there is missing data from just one of the 46 
variables per offence chain the Statistical Package for the Social Sciences (SPSS) programme will not include any data at all from that case in the cluster analysis, thereby substantially reducing the amount of participant data available for use in the analyses. To ensure all remaining variables carried an equal weighting in the cluster analyses all variables were converted to z scores using SPSS.

In addition, each offence chain was assigned an offence type based on the information recorded. A robbery-based offence type was assigned if the offence narrative described an offence where robbery was the overarching theme or goal; whether or not the offender went on to commit an assault too. Similarly, an assault-based offence type was assigned if the offence narrative described an offence where the overarching theme or goal was inflicting harm on another person; whether or not the offender went on to steal any item during the incident.

\section{Results Study 2}

Cluster analyses were conducted on the variables by category to produce a two-cluster solution for each category. As noted above, this study emphasises the offence process: the way that different categories of information about the offence actually reflect a temporal order. Temporal order was not important in Study 1. To make this distinction clearer, the major categories used in the cluster analysis will be referred to in Study 2 as phases. As described below, the seven categories from Study 1 are collapsed here into five phases distinguished by where they occur in time in the offence chain.

Based on the PMA (Chambers, 2006; Chambers et al., 2009), all remaining variables under the lifestyle and coping strategies categories were cluster analysed together to produce a single two-cluster solution for a new phase called Lifestyle and Coping Strategies. A further four cluster analyses were conducted, one of which was on the variables in the precipitating events and goal setting categories to produce a single two-cluster solution for a new phase 
called Precipitating Events and Goal Setting. The final three cluster analyses were conducted, one each on the variables in the planning, violence enactment, and evaluations categories. Table 19 displays the variables included in each cluster analysis and identifies those for which there were significant differences between clusters (see Appendix F for full SPSS generated solutions).

Table 19.

Variables included in cluster analyses

Variables by phase

Lifestyle and Coping

Relationship Status*

Mental health problems

Financial stressors

Social life/family support**

Gang activity*

Criminal lifestyle/associates**

Reliable income**

Employment/source of income**

Living Arrangement

Quality/stability of living arrangement**

Substance use ${ }^{* *}$

Increased substance use

Help seeking

Rumination**

Conflict avoidance strategies*

\section{Planning}

Consider consequences**

Degree of planning**

Conscious awareness of intentions**

Weapon use **

Co-offenders**

Offender role

Victim/offender relationship**

Emotional arousal*

\section{Violence Enactments}

Level of violence (injury)**

Victim reaction (resistance)

Offence duration**

Offender self-control**

\section{Evaluations}

Precipitating Events and Goal Setting Feeling towards outcome -soon after**

Family argument

Feeling towards outcome - later date**

Intimate partner argument*

Regret (own outcome)**

Gang related conflict**

Remorse/guilt (for victim)**

Intoxication

Thoughts about offence after commission** 
Proximal mood**

Indirect provocation**

Direct provocation**

Defence**

Reputation*

Retribution**

Revenge

Material gain**

Thrill seeking*

Catharsis**

*Denotes a significant difference between clusters $p<.05$, ** for $p<.01$

The five two-cluster solutions produced from the cluster analyses were used to construct a Pathways Model of Violent Offences (PMVO). Each phase was divided into two subcategories, or clusters, which were labelled according to their predominant, significantly different content. Those subcategories reflect the results of the cluster analysis and all offences could then be allocated to one of the two subcategories in each of the five phases of the model. Figure 2 below displays a visual representation of the model. 


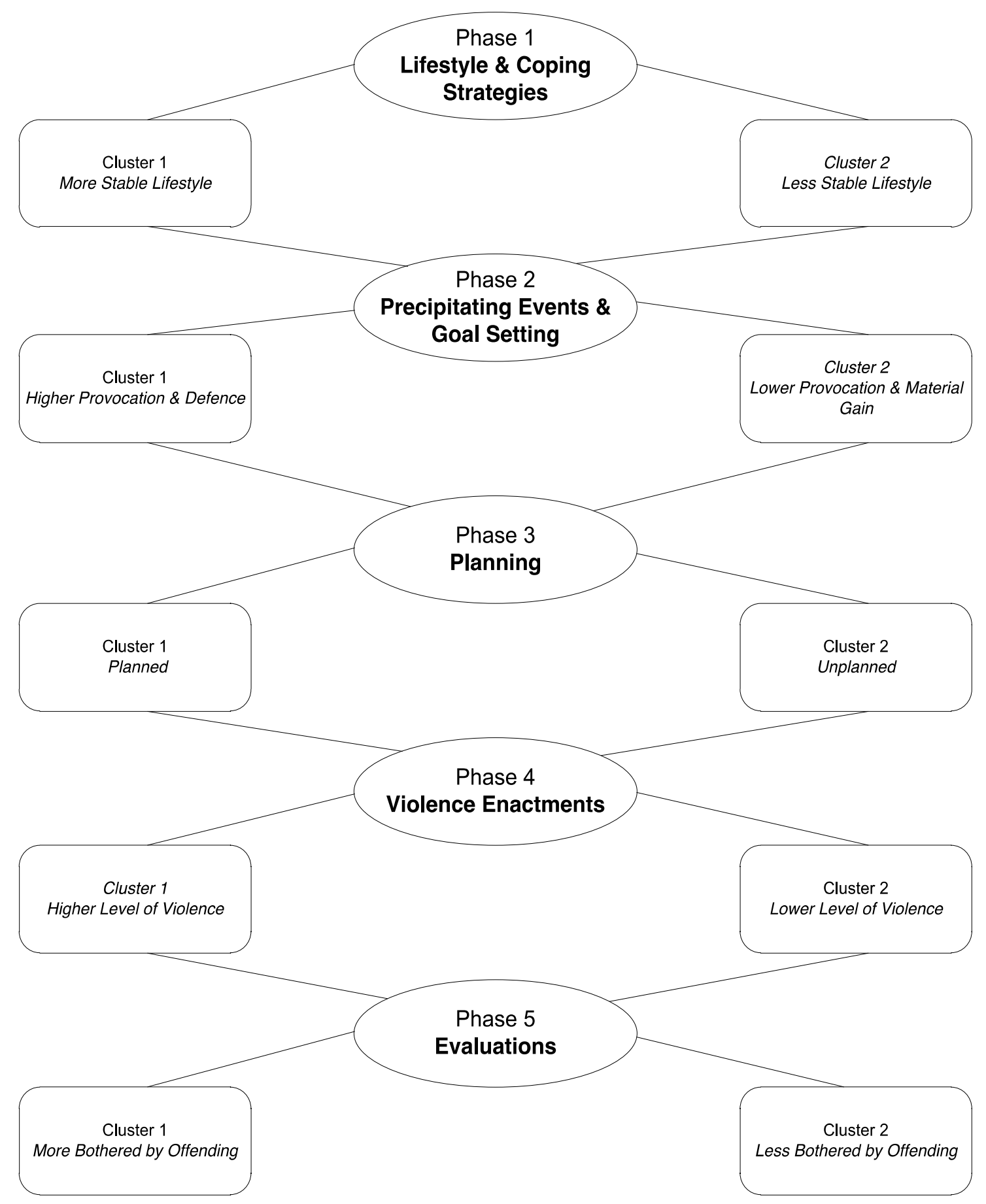

Figure 2. A visual representation of the Pathways Model of Violent Offences

The next section provides a detailed description of the five phases of the model.

Extracts from offence chains have been incorporated in the cluster descriptions to help

illustrate the characteristics described (the number at the end of each extract is an 
identification number). A description of the main offence pathways through the model will follow.

\section{Cluster Characteristics for Each Phase of the Model}

Pre-offence lifestyle and coping strategies phase. The lifestyle and coping strategies phase (Figure 3) incorporates 15 variables covering a broad range of lifestyle characteristics (e.g., relationships, criminal lifestyle, employment) and characteristics relating to, or indicating a person's ability to cope with life’s stressors (e.g., increased substance use, help seeking behaviours). Cluster analysis of the variables from this phase produced the following solution. An Analysis of Variance (ANOVA) indicated significant differences between the two clusters on 10 of the 15 variables (see Table 19 above for details).

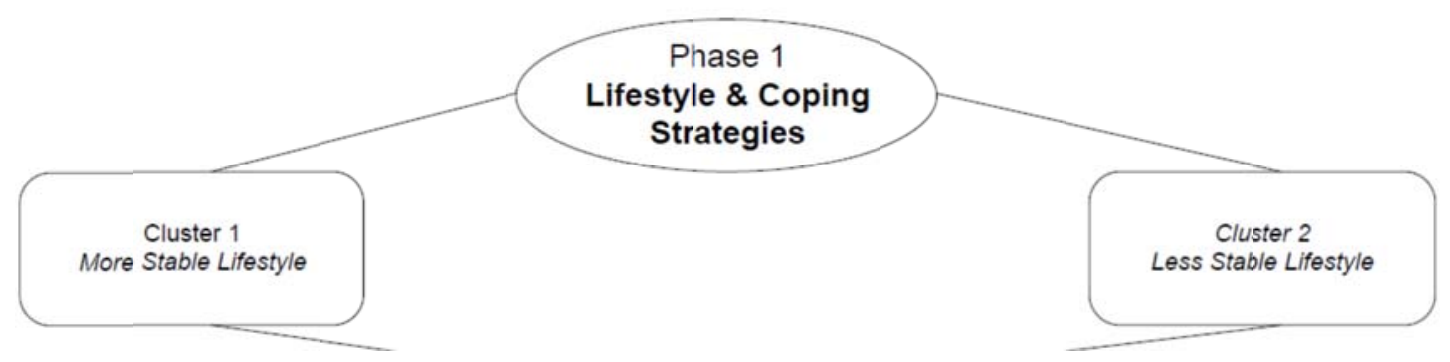

Figure 3. The lifestyle and coping strategies phase

Cluster 1 - More stable lifestyle ( $n=59)$. The offenders committing these offences were likely earning money either without paying income tax (cash in hand) or through legitimate employment. Results indicated that reliability of income was at the regular rather than sporadic end of the continuum. Offences were also characterised by offenders who were likely to have low-level criminal lifestyles. That is, they were less likely to be committing crime on a regular basis, or funding their lifestyles through crime. Similarly they were less likely to be regularly spending time with criminal friends or associates. For instance:

"Had good mates from childhood, was living with my parents and worked at a [marine] farm” (3207) 
“I’ve lots of family; I’m close to my mum and a manager at [a video store]” (1904) The men in this cluster used substances on a moderate to occasional basis. Moderate rumination was more likely in this cluster than in Cluster 2.

Cluster 2 - Less stable lifestyle (n=91). The offences in this cluster were committed by offenders who were likely to be unemployed, on benefits or earning money illegally through crime. This employment situation is likely the reason income reliability was 'sporadic' and criminal lifestyles were moderate to high. Substance use by men in this cluster was frequent to excessive. This cluster also reflected low levels of rumination. The following extracts help to illustrate these characteristics:

"I do three to four burglaries a week for money. I need \$1000 to \$2000 a week to pay for my drinking and lifestyle” (601)

“No job and drug debts. Had a dope habit, spending all my money on tinnies [packet of cannabis] (1805)

\section{Pre- and during-offence precipitating events and goal setting phase. The} precipitating events and goal setting phase (Figure 4) incorporates 14 variables, covering events and situations occurring in the lead up to offending that may have contributed to the offence occurring. For example, had the offender had any arguments with family members or his partner before the offence? Was the offending provoked, or carried out under the influence of drink or drugs? This phase also considers what the offender aimed or hoped to achieve by offending (i.e. his goals). For example, was the offending behaviour an attempt at self-defence or to protect family from a threat, a bid to steal money, or a means of exacting revenge for a personal slight? An ANOVA revealed 11 of the 14 variables differed significantly between clusters. 


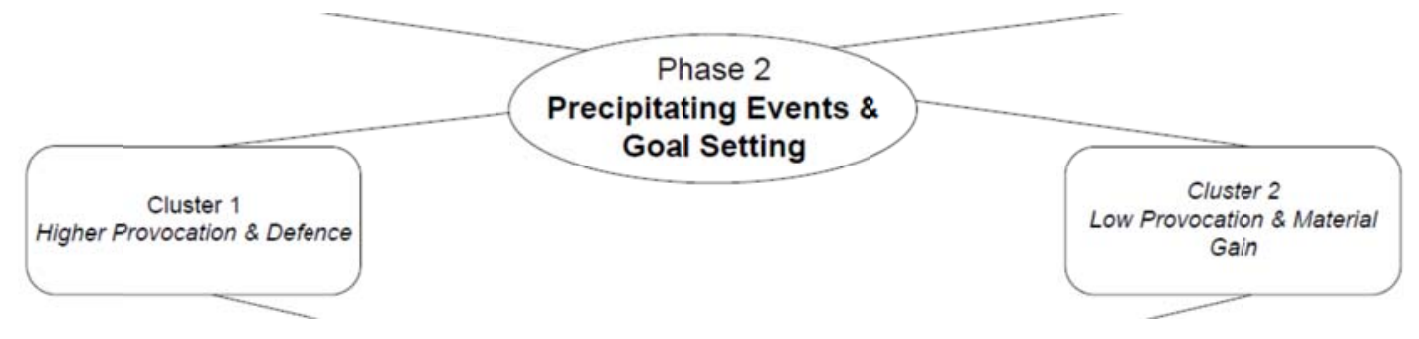

Figure 4. The precipitating events and goal setting phase

Cluster 1 - Higher provocation and defence $(n=42)$. Offences in this cluster were carried out by offenders who were more likely than Cluster 2 to have been provoked both indirectly (e.g., threats made against a family member) and directly, albeit to a low to moderate level (e.g., non-verbal gesture, partner infidelity, or insults). Offenders were most likely to have had goals of defence (see Study 1 method or Appendix C for definitions). The following extract describes a situation where a group including the victim confronted the offender just prior to the offence:

“I could have left, but I didn’t, I had a violent rep. I felt fearful and pressured, it was him or me. Confrontation was inevitable and I decided to strike first, hoping this would end the incident” (203)

Cluster 2 - Lower provocation and material gain $(\boldsymbol{n}=108)$. Offences in this cluster are characterised by offenders who were unlikely to have been provoked indirectly or directly. Offenders were most likely to have had goals of material gain. The following extract embodies these characteristics:

"I had fantasies about money. What kind of man am I? There is money everywhere, go and get it” (1805)

Pre- and during-offence planning phase. The planning phase (Figure 5) incorporates eight variables covering a range of planning related characteristics, in terms of both determining lack of planning as well as actual preparation. For example did the offender consider any of the potential negative consequences of offending (e.g., getting caught and 
going to prison)? Was there any degree of planning for the offence? Did he use a weapon? An ANOVA revealed seven of the eight variables differed significantly between clusters.

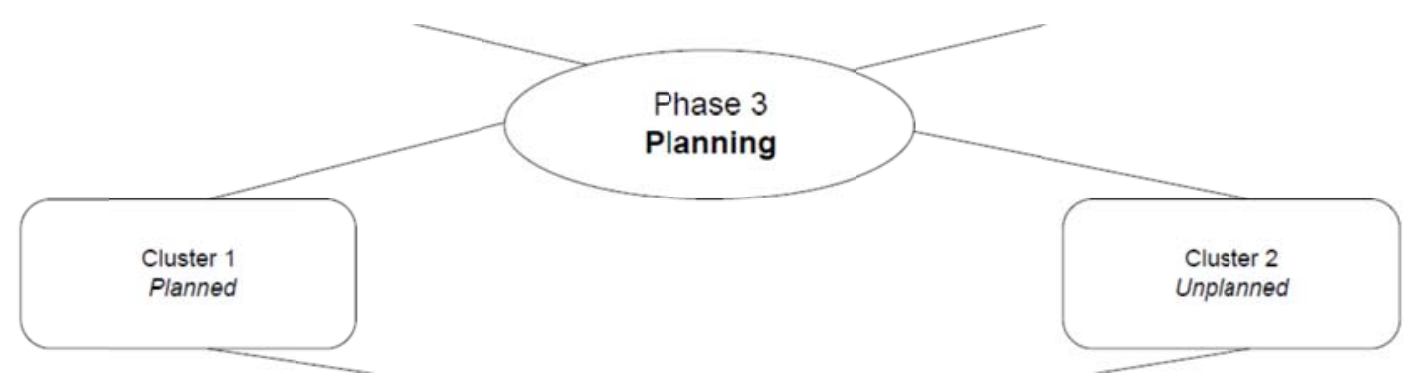

Figure 5. The planning phase

Cluster 1 - Planned ( $\mathbf{n = 7 9 ) . ~ T h e ~ o f f e n c e s ~ i n ~ t h i s ~ c l u s t e r ~ a r e ~ c h a r a c t e r i s e d ~ b y ~ a ~ s m a l l ~}$ amount of planning, for example, scene or victim selection or appropriating weapons in advance. Offenders also demonstrated a full conscious awareness of their intention to commit the crime. The offences in this cluster are likely to involve use of a weapon. These characteristics are illustrated by the following extract:

"We cased the place; I bought a wig and specs [disguise] and arranged guns and a driver” (2107)

Cluster 2 - Unplanned $(\boldsymbol{n}=71)$. The offences in this cluster are characterised by a lack of planning, or offences that were opportunistic in nature. Offenders tended to have some conscious awareness of their intention to commit the crime, and often knew the victims. The following extract illustrates an opportunistic offence from an offender who describes suffering morphine withdrawal symptoms just before his offence:

"Saw her [victim] collecting money, I followed her for a little bit then punched her and tried to snatch her handbag” (504)

During-offence violence enactment phase. The violence enactments phase (Figure 6) incorporates four variables covering the actual commission of the offence. This is the during-offence aspect; from the extent of injury caused to the victim to the resistance 
displayed by the victim, or self-control reported by the offender. An ANOVA revealed three of the four variables differed significantly between clusters.

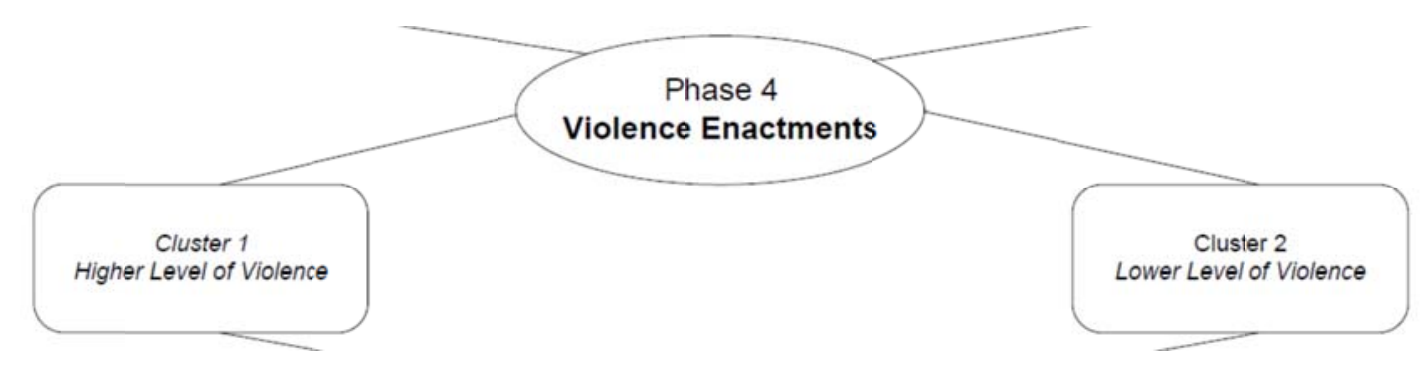

Figure 6. The violence enactments phase

Cluster 1 - Higher level of violence $(n=60)$. This cluster is characterised by offences involving moderate to high levels of violence, causing serious (e.g., broken limbs, gunshot wounds) to severe (e.g., life-threatening or cause lasting impairment) victim injuries. An offender's use of violence may appear to lack control but he is able to stop inflicting harm, displaying some level of self-control. The following extract is from the offence chain of an incarcerated offender who was in a bad mood and assaulted a fellow prisoner who was cheeky to him:

“I was going to use minimal force...because I wanted minimal consiequences. Kicked and punched [victim] unconscious dragged him into his cell and gave him a choker hold to knock him out again. I was [feeling] a bit fuzzy cos of the pills but I didn’t totally lose it like I normally do” (2102)

Cluster 2 - Lower level of violence $(\boldsymbol{n}=\mathbf{9 0})$. This cluster is characterised by offences involving low to moderate levels of violence, causing minor (e.g., bruises, small cuts) to moderate (e.g., severe bruising, larger wounds) victim injuries. Offenders tended to use as much violence as necessary to achieve their goals, demonstrating full-self control. In the following extract the offender describes having an argument with his partner, after which he wanted to be left alone: 
“I told her I needed time-out, she wouldn’t let me and she kept trying to pull my pants down so I cracked her. It perforated her eardrum” (2008)

Post-offence evaluations phase. The evaluations phase (Figure 7) incorporates five variables that aim to assess how an offender felt about the outcome of the offence after commission, or how it had affected him. The variables covered domains such as regret for the offender's own outcome or remorse for the victim. It also aims to record whether the offender thought the outcome of the offence was satisfactory; either soon after the offence or at some later date after the offender had time to reflect. An ANOVA revealed all five variables differed significantly between clusters.

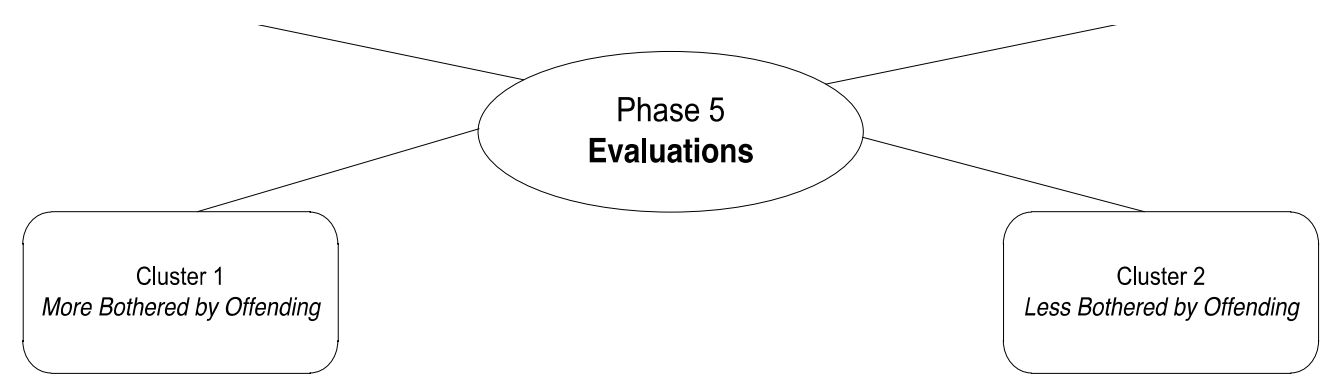

Figure 7. The evaluations phase

Cluster 1 - More bothered by offending ( $\mathbf{n = 7 8 ) . ~ T h i s ~ c l u s t e r ~ i s ~ c h a r a c t e r i s e d ~ b y ~}$ offenders who were generally dissatisfied with the offence outcome, both shortly after commission and at a later date. Offenders likely felt some remorse for the victim and also felt some regret about their own outcome. Offenders also tended to be preoccupied by the offence and unable to concentrate after commission. The following extract is from an offence chain where the offender owed money to drug dealers and decided to commit a robbery in order to raise enough money to pay off his drug debt:

"What did I just do? I am feeling so bad about it, I feel sorry for the family. I try to forget what I have done” (403) 
Cluster 2 - Less bothered by offending ( $n=72)$. Offences in this cluster are characterised by offenders who either did not disclose their feelings about the outcome soon after commission or felt ambivalent/generally satisfied about the outcome. However, this changed towards feeling generally dissatisfied with the outcome at a later date. Offenders erred towards feeling some regret for their own outcome, but little remorse for the victim. The following extract is taken from an offence chain where the offender was unhappy with his boss's attitude towards him. He arranged a social meeting with the victim and a cooffender where they assaulted the victim. Soon after the assault the offender reports:

“I am feeling happy it is done. Good, excited and hyped. Next day I felt bad, regretted my actions and resolved not to do it again” (103)

\section{Offence Pathways}

The results of the cluster analysis not only define the characteristics of each cluster, but also enable each offence to be allocated to one of the two clusters in each phase. In the next analytic step, the pathway through the model for each offence-which cluster it fell into in each phase-was determined. A decision was made to remove the Evaluations phase from the pathway allocation step of this study because it didn't appear to be related to the other phases in any meaningful way. As there was no standard template for therapists or offenders to use to construct offence chains, the information in this post-offence phase was highly variable, covering very different time frames between offenders. For a substantial number of offenders there was insufficient data to code the variables, and for others the data only referred to either soon after the offence, or to how the offender felt at the usually much later unspecified date when the offence chain was constructed. Although the data were retained for descriptive purposes in Study 1, they were judged too inconsistent for use in pathway construction. 
Sixteen different pathways emerged from this process. Of the 16, the 6 highest frequency pathways accommodating $62.7 \%$ of participants were initially selected for further exploration and discussion. Further examination showed that each of these 6 main pathways was associated with a second pathway that differed only in the precipitating events and goal setting phase. These 6 sub-pathways accommodated a further $20.7 \%$ of the sample; therefore in total these 12 pathways and sub-pathways accounted for $83.3 \%$ of the sample

The main pathways. The 6 most frequent pathways are described first. As displayed in Table 20 below, there are a number of similarities, in the form of shared phases between the main pathways, but there are also a number of differences. For the similarities, it is interesting to note that all Pathways from 1 through to 6 share the same subcategory of lower provocation and goals of material gain for the precipitating event and goal setting phase. Pathways 1, 2, 3 and 4 also share the same subcategory of less stable for the lifestyle and coping phase. Furthermore, Pathways 1 and 2 share the same planned subcategory for the planning phase, meaning Pathways 1 and 2 share the same route through the model apart from the violence enactments phase, where Pathway 1 follows the lower levels of violence subcategory, and Pathway 2 the higher level of violence subcategory.

In a similar vein, Pathways 3 and 4 share the same route through the first three phases of the model, although during the planned phase they share the unplanned subcategory. They also differ in terms of the violence enactments phase, where Pathway 3 follows the lower level of violence subcategory and Pathway 4 follows the higher level of violence subcategory.

Pathways 5 and 6 are the only two Pathways following the more stable subcategory of the lifestyle and coping phase, and as already noted they share the lower provocation and material gain subcategory for the precipitating events and goal setting phase. They differ on the final two phases, with Pathway 5 in the planned subcategory of the planning phase, and lower level of violence subcategory of the violence enactment phase. In contrast Pathway 6 is 
in the unplanned category of the planning phase and higher level of violence category of the violence enactments phase.

The sub-pathways. As noted above, the next six pathways paralleled Pathways 1 to 6, sharing the same route through all the phases of the model apart from the precipitating events and goal setting phase. Corresponding to their similarity to one of the six main pathways the sub-pathways are labelled 1A through to 6A, and are outlined in Table 21 . All six of the subpathways share the higher provocation and defence subcategory of the precipitating events and goal setting phase.

In terms of demographics, the results of an Analysis of Variance (ANOVA) revealed no significant differences between any of the pathways or sub-pathways for age at start of the rehabilitation programme $(F(11,112)=.36, p=.97)$, number of convictions $(F(11,112)=$ $1.05, p=.41)$, number of violent convictions $(F(11,111) .65, p=.78)$ or age at first conviction $(F(11,111)=.77, p=.67)$. 
Table 20.

Six Main Routes through the Pathways Model of Violent Offences

\begin{tabular}{|c|c|c|c|c|c|c|}
\hline \multicolumn{7}{|c|}{ Pathway } \\
\hline & 1 & 2 & 3 & 4 & 5 & 6 \\
\hline $\begin{array}{l}\text { Number of } \\
\text { Offences }\end{array}$ & 33 (22\%) & 11 (7.3\%) & 12 (8\%) & 14 (9.3\%) & 13 (8.7\%) & 11 (7.3\%) \\
\hline \multicolumn{7}{|l|}{ Phase } \\
\hline $\begin{array}{l}\text { Lifestyle \& } \\
\text { Coping }\end{array}$ & Less stable & Less stable & Less stable & Less stable & More stable & More stable \\
\hline $\begin{array}{l}\text { Precipitating } \\
\text { Event \& Goals }\end{array}$ & $\begin{array}{c}\text { Lower } \\
\text { provocation \& } \\
\text { material gain }\end{array}$ & $\begin{array}{c}\text { Lower } \\
\text { provocation \& } \\
\text { material gain }\end{array}$ & $\begin{array}{c}\text { Lower } \\
\text { provocation \& } \\
\text { material gain }\end{array}$ & $\begin{array}{c}\text { Lower } \\
\text { provocation \& } \\
\text { material gain }\end{array}$ & $\begin{array}{c}\text { Lower } \\
\text { provocation \& } \\
\text { material gain }\end{array}$ & $\begin{array}{c}\text { Lower } \\
\text { provocation \& } \\
\text { material gain }\end{array}$ \\
\hline Planning & Planned & Planned & Unplanned & Unplanned & Planned & Unplanned \\
\hline \multicolumn{7}{|l|}{ Offence Types } \\
\hline Robbery & 30 (20\%) & 5 (3.3\%) & $3(2 \%)$ & $2(1.3 \%)$ & $9(6 \%)$ & 0 \\
\hline Assault & $3(2 \%)$ & $6(4 \%)$ & $9(6 \%)$ & $12(8 \%)$ & $4(2.7 \%)$ & 11 (7.3\%) \\
\hline
\end{tabular}


Table 21.

Sub-pathway Routes through the Pathways Model of Violent Offences

\begin{tabular}{|c|c|c|c|c|c|c|}
\hline \multicolumn{7}{|c|}{ Sub-Pathway } \\
\hline & $\mathbf{1 A}$ & $2 A$ & 3A & 4A & $5 A$ & 6A \\
\hline Number of Offences & $4(2.7 \%)$ & $6(4 \%)$ & $7(4.7 \%)$ & $4(2.7 \%)$ & $4(2.7 \%)$ & $6(4 \%)$ \\
\hline \multicolumn{7}{|l|}{ Phase } \\
\hline $\begin{array}{l}\text { Lifestyle \& } \\
\text { Coping }\end{array}$ & Less stable & Less stable & Less stable & Less stable & More stable & More stable \\
\hline D - ita & Higher & Higher & Higher & Higher & Higher & Higher \\
\hline 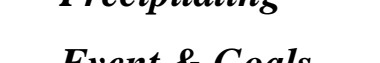 & provocation \& & provocation \& & provocation \& & provocation \& & provocation \& & provocation \& \\
\hline & defence & defence & defence & defence & defence & defence \\
\hline Planning & Planned & Planned & Unplanned & Unplanned & Planned & Unplanned \\
\hline Violence & Lower level of & Higher level of & Lower level of & Higher level of & Lower level of & Higher level of \\
\hline Enactments & violence & violence & violence & violence & violence & violence \\
\hline
\end{tabular}




\section{Pathways and Offence Types}

The main pathways. Table 22 below displays the number of robbery- or assault-based offences described in the offence chains in each of the main pathways. Pathway 1, which is the most 'popular' route, also appears to reflect a largely robbery based pathway, with 30 offences describing a robbery-based offence. In contrast, Pathways 4 and 6 appear to represent assault-based pathways, with all offences in Pathway 6 recorded as assault-based, and 12 of 14 offences in Pathway 4 recorded as assault-based. In the remaining Pathways 2, 3 and 5 it is less clear-cut. In these pathways there is a mixture of both assault- and robbery-based offence types.

Table 22.

Main Pathways by Offence type

\begin{tabular}{lcccccc}
\hline & \multicolumn{7}{c}{ Pathway } & & \\
& $\mathbf{1}$ & $\mathbf{2}$ & $\mathbf{3}$ & $\mathbf{4}$ & $\mathbf{5}$ & $\mathbf{6}$ \\
\hline $\begin{array}{l}\text { Number of } \\
\text { Offences }\end{array}$ & 33 & 11 & 12 & 14 & 13 & 11 \\
Offence Types & $(22 \%)$ & $(7.3 \%)$ & $(8 \%)$ & $(9.3 \%)$ & $(8.7 \%)$ & $(7.3 \%)$ \\
\multicolumn{1}{l}{ Robbery } & 30 & $5(3.3 \%)$ & $3(2 \%)$ & $2(1.3 \%)$ & $9(6 \%)$ & 0 \\
& $(20 \%)$ & & & & & 11 \\
Assault & $3(2 \%)$ & $6(4 \%)$ & $9(6 \%)$ & $12(8 \%)$ & $4(2.7 \%)$ & $(7.3 \%)$ \\
\hline
\end{tabular}

The robbery-based Pathway 1 is characterised by less stable lifestyle characteristics, a basic level of planning and less serious victim injuries. In contrast, the assault based Pathways 4 and 6 represent both a less stable and more stable lifestyle respectively, they both also indicate an unplanned or opportunistic crime where the victims suffer more serious injury.

On the surface these particular Pathway divisions by offence type do make some sense, fitting within stereotypical concepts. Robbery is generally thought of as a 
planned, instrumentally aggressive offence so it is unsurprising that a 'robbery pathway' reflects a level of planning and lower levels of violence. Likewise, an assault is often thought of as an angry, reactively aggressive response to a situation. Thus an 'assault pathway' that reflects a lack of planning and higher levels of violence isn't exactly a surprise. What is worth noting is that even the 'assault pathways' are characterised by lower provocation and goals of material gain (as are all the main pathways) and this could be considered unusual as assault often associated with provocation. Also of interest are the results for Pathways 2, 3 and 5 which all consist of a mixed selection of assault-based and robbery-based offences. Pathways 2, 3 and 5 reflect a mixture of less stable and more stable lifestyle characteristics. They also reflect a mixture of basic planning with both higher and lower levels of violence. This tends to suggest that an offence involving a degree of planning does not necessarily mean an offender will, or is able to utilize violence with full self-control.

The sub-pathways. As previously noted, each of the sub-pathways $1 \mathrm{~A}$ through to 6A corresponds with a main pathway (1 through to 6 ), following the same route through the PMVO. The only difference is that all the sub-pathways share the same subcategory of higher provocation and goals of defence for precipitating events and goal setting phase. This is in direct contrast to the six main pathways which all share the opposite subcategory (lower provocation, material gain) for this phase.

Without exception all offences in all six sub-pathways described assault-based offences. Therefore all six of the sub-pathways appear to represent 'assault pathways'. In terms of the precipitating events and goal setting phase, perhaps the dominance of assault-based offences makes more intuitive sense here, since it is more fitting with a traditional ideas of reactive aggression (e.g., Cornell et al., 1996) since all of the sub- 
pathways reflect an increased likelihood of the participants being provoked to some degree either directly and indirectly, or both.

The following section considers these results within the context of relevant theory. Comparisons are also made between the current results and those of similar offence process models.

\section{Discussion Study 2}

The aim of Study 2 was to investigate whether it was possible to construct a parsimonious series of pathways to represent the offence process for this diverse sample of violent offences by deriving pathways using a quantitative based approach. Therefore, cluster analysis was utilised and a resultant model, the Pathways Model of Violent Offences (PMVO) was constructed. Six main offence process pathways (1-6, see Table 20 on p. 81) were revealed, each with an associated sub-pathway (1A-6A, see Table 21 on p. 82). The offence types associated with each pathway were also recorded (see Table 22 on p. 83). An ANOVA revealed there were no significant differences across the pathways in offender age, age at first conviction, and number of violent and non-violent convictions.

In the following sections the Study 2 PMVO pathway results will be discussed using Megargee’s (1966) theory on under-controlled and over-controlled offenders, and the instrumental-reactive violence dichotomy as a guide. Within this framework both expected and more unexpected associations between offence types (robbery and assault) and pathway phases (e.g., lifestyle and coping phase or planning phase) will be examined. For example, according to the instrumental-reactive violence dichotomy we might expect to see an association between goals of material gain and planning and in turn associate both of these characteristics with a robbery offence. 
Comparisons will then be drawn between PMVO pathways and two relevant studies, Chambers (2006; Chambers et al., 2009) Pathways Model of Assault (PMA), and Nightingale’s (2002) Aggravated Robbery Model (ARM).

\section{Expected and Unexpected Pathway Associations}

Less stable and more stable lifestyle characteristics. It is well documented that leading a chaotic lifestyle is common for many offenders (e.g., Zamble \& Quinsey, 1997; Chambers, 2006). Therefore it is unsurprising that four out of six pathways (Pathways 1, 2, 3 \& 4) revealed in the current study consist of offences where less stable lifestyle and coping characteristics were recorded for the offender. A less stable lifestyle is associated with lower levels of employment, with more offenders on benefits or funding their lifestyles through their moderate to high criminal lifestyle. They likely associate with criminal peers, demonstrate low levels of rumination but engage in frequent to excessive drug use.

Yet, what is a little more unexpected from this sample of offences is that two of the six pathways (Pathways 5 \& 6) were characterised by offences where more stable lifestyle and coping characteristics were recorded for the offender. A more stable lifestyle reflects higher levels of employment (either legitimate or without paying income tax), and a lower level of criminal lifestyle (i.e., committing fewer crimes and having fewer criminal friends/associates). Offenders committing these offences were also more likely to demonstrate moderate levels of rumination and more moderate substance use. Megargee’s (1966) theory on under-controlled and over-controlled offender types provides a useful framework with which to examine the two types of lifestyle described in the offences of the current study.

According to Megargee (1966) under-controlled offenders are likely to be repeat offenders, easily provoked and more likely to respond with less extreme levels 
of violence. Over-controlled offenders are unlikely to have a violent history but severe violence may result from extreme provocation. With this in mind it is speculated that Pathway 1 to 4 offences were committed by offenders who resemble Megargee's definition of the under-controlled offender type. Two main points provide some support for this speculation.

First, the characteristics of a less stable lifestyle indicate that the offences were committed by persistent offenders engaging in a higher level of criminal lifestyle. The conviction rates lend some support for this, with men associated with a less stable lifestyle having a greater number of convictions (violent convictions $M=7.42, S D$ $=5.58$, non-violent $M=47.31, S D=35.16$ ) than those associated with a more stable lifestyle (violent convictions $M=6.79, S D=6.16$, non-violent $M=36.80, S D=36.85$ ). However, whilst a one-tailed independent samples t-test on violent $(t(123)=.54, p$ $=.29)$ and non-violent $(t(123)=1.47, p=.07)$ convictions revealed the differences were not significant, results were trending towards significant for non-violent convictions.

Second, not only were Pathway 1 to 4 offences associated with a less stable lifestyle, they were, in line with Megargee’s (1966) definition also associated with lower levels of provocation. Thus, a relatively unstable lifestyle, violent offences precipitated by low levels of provocation combined with a history of violence appears to be consistent with Megargee's definition of an offence committed by an undercontrolled offender type.

In contrast, Pathways 5 and 6 were associated with offences where offenders described a more stable lifestyle. What is interesting to examine here is why these offences occurred when the offenders appeared to have a more stable lifestyle? It could be that the offenders who committed these offences can be likened to 
Megargee’s (1966) over-controlled offender type. We would therefore not expect these offenders to have an extensive history of violence. Indeed, as detailed above the violent offence history for offenders who committed the offences in Pathways 5 and 6, whilst not significantly different, is lower than those in Pathways 1-4.

However, according to Megargee (1966) over-controlled offender types generally only use violence as a response to high levels of provocation. Pathway 5 and 6 offences are characterised by low levels of provocation, which as a result is inconsistent with Megargee’s description. Thus, another plausible suggestion is that these two pathways represent offences committed by offenders who are in the process of desisting from crime, but who, when presented with an opportunity will still take it. Or alternatively, offending on this occasion was an attempt at problem-solving a specific issue, such as lack of money. For Pathway 5, the fact that over two thirds of the offences were robberies with some level of planning adds weight to this suggestion. However, this is clearly not the case for Pathway 6 where offences were unplanned and all assault offences.

The offences in Sub-pathways 5A and 6A may provide a better representation of Megargee’s (1966) idea of over-controlled offender types. Sub-pathways 5A and 6A are not only characterised by a more stable lifestyle, they are also associated with higher levels of provocation. In addition, the offences following these two subpathways account for only a small number of the total sample, $6.7 \%$ of all offences, a plausible frequency. In combination, it is speculated that these characteristics resemble Megargee’s (1966) description of an over-controlled offender type (relatively uncommon in offender populations but who use violence in response to high levels of provocation). Moreover, lending support for this speculation, the mean violent $(M=5.80, S D=5.55)$ and non-violent $(M=26.80, S D=16.51)$ conviction 
rates of Pathways 5A and 6A are lower than the rest of the sample (violent $M=7.37$, $S D=5.74$, non-violent $M=45.98, S D=36.64)$. One-tailed independent t-tests revealed the differences reached significance for the non-violent convictions ( $t$ (123) $=3.07, p>.001)$, but not the violent convictions $(t(123)=.83, p=.20)$.

Level of planning was also pertinent in Chambers (2006) identification of over-controlled and under-controlled offenders. Chambers discovered that level of planning differentiated offences committed by under-controlled versus overcontrolled offenders in her sample. More specifically, a lack of planning was associated with offences committed by under-controlled offender types. In contrast, the potentially under- and over-controlled offenders of the PMVO pathways and subpathways reflect a mixture of both planned and unplanned offences. It would therefore be easy to conclude that the results of the current study do not support Chambers findings in relation to planning.

However, the limited cognitive information (e.g., offender thoughts or feelings) in the offence narratives means the current study may not have been as thorough in recording planning activity as Chambers was in her research. For instance, the unplanned category of the current study may not necessarily tell the full story for the offences in this sample. It is unlikely that levels of implicit planning would have been consistently detected. According to Chambers (2009), implicit planning refers to a situation where the offender does not appear to be cognizant of their preparatory steps to offending.

Similarly, unplanned doesn’t accurately reflect a situation where little or no planning was required because of the level of expertise or automaticity of the offender describing that offence. For example, the offender has committed numerous similar 
robberies and has well established robbery scripts, or the use of violence is such an ingrained response to conflict it is utilised without apparently conscious thought.

Ward and Hudson's (1998) approach and avoidance goals from the sex offender self-regulation model could prove particularly useful in investigating the finer details of the more proximate offence process. Approach goals (approachautomatic, approach-explicit) represent situations where the offender is determined to offend, whereas avoidance goals (avoidant-passive, avoidant-active) represent situations where the offender wants to avoid offending. Specifically, identifying an approach-automatic goal would help distinguish between automatic or expert offending from other types of unplanned offending. In addition, differentiating between approach-automatic and avoidant-passive goals would further unpack the occurrence of implicit planning.

\section{Lower provocation associated with higher levels of violence in Pathways 2,}

4 and 6. The conventional view of the instrumental-reactive violence dichotomy would suggest that Pathway 2, displaying goals of material gain and a level of planning, represents a classic instrumental offence (Buss, 1961). Pathway 2 also consists of approximately half robbery and half assault offences. Yet the higher levels of violence contradict the assertion that offenders committing instrumental offences generally use as much violence as required to achieve their goal (Tapscott, Hancock, \& Hoaken, 2012). Therefore, one straightforward explanation for the higher levels of violence could be that due to the circumstances of the offence the violence was required to achieve the goal. However, this does seem unlikely in the absence of provocation, unless it was perhaps required to overcome increased victim resistance.

On the other hand, higher levels of violence could reflect offences where the offender had mixed motives. For instance, an offender could have a goal of material 
gain where low levels of violence were actually required to achieve the transfer of goods. However, the offender employed higher levels of violence to punish the victim for some infraction or to increase the offender's reputation. In this case, the association of lower provocation and material gain goals with higher levels of violence would add weight to some criticisms of the instrumental-reactive violence dichotomy. Some researchers (e.g., Bushman and Anderson, 2001) argue the instrumental-reactive violence dichotomy is inflexible and tends to assume that offences are either instrumental or reactive. Yet in reality many offences reflect elements of both.

Mixed motives may also best explain the low provocation and increased violence associated with Pathways 4 and 6. Unlike Pathway 2, which was associated with planning and consisted of roughly equal numbers of assault and robbery offences, Pathways 4 and 6 offences were not planned and consisted almost entirely of assaultbased offences. It is difficult to reconcile the fact that nearly all the offences were assault-based but also associated with goals of material gain and low provocation without speculating there was a strong likelihood that the offender may have had both an instrumental goal with some form of reactive response.

\section{Comparison of PMVO Pathways with the ARM and PMA}

On a general note about the following section, whilst some speculative comparisons are drawn it is not possible to make accurate direct comparisons between the current study and those of Chambers (2006) and Nightingale (2002). Direct comparisons are difficult because both the PMA (Chambers, 2006) and the ARM (Nightingale, 2002) were constructed from substantially more detailed offence narratives, albeit with much smaller sample sizes. In particular, both models examined the offender's developmental history and cognitive aspects; such as affect and 
attitudes to violence along with the offence process itself. In addition, post-offence evaluations were also considered. In contrast, due to the limited nature of the archival data the current study includes information from immediately before, and during the offence process.

The discussion will first consider the distribution of offences within the PMVO pathways before drawing speculative comparisons between the PMVO pathways and those of the PMA (Chambers, 2006; Chambers et al., 2009) and ARM (Nightingale, 2002). More specifically, the fact that none of the PMVO pathways resemble the majority pathways of either the PMA (Pathway 1) or the ARM (Positive Affect Pathway) will be discussed followed by three apparent similarities between the studies: 1) PMVO Pathway 1 and ARM Negative Affect pathway, 2) PMVO Pathway 5A and PMA Pathway 4, and 3) PMVO Pathway 6A and PMA Pathway 5.

Offence distribution. Of the total sample $(n=150), 62 \%(n=93)$ of the offences describe an assault and 38\% ( $n=57)$ describe a robbery. Overall the 12 PMVO pathways and sub-pathways account for $83.3 \%$ of the total sample. The pathways also account for roughly equal percentages of each offence type, $85 \%$ $(n=49)$ of all robbery offences and almost $82 \%(n=76)$ of all assault offences. A single pathway: PMVO Pathway 1 accounts for the bulk of the robberies with 55.6\% $(n=30)$. The remaining $29.4 \%$ ( $n=19$ ) of the robberies are divided between a further four pathways. Thus, the robbery offences are distributed across five pathways with most contained within PMVO Pathway 1. In contrast, the assault offences are divided between all 12 pathways with Pathway 4 containing the most assault offences in a single pathway with only12.9\% $(n=12)$ offences. This raises the question of why are robbery offences confined to only a few of the pathways when assault offences are distributed across all the pathways? 
The greater diversity of assault offences compared to robberies is in line with previous research. Nightingale (2002) only identified two main pathways in her research on aggravated robbery, whereas Chambers (2006; Chambers et al., 2009) identified five main pathways in her work on assault. In both of these cases the selection criteria were also fairly narrow, unlike the current study. Chambers selected assaults only where the "main objective was to hurt the victim” (Chambers, 2006, p.80), and Nightingale included mainly 'traditional' robberies (ultimate goal of material gain), though her model did display some promise in accommodating assault robberies too. Therefore, it is plausible that 'traditional' and assault-based robberies may demonstrate similar offending characteristics. As a result, and in line with the results of the current study, we could expect there to be fewer pathways to robbery offending overall.

|Reasons for the differences in distribution of assault and robbery offences among the pathways of the current study can only be speculated upon. However, it can be argued with more certainty that in line with previous research, some of the pathways of the current study support the idea there are different routes to offending both between (e.g., Zamble \& Quinsey, 1997) and within (e.g., Chambers, 2006; Nightingale, 2002) different types of offences. On the flip side, robberies and assaults also load onto the same pathway on some occasions. Both offence types loaded onto one pathway indicate that perhaps routes to different types of offending are not always distinct.

Majority pathways of the PMA and ARM. Surprisingly, none of the PMVO pathways singularly appeared to resemble either of the most common pathways of the ARM (Nightingale, 2002) or the PMA (Chambers, 2006; Chambers et al., 2009). For the ARM the most common was the Positive Affect Pathway. This pathway was 
characterised by younger offenders ( $M=18$ years old) who felt good in the lead up to offending, and the robbery was part of a valued criminal lifestyle (Nightingale). One explanation for the disparate results of the PMVO and ARM Positive Affect Pathway relates to offender age. Indeed, it is generally acknowledged that offending patterns alter as criminals’age (e.g., Piquero, Oster, Mazerolle, Brame, \& Dean, 1999). The mean age of offenders who committed the offences of the current sample is nearly 31 years, much older than the 18 years of the ARM Positive Affect Pathway offenders. As a result the two samples may reflect a different profile of robbery offender.

More specifically, the Positive Affect Pathway appears to reflect young, sensation-seeking males who value their criminal lifestyle (Nightingale, 2002). In contrast, the offenders in the current sample, likely reflect a relatively more mature sample. It is acknowledged that increasing age leads to better emotional control (Kochanska, Merry, \& Harlan, 2000), and a reduction in sensation-seeking behaviour (Costa \& McCrae, 1994). In addition, since the process of desistance from offending is also associated with increasing age (Sampson \& Laub, 2005), at least some of the current sample are likely to have been attempting to avoid offending. Desistance for some of these offenders most probably represents an avoidance goal, and avoidance goals are generally associated with negative affect (Ward \& Hudson, 1998). In summary, the current sample represents a different profile perhaps better described as more mature, a tendency toward negative affect and with at least some offences committed by offenders trying to desist from crime.

In the PMA (Chambers, 2006; Chambers et al., 2009), Pathway 1 (40\% of the sample) is the most common. On account of the similarities to Megargee's (1966) under-controlled offender type Chambers also posits, Pathway 1 represents the “typical violent offender” (Chambers et al., 2009, PMA p. 1439). PMA Pathway 1 is 
characterised by offences committed by offenders with unstable lifestyles where violence was an instant reaction to perceived threat. According to Chambers et al., (2009) these offenders resemble Megargee’s $(1966,1979)$ under-controlled type of offender who believes violence is an appropriate and necessary problem-solving tool. Goals of violence are mixed and varied for these offenders, for example a defence goal could evolve into one of revenge.

Whilst no singular PMVO pathway resembles PMA Pathway 1, it is suggested that an amalgamation of PMVO Pathways 3, 3A, 4 and 4A would produce a single pathway that does resemble PMA Pathway 1. The logic lies in the detail of the PMVO phases, particularly levels of provocation and goals and levels of violence. What Pathways 3, 3A, 4 and 4A do share are offences committed by offenders with less stable lifestyle characteristics and an apparently unplanned offence. Combined they also reflect both higher and lower levels of provocation, mixed goals (i.e., defence and material gain) and both higher and lower levels of violence. In addition, all four of these pathways are mainly made up of assault offences.

Other than differentiating between under-controlled (lower levels of violence common) and over-controlled (associated with severe violence) offender types Chambers does not appear to differentiate levels of violence within the three pathways she describes as under-controlled (Pathways 1, 2 \& 3, 80\% of the sample). Yet, offenders included in Chambers (2006; Chambers et al., 2009) research had been convicted of a range of offences; 1) Assault causing injury, 2) Assault causing serious injury, and 3) Assault other. Thus, it is speculated, based on the PMVO model, that PMA Pathway 1 would consist of offences reflecting various levels of violence.

Furthermore, PMA Pathway 1 offenders are described as under-controlled, and would therefore have a low tolerance for provocation, but that does not 
necessarily mean that in committing these offences, offenders were not subjected to higher levels of provocation. Similarly, PMA Pathway 1 offences are described as having multiple goals, and goals that may change during the offence process.

In summary, in some respects the added levels of differentiation of PMVO Pathways in terms of violence and goals means that comparing the PMVO pathways with the PMA Pathways is arguably like comparing apples with pears. By amalgamating PMVO Pathways 3, 3A, 4 and 4A the added levels of differentiation are eliminated, and if the resulting new pathway is compared with PMA Pathway 1 similarities are apparent. More specifically, both the amalgamated PMVO Pathway and the PMA Pathway 1 consist of unplanned assault offences likely committed by offenders who resemble Megargee’s (1966) under-controlled offender type. However, other than drawing attention to similarities between the two models that are not immediately obvious, there is no real benefit to amalgamating the four PMVO pathways, as the finer-grained level of detail of the proximate offence process is lost.

PMVO Pathway 1 and ARM Negative Affect pathway. PMVO Pathway 1 and the Negative Affect Pathway of the ARM (Nightingale, 2002) appear to share a number of offence characteristics beyond simply that they both reflect robbery offence pathways. The Negative Affect Pathway is characterised by offences where the offenders view their lives negatively and the offences were generally committed in response to an increasing desperation for money or drugs. The offenders were also likely to use low levels of violence to achieve their goals.

Similarly, PMVO Pathway 1 offences consist of offenders who report an unstable lifestyle, with a high level of substance abuse and crime. Offences in both pathways are also likely to be reflected by lower levels of violence. Age was another differentiating factor between Nightingale's two pathways, with offences committed 
by older offenders (24 years) associated with the Negative Affect Pathway, compared to the significantly younger offenders (18 years) of the Positive Affect Pathway. The mean age of offenders in PMVO Pathway 1 is 31.24 years, which is consistent with the ARM findings. In summary, both the PMVO Pathway 1 and the ARM negative affect pathway share similarities in terms of offence type, level of violence, substance use and offender age.

PMVO Pathway 5A and PMA Pathway 4. There are a number of commonalities shared by these two pathways. For instance, both pathways consist of assault offences committed by offenders who arguably resemble Megargee’s (1966) over-controlled offender type. Both pathways are also low frequency pathways in that they each consist of a minority proportion of the total sample (PMA Pathway 4 - 14\%, PMVO Pathway 5A - 2.7\% of sample).

Similarly, both pathways are associated with offenders with a stable lifestyle and planned offences. Consistent with Megargee’s (1966) description of an overcontrolled offender, Chambers reports that prior to the offence PMA Pathway 4 offenders were generally against violence and had placid temperaments. Of note however is the presence of extensive rumination about their victims and the situation in the run up to offending (e.g., cognitive rehearsal, imagining violent acts against victim). Chambers suggests it was this extensive rumination that aided offenders in preparing for “the unfamiliar application of violence” (Chambers, 2006, p. 275). Ultimately, these offenders chose to use violence in the absence of any other satisfactory approach to resolving the situation.

Along with the other commonalities, rumination also features in the offences in PMVO Pathway 5A. Moderate levels of rumination are associated with offences where a more stable lifestyle is recorded for the offender, this includes PMVO 
Pathway 5A. Beyond simply identifying the presence or absence of rumination Chambers (2006) was also able to differentiate between different types of rumination. For example cognitive rehearsal or imagining harming the victim was associated with PMA Pathway 4 offences, whereas PMA Pathway 5 offences discussed below were associated with a more internally focused rumination or self-blame rumination. Unfortunately, information coded for rumination in the PMVO was not sensitive enough to differentiate between types.

The results of both the PMA and the PMVO indicate rumination is associated with offences committed by over-controlled offender types. As such, a more detailed examination of rumination could be an interesting angle for future pathways research. Ultimately, for both pathways violence appears to have been the eventual response to an ongoing situation, where rumination was involved in overcoming existing reservations regarding the utility of violence.

PMVO Pathway 6A and PMA Pathway 5. These two assault pathways have a number of other similarities. For instance, both consist of offenders who reported a more stable lifestyle yet inflicted a high level of violence. In this respect, the perpetrators of these offences resemble Megargee’s (1966) over-controlled offender type. For PMA Pathway 5 Chambers (2006) described the offence as implicitly planned and the result of an emotional overload. In terms of PMVO Pathway 6A, the offences were recorded as unplanned but as previously discussed the nature of the data made it unlikely levels of implicit planning would have been detected. Violence as a result of emotional overload does however make some sense of the unexpected associations of the PMVO Pathways 6A. For example, it may help explain why an offender living a more stable lifestyle commits an apparently unplanned serious assault. 
In addition rumination was also detected in offences from both pathways. Chambers (2006) identified that an internally focused rumination was involved in PMA Pathway 5 offences. Unfortunately, only the presence of moderate levels of rumination in general were recorded in the PMVO Pathway 6A, so further research in this area is required.

\section{Implications}

Study 1 aimed to address a conspicuous gap in the current violence literature. The completion of Study 1 provided a detailed descriptive breakdown of characteristics associated with a heterogeneous sample of violent offences. A particular strength of the study overall is that the data represents offences from a highrisk sample of violent offenders. It also provided the data for the further investigation conducted in Study 2.

Study 2 used the descriptive results provided by Study 1 to further explore the heterogeneity of violent offences. Study 2 aimed to investigate whether it was possible to construct a series of pathways to represent the offence process for this diverse sample of violent offences. Twelve pathways accounting for $83.3 \%$ of the sample were revealed, almost half of which supported the idea that different types of offence shared a number of common characteristics. Comparison of the pathways of the current study with previous descriptive research on aggravated robbery offences (Nightingale, 2002) and assault offences (Chambers, 2006; Chambers et al., 2009) identified a number of similarities. The remaining $16.7 \%$ of the sample unaccounted for by the pathways consisted of a variety of individual, idiosyncratic routes through the PMVO.

Theoretical Implications. The results of the current study are consistent with aspects of existing models of the specific offence types of assault (Chambers, 2006; 
Chambers et al., 2009) and robbery (Nightingale, 2002). Moreover, with respect to the more proximate characteristics of the offence process (i.e., during the offence) the PMVO both builds on the work, and extends the scope of these existing models, particularly the PMA (Chambers). The PMVO provides greater detail on proximate offence characteristics such as levels of provocation and severity of violence. This greater detail demonstrates the diversity of offences committed by offenders labelled as under-controlled in the current study, and also arguably in previous research (Chambers, 2006; Megargee, 1966).

In a similar vein the results of the current study also appear to be in line with Megargee's (1966) theory on under-controlled and over-controlled offender types. In particular, a number of pathways (Pathways 1-4) in the current sample are associated with characteristics that resemble Megargee’s description of an under-controlled offender type (a less stable lifestyle and low levels of provocation). In addition, a small proportion of offences contained within two pathways (Sub-pathways 5A \& 6A) are associated with characteristics resembling Megargee's description of an overcontrolled offender type (more stable lifestyle and higher levels of provocation).

There are however, a number of offence pathways that are not accurately encapsulated by either description of Megargee’s under-controlled or over-controlled offender types. Therefore, the current results are perhaps more in line with Blackburn's (1986) work, which although based on Megargee’s findings, suggests there is substantial diversity among offenders who would fall under the descriptive umbrella of under-controlled or over-controlled offender types.

As a result of methodological differences there is little to be gained by directly comparing the PMVO pathways with Blackburn’s groups, but Blackburn found four groups of offender type. Two were classed as over-controlled, with lower scores of 
hostility and aggression, and two were classed as under-controlled with higher scores on hostility and aggression. On the basis of different levels of lifestyle stability, provocation and violence severity an argument could be made for the existence of up to eight groups from the PMVO pathways, half pertaining under-controlled and half to over-controlled offender types.

With respect to the debate surrounding the instrumental-reactive violence dichotomy the current study provides some interesting results. The PMVO pathway results appear to represent apparently instrumental offences (e.g., Pathway 1), reactive offences (e.g., Sub-pathway 4A) and offences that might be better explained as mixed motive or containing elements of both types of violence (e.g., Pathway 4). Therefore whilst it seems a number of offences could be adequately categorised by the dichotomy, rigidly adhering to it could leave a portion of the current sample offences either difficult to classify or forced to fit, which is not necessarily reflecting the actual events. Thus, the concerns raised about the dichotomy regarding the oversimplification of violence (e.g., Anderson \& Bushman, 2001; Woodworth \& Porter, 2002), are certainly valid for a proportion of the offences in the current sample. For the purposes of the current research, Woodworth and Porter’s (2002) dimensional approach with instrumental and reactive violence situated at opposite ends of a continuum would have successfully encapsulated the majority of the sample.

Treatment Implications. The identification of recurring common characteristics shared within and sometimes between offence types may help clinicians to develop specific offence relapse interventions. Polaschek (in press) recently highlighted that beyond sex offender rehabilitation there is a lack of midlevel intervention theories. These mid-level theories provide conceptual frameworks for designing more specific interventions for offenders with specific characteristics. It 
is therefore hoped the current research would help fuel the future development of mid-level theories by providing rich descriptive information on violent offence characteristics.

More specific implications relate to the heterogeneity of violent offences as revealed by the current research. In particular it underlines the need to consider and treat the perpetrators of these offences as individuals and tailor treatment goals and interventions accordingly, in line with the principles of risk, need and responsivity (Andrews \& Bonta, 2010). Allocating offenders by offence process similarities is one option.

Other descriptive studies have suggested that it may make sense to allocate offenders in treatment based on certain aspects of their offence processes: for example, allocation based on shared self-regulation styles, offence goals (e.g., Cassar, et al., 2003), or offender type (Chambers, 2006). The argument behind such allocations is that offenders sharing certain common features are likely to have similar treatment needs (Cassar et al., 2003). The results of the current study also tend to support this argument, specifically in terms of the differences between offences where offenders demonstrated less stable versus more stable lifestyle characteristics. Arguably these two types resemble Megargee’s (1966) under-controlled and over-controlled offender types where the requirement for differential approaches to treatment has been highlighted (Chambers, 2006).

That the current study, and other similar descriptive studies are based on a single offence per offender carries with it a caveat to the treatment implications described above. The results of such descriptive studies tend to imply each offence is a typical representation of offending behaviour for that perpetrator, when in fact it 
may represent an atypical sequence of events. Future longitudinal descriptive studies would assist in clarifying this situation.

\section{Limitations and Future Research}

There are a number of limitations associated with the current study, the majority of which fall under one of the following four main headings: 1) offender perspective, 2) use of archival data, 3) convenience samples, and 4) analyses. These four areas will be discussed in the following section.

1) Offender perspective. The current research is a retrospective study based solely upon offence chains written from the offender perspective. Although the offender perspective is important, relevant and not to be ignored (Camp et al., 2013), issues with self-report data are widely acknowledged (e.g., Coolican, 1994; Wright \& Decker, 1997). For example, issues with recall, distortion or omission of facts and social desirability. However, corroboration of offence narratives used in the current study was sought to some degree. The offence narratives were often constructed with the assistance of therapists with access to file information, and offenders were invited to reconcile any discrepancies between their report of events and the file information

(D. Polaschek, personal communication, $23^{\text {rd }}$ February, 2013,).

2) Use of archival data. The use of archival data meant the available offence chains varied considerably in the level of descriptive detail, ranging from a comprehensive description of the entire process to the briefest of details confined to the offence. Particularly problematic as a result of data inconsistency was information recorded on post-offence evaluations. Although reported in Study 1, these data were not included in Study 2. Future studies, using alternative or multiple data sources may prove more successful in accurately capturing such information. In this case a semistructured interview approach would have been useful in collating more 
comprehensive offence narratives from all offenders, thus providing a more consistent foundation for analysis in Study 2.

3) Use of a convenience sample. Essentially the archival data provided access to a convenience sample consisting of a wide variety of offences that were selected only on the basis the offence chain contained sufficient detail. Furthermore, all offence chains in this sample were obtained from offenders who completed them as part of their rehabilitation programme. The sample is therefore not necessarily representative of the New Zealand violent offender population. In order for offenders to attend rehabilitation they must be identified as eligible and also willing to attend. Therefore the sample does not reflect those violent offenders who were still at large, were imprisoned but ineligible (for whatever reason), or those that were eligible but refused to take part in the programme. Since the focus of the current study was on a sample of high-risk violent offences, the selection criteria of the current sample did not take into consideration other relevant aspects relating to generalisability of results. For instance, age range, offence type and cultural differences were not considered in the selection procedure. These are discussed in more detail below.

In terms of age, the mean age of the offenders in the current sample was nearly 31 years with a range of 18 to 60 years, however this was for offender age at the start of the rehabilitation process, not the age of the offender when the actual offence was committed. It would also be worth investigating offence pathways within age brackets since it is acknowledged that offending patterns are subject to change across an individual’s lifetime (Moffit, 1993; Sampson \& Laub, 2005).

In terms of offence type the range of offences in this study was diverse. Whilst investigating offence diversity was at the heart of the current study, it also represents a limitation. Broadly speaking the current sample consisted of two main offence 
types; assault-based (including murder) and robbery-based. However, the heterogeneity even within each of these offence types was extensive. For instance, there were levels of violence ranging from verbal threats to deadly force along with a variety of offender goals.

Moreover, the different offence types were not all equally represented in the sample. This unequal distribution could be problematic as Nightingale (2002) found with the ARM. She discovered that whilst the ARM worked well with more traditional robberies and showed some promise with assault-based robberies, it was less successful in encapsulating revenge-based robberies. Careful selection of the sample to represent different offence types in equal numbers could address this issue in future work. In addition, some of the current results show both robberies and assaults sharing the same pathway, whilst others appear to consist of just one offence type. Zamble and Quinsey (1997) also argue that offence characteristics are strongly influenced by the type of crime committed by the offender. A longitudinal approach examining different offences committed by the same offender across time would be desirable to further investigate pathways as a function of offence type.

In terms of cultural differences, over half of the current sample of offences were committed by offenders who identified as Maori, just over a quarter as Pakeha/European and the rest as Other. It is possible that due to the greater proportion of Maori offenders in this sample of offences that the PMVO Pathways are more representative of offences committed by Maori offenders. In the first instance more research is required to establish whether cultural differences are reflected by differences in violent offending characteristics.

4) Analyses. In the course of following the structure of Chambers (2006; Chambers et al, 2009) PMA for Study 2, $k$-means cluster analysis was employed to 
create the preset number of two clusters for each phase. The results of the cluster analysis were used to construct the PMVO. It is possible that restricting the number of clusters per phase to two resulted in a loss of the finer detail of the offence process information. Although it was well outside the scope of the current research, future work could consider using a hierarchical cluster analysis technique to determine the optimum number of clusters that best retains the richness of detail in the original information. In addition, whilst the sample size was adequate for the current exploratory study, an increased sample size would afford a greater selection of analysis techniques with which to examine the data (e.g., Structural Equation Modelling).

\section{Conclusion}

The data examined in the current study was originally recorded over the course of a decade of New Zealand violence prevention programmes. Thus the high-risk sample of offences in the current study likely bears more than a passing resemblance to the diversity of offences committed by offenders who take part in rehabilitation programmes in New Zealand. The diversity of offences committed by offenders in treatment is of particular relevance when we consider that the results of Study 2 revealed almost half of the 12 pathways consisted of a diverse mixture of offences (i.e., both robbery and assault offences in a single pathway). This finding suggests that perhaps Zamble and Quinsey’s (1997) view that pathways to offending are differentiated by offence type (whether or not the offender has a varied criminal history), is not so straightforward. The presence of both types of offence in a single pathway arguably demonstrates that, upon initial investigation, there appear to common, shared characteristics among a heterogeneous sample of violent offences.

In light of the ongoing debate about rehabilitation providing a 'one size fits all' 
service (e.g., Howells \& Day, 2002), the discovery of mixed offence pathways in the current study are reassuring. However, on the flip side the remaining pathways were associated with only one type of offence. Although more research on samples of heterogeneous violent offences is required, the results provide food for thought in terms of whether general rehabilitation needs are different for offenders depending upon the type of offence they most recently committed.

The current study (Studies 1 and 2) makes a number of contributions to our understanding of the heterogeneity of violent offences. It describes the characteristics of violent offending as a temporal process underlining the fact that characteristics across broad domains influence the offence process. Whilst the descriptive nature of the current study doesn't explain why the offences occurred, it does begin to plug the gap in the literature on violent offence heterogeneity. The richness of detail captured by Study 1 and further explored in Study 2 has the potential to provide the foundation for future research, and also contribute to theory development as well as offender rehabilitation. 


\section{References}

Anderson, C. A., \& Bushman, B. J. (2002). Human aggression. Annual Review of Psychology, 53(1), 27-51.

Andrews, D. A., \& Bonta, J. (2010). The Psychology of Criminal Conduct (5th ed.). New Providence, NJ: Anderson.

Bakeman, R., \& Quera, V. (2011). Sequential Analysis and Observational Methods for the Behavioral Sciences. Cambridge, UK: Cambridge University Press.

Bandura, A. (1973). Aggression: A Social Learning Analysis. New Jersey: Prentice Hall

Barratt, E. S., \& Felthous, A. R. (2003). Impulsive versus premeditated aggression: implications for mens rea decisions. Behavioral Sciences and the Law, 21(5), 619-630.

Berkowitz, L. (1993). Aggression: Its Causes, Consequences, and Control. New York: McGraw-Hill

Blackburn, R. (1986). Personality in relation to extreme aggression in psychiatric offenders. The British Journal of Psychiatry, 114(512), 821-828.

Broomhall, L. (2005). Acquired sociopathy: A neuropsychological study of executive dysfunctions in violent offenders. Psychiatry, Psychology and Law, 12, 367-387.

Bushman, B. J., \& Anderson, C. A. (2001). Is it time to pull the plug on hostile versus instrumental aggression dichotomy? Psychological Review, 108(1), 273-279

Buss, A. H. (1961). The Psychology of Aggression. New York: Wiley.

Camp, J. P., Skeem, J. L., Barchard, K., Lilienfeld, S. O., \& Poythress, N. G. (2013).

Psychopathic predators? Getting specific about the relation between psychopathy and violence. Journal of Consulting and Clinical Psychology. Advance online publication. doi: 10.1037/a0031349

Campbell, A., \& Muncer, S. (1994). Men and the Meaning of Violence. In J. Archer (Ed.), Male violence (pp. 332-351). London and New York: Routledge 
Canter, D. (2000). Offender profiling and criminal differentiation. Legal and Criminological Psychology, 5, 23-46.

Carver, C. S., \& Harmon-Jones, E. (2009). Anger is an approach-related affect: Evidence and implications. Psychological Bulletin, 135(2), 183-204.

Cassar, E., Ward, T., \& Thakker, J. (2003). A descriptive model of the homicide process. Behaviour Change, 20(2), 76-93.

Chaiken, M. R., \& Chaiken, J. M. (1984). Offender types and public policy. Crime and Delinquency, 30(2), 195-226.

Chambers, C., Ward, T., Eccleston, L., \& Brown, M. (2009). The Pathways Model of Assault: A qualitative analysis of the assault offender and offense Journal of Interpersonal Violence 24(9).

Chambers, J. (2006). The violence situation: A descriptive model of the offence process of assault for male and female offenders. Doctor of Philosophy, University of Melbourne.

Coolican, H. (1994). Research Methods and Statistics in Psychology (2nd ed.). London: Hodder \& Stoughton.

Cornell, D. G. (1996). Coding guide for violent incidents: Instrumental versus hostile/reactive aggression. Unpublished manuscript.

Cornell, D. G., Warren, J., Hawk, G., Stafford, E., Oram, G., \& Pine, D. (1996). Psychopathy in instrumental and reactive violent offenders. Journal of Consulting and Clinical Psychology, 64(4), 783-790.

Cornish, D. B., \& Clarke, R. V. (1986). The Reasoning Criminal: Rational Choice Perspectives on Offending. New York: Springer-Verlag.

Costa, P. T., \& MCCrae, R. R. (1996). Stability and Change in Personality from Adolescence through Adulthood. In C. F. Halverson \& G. A. Kohnstamm (Eds.), The Developing 
Structure of Temperament and Personality from Infancy to Adulthood (pp. 139-150). Hillsdale, NJ: Erlbaum.

Department of Corrections. (2012). Prison facts and statistics. Retrieved from http://www.corrections.govt.nz/about-us/facts_and_statistics/prisons/ps-march2012.html

Fontaine, G. R. (2007). Disentangling the psychology and law of instrumental and reactive subtypes of aggression. Psychology, Public Policy, and Law, 13, 143-165.

Hicks, B., Markon, K., Patrick, C., Krueger, R., \& Newman, J. (2004). Identifying psychopathy subtypes on the basis of personality structure. Psychological Assessment, 16(3), 276-288.

Hochstetler, A., Copes, H., \& Williams, J. P. (2010). “That’s Not Who I Am:” How Offenders Commit Violent Acts and Reject Authentically Violent Selves. Justice Quarterly, 27(4), 492-516.

Howells, K., \& Day, A. (2002). Grasping the nettle: Treating and rehabilitating the violent offender. Australian Psychologist, 37(3), 222-228.

Indermaur, D. (1995). Violent Property Crime. Sydney: The Federation press.

Kochanska, G., Murray, K. T., \& Harlan, E. (2000). Effortful control in early childhood: Continuity and change, antecedents, and implications for social development. Developmental Psychology, 36, 220-232.

Laws, D. R. (1989). Relapse Prevention with Sex Offenders. New York: Guilford.

Linden, W., Hogan, B. E., Rutledge, T., Chawla, A., Lenz, J. W., \& Leung, D. (2003). There is more to anger coping than "in" or "out". Emotion, 3(1), 12-29.

Marlatt, G. A., \& Gordon, J. R. (1985). Relapse prevention: A Self-Control Strategy for the Maintenance of Behavior Change. New York: Guilford.

McMurran, M., \& Howard, R. (2009). Personality, Personality Disorder and Violence: An 
Evidence Based Approach (Vol. 42): Wiley.

Megargee, E. I. (1966). Undercontrolled and overcontrolled personality types in extreme antisocial aggression. Psychological Monographs: General and Applied, 80(3), 1-29.

Megargee, E. I. (1979). Classifying Criminal Offenders. Beverly Hills: Sage.

Meloy, J. R. (1997). Predatory violence during mass murder. Journal of Forensic Science, 42, 326-329.

Moffitt, T. E. (1993). 'Life-course persistent' and 'adolescence-limited' antisocial behavior: A developmental taxonomy. Psychological Review, 100(4), 674-701.

Mooi, E., \& Sarstedt, M. (2011). A Concise Guide to Market Research: The Process, Data, and Methods using IBM SPSS Statistics. Berlin: Springer-Verlag.

Morrison, B., Smith, M., \& Gregg, L. (2010). The New Zealand Crime and Safety Survey 2009: Main Findings Report. Wellington.

Murdoch, S., Vess, J., \& Ward, T. (2010). Descriptive model of the offence process of women violent offenders: distal background variables. Psychiatry, psychology and law, 17(3), 368-384.

New Zealand Police. (2010). New Zealand Crime Statistics 2009: A Summary of Recorded and Resolved Offence Statistics. Retrieved from https://www.police.govt.nz/sites/default/files/services/statistics/00_National_Official_ Stats_2009.pdf.

New Zealand Police. (2012). New Zealand Crime Statistics 2011: A Summary of Recorded and Resolved Offence Statistics. Retrieved from http://www.police.govt.nz/sites/default/files/00_national_2011_official_stats.pdf.

Nightingale, J. (2002). Feeling a million dollars: A grounded theory investigation of preliminary offence chains in aggravated robbery. Doctor of Philosophy, Victoria University, Wellington. 
Pallone, N. J., \& Hennessy, J. J. (1993). Tinderbox Criminal Violence: Neurogenic Impulsivity, Risk-taking, and the Phenomenology of Rational Choice. In R. V. Clarke \& M. Felson (Eds.), Routine Activity and Rational Choice (pp. 127-157). Ncw York: Brunswick Transaction.

Patrick, C. J., \& Zempolich, K. A. (1998). Emotion and aggression in the psychopathic personality. Aggression and Violent Behaviour, 3, 303-338.

Piquero, A., Oster, R. P., Mazerolle, P., Brame, R., \& Dean, C. W. (1999). Onset age and offense specialization. Journal of Research in Crime and Delinquency, 36(3), 275299.

Pithers, W. D. (1990). Relapse Prevention with Sexual Aggressors: A Method for Enhancing Therapeutic Gain and Enhancing External Supervision. In W. L. Marshall \& H. E. Barbaree (Eds.), Handbook of Sexual Assault: Issues, Theories and Treatment of the Offender (pp. 343-361). New York: Plenum.

Pithers, W. D., Marques, J. K., Gibat, C. C., \& Marlatt, G. A. (1983). Relapse prevention with sexual aggressives: A self-control model of treatment and maintenance of change. In J. G. Greer \& I. R. Stuart (Eds.), The sexual aggressor: Current Perspectives on Treatment (pp. 214-239). New York: Van Nostrand Reinhold.

Polaschek, D. L. (2003). Relapse prevention, offense process models, and the treatment of sexual offenders. Professional Psychology: Research and Practice, 34(4), 361-367.

Polaschek, D. L. (in press). How to train your dragon: An introduction to the special issue on treatment programmes for high-risk offenders. Psychology, Crime \& Law.

Polaschek, D. L., \& Collie, R. M. (2004). Rehabilitating serious violent adult offenders: An empirical and theoretical stocktake. Psychology, Crime \& Law, 10(3), 321-334.

Polaschek, D. L., Hudson, S. M., Ward, T., \& Siegert, R. J. (2001). Rapists' offense processes: A preliminary descriptive model. Journal of Interpersonal Violence, 16(6), 
523-544.

Polaschek, D. L., Wilson, N. J., Townsend, M. R., \& Daly, L. R. (2005). Cognitivebehavioral rehabilitation for high-risk violent offenders an outcome evaluation of the Violence Prevention Unit. Journal of interpersonal violence, 20(12), 1611-1627.

Polaschek, D. L. L. (2006). National Violence Prevention Unit Evaluation Report III:

Psychometric and recidivism analyses for the retrospective evaluation sample. Unpublished report for the Department of Corrections. Wellington, NZ.

Ramirez, J. M., Rodríguez, A., \& Manuel, J. (2003). Aggression's typologies. International Review of Social Psychology, 16(3), 125-141.

Sampson, R. J., \& Laub, J., H. (2005). A life-course view of the development of crime. Annals of the American Academy of Political and Social Science, 62, 12-45.

Simon, L. M. (1997). Do criminal offenders specialize in crime types? Applied and Preventive Psychology, 6(1), 35-53.

Stanford, M. S., Houston, R. J., Villemarette-Pittman, N. R., \& Greve, K. W. (2003). Premeditated aggression: Clinical assessment and cognitive psychophysiology. Personality and Individual Differences, 34, 773-781.

Strauss, A., \& Corbin, J. (1998). Basics of Qualitative Research: Techniques and Procedures for Developing Grounded Theory (2nd ed.). London: Sage Publications.

Sukhodolsky, D. G., Golub, A., \& Cromwell, E. N. (2001). Development and validation of the Anger Rumination Scale. Personality \& Individual Differences, 31(5), 689-700.

Tapscott, J. L., Hancock, M., \& Hoaken, P. N. (2012). Severity and frequency of reactive and instrumental violent offending. Criminal Justice and Behavior, 39(2), 202-219.

Walsh, D. (1986). Heavy business: Commercial Burglary and Robbery. London: Routledge. Walters, R., \& Bradley, T. (2005). Introduction to Criminological Thought. Australia: Pearson Education. 
Ward, T., \& Hudson, S. M. (1998). The construction and development of theory in the sexual offending area: A metatheoretical framework. Sexual Abuse: A Journal of Research and Treatment, 10(1), 47-63.

Ward, T., Louden, K., Hudson, S. M., \& Marshall, W. L. (1995). A descriptive model of the offense chain in child molesters. Journal of Interpersonal Violence, 10, 452-472.

Watson, D., \& Tellegen, A. (1985). Toward a consensual structure of mood. Psychological Bulletin, 98(2), 219-235.

Weinshenker, N. J., \& Siegel, A. (2002). Bimodal classification of aggression: Affective defense and predatory attack. Aggression and Violent Behaviour, 7, 237-250.

Woodworth, M., \& Porter, S. (2002). In cold blood: Characteristics of criminal homicides as a function of psychopathy. Journal of Abnormal Psychology, 111(3).

Wright, R., \& Bennett, T. (1990). Exploring the Offender's Perspective: Observing and Interviewing Criminals. In K. L. Kempf (Ed.), Measurement Issues in Criminology (p. 138-151). New York: Springer-Verlag.

Wright, R. T., \& Decker, S. H. (1997). Armed Robbers in Action: Stickups and Street Culture. Boston: Northeastern University Press.

Zamble, E., \& Porporino, F. J. (1988). Coping, Behavior, and Adaptation in Prison Inmates. New York: Springer-Verlag Publishing.

Zamble, E., \& Quinsey, V. L. (1997). The Criminal Recidivism Process. Cambridge, UK: Cambridge University Press.

Appendix A 


\section{The Ross-Oxnam VPU Offence Chain Coding Sheet}

\section{$\underline{\text { Pre-Offence/Background Variables }}$}

\section{A - Relationships}

A1 - Quality of current romantic relationship
a) Strong, stable, loving
b) Satisfactory, some conflict
c) Strained, quite conflictual
d) Significant conflict, presence of abuse
e) Not currently in a relationship
z) Insufficient information available

A2 - Marital status
a) Single
b) De-facto relationship
c) Married
d) Separated/divorced from partner
z) Insufficient information available

A3 - Children/Dependents
a) No children
b) Own children in home
c) Partners children in home
d) Blended family
e) Own children live elsewhere
z) Insufficient information available

A4 - Childhood history described
a) Strong, stable, loving
b) Satisfactory, some conflict
c) Strained, quite conflictual
d) Significant conflict, presence of abuse
z) Insufficient information available

\section{B - Lifestyle}


B1 - Work history

a) Predominantly employed

b) Mostly unemployed with occasional work (e.g. unemployed for last couple of years but just got a job, seasonal work, etc.)

c) Studying

d) Predominantly unemployed but looking for work

e) Lifestyle unemployed

z) Insufficient information available

B2 - Living situation

a) Living with parents

b) Living with partner

c) Living alone

d) Flatting

e) No fixed abode

z) Insufficient information available

B3 - Criminality

a) Little or no prior criminal history

b) Some past or present involvement in crime

c) Actively involved in criminal lifestyle

d) Lifestyle dominated/supported by crime

z) Insufficient information available

B4 - Antisocial peers / gang involvement

a) No antisocial peers

b) Antisocial peers but not gang involvement

c) No gang involvement

d) Past gang involvement only

e) Actively involved in gang

f) Past gang involvement; current involvement with antisocial peers.

z) Insufficient information available

Name of gang:

B5 - Self-image described

a) Positive self-image not derived from antisociality (e.g. being a good father)

b) Positive self-image derived from criminal reputation (e.g. being macho/staunch)

c) Negative self-image (e.g. "I’m a failure” / "I'm a bad provider”)

z) Insufficient information available 
B6 - Religious beliefs/church involvement

a) Strong

b) Some

c) None

z) Insufficient information available

B7 - Cultural involvement

a) Strong cultural ties (e.g. speaking a language, following practices)

b) Cultural affiliation not actively demonstrated (e.g. Identifies tribe but no involvement)

c) No cultural involvement / lack of cultural awareness

d) Rejects cultural heritage

z) Insufficient information available

\section{C - Stressors - Indicate the most significant}

a) Psychological problems

b) Grief

c) Relationship conflict

d) Financial problems

e) Victim of abuse

f) Addictions

g) Work stress

h) No stressors

i) Other - describe:

z) Insufficient information available

\section{D - High Risk Situation (HRS)}

D1 - Appraisal of High Risk Situation

a) Aware of HRS. Tries to avoid the situation

b) Aware of HRS. Does nothing to avoid it

c) Aware of HRS. Actively pursues it

d) No awareness of entering a HRS

e) No HRS apparent

z) Insufficient information available

D2 - Type of HRS entered into - circle most significant 
a) High use of alcohol or drugs e.g. using a lot or going somewhere where there will be pressure to.

b) Contact with antisocial peers e.g. people that will encourage or not discourage violence

c) Contact with people who they are likely to be violent towards e.g. the partner that gets beaten, a known enemy/rival

d) Other:

e) No HRS apparent

z) Insufficient information available

\section{E - Alcohol and Drugs}

E1 - Alcohol use

a) Does not drink

b) Drinks occasionally e.g. once a week or only socially

c) Drinks frequently e.g. several times a week

d) Drinks excessively everyday e.g. six pack a day, bottle of spirits

e) Binges excessively e.g. same as above but only on weekends or social occasions

z) Insufficient information available

E2 - Drug use

a) Does not use

b) Uses occasionally e.g. once a week or only socially

c) Uses frequently e.g. several times a week

d) Uses excessively everyday e.g. more than two joints a day, poly-drug use everyday

z) Insufficient information available

E3 - Types of Drugs - circle as many as appropriate

a) Cannabis e.g. joints, hash, dope

b) Stimulants e.g. methamphetamine, speed, E, P

c) Depressants e.g., tranquillisers, Rohipnol -“rollies”, morphine, "misties”

d) Hallucinogens e.g. LSD, mushrooms

z) Insufficient information available

\section{During the Offence}

\section{F - Planning}

F1 - Degree of Planning

a) Elaborate, well-planned offence (e.g. carefully selected scene, detailed role assignment). 
b) Some evidence of planning, not clearly organised and thought through (e.g. cased the scene)

c) General offence plan, few details (e.g. "let's do a burg tonight”)

d) Opportunistic. No planning, spur of the moment planning (e.g. the shop's empty, let's rob it / he's pissing me off. I'm going to smash him).

z) Insufficient information available.

F2 - Changes to the plan

a) Follows plan exactly

b) Generally follows plan, some changes (e.g. role changes)

c) Major changes to plan (e.g. change of scene, roles, offence)

d) Plan not followed, actively abandoned.

e) No plan, not applicable.

z) Insufficient information available

\section{G - Weapons}

G1 - Type of weapon used by offender
a) No weapons present
b) Firearm
c) Stab/cutting weapon
d) Blunt instrument
e) Any available object (e.g. bottle)
z) Insufficient information available

G2 - Weapon use
a) No weapon
b) Had weapon but did not use it
c) Threatened with weapon
d) Used weapon
z) Insufficient information available

\section{H- Role of offender}

a) Bystander, no active role

b) Getaway driver

c) "Heavy" (e.g. role is to look threatening, may carry weapon, does not actively assault)

d) Active role (e.g. takes active part in assault/robbery, takes the money)

e) Leader of co-offenders in the offence

f) Sole offender e.g. had to assume all roles

z) Insufficient information available 


\section{I - Victim}

I1 - Number of victims
a) 0
b) 1
c) 2
d) 3
e) 4 or more
z) Insufficient information available

I2 - Victim gender
a) Male
b) Female
c) Had both male and female victim
z) Insufficient information available

I3 - Victim’s relationship to offender - circle as applies to each victim
a) Very close relationship (e.g. immediate family member, romantic partner)
b) Close relationship (e.g. friend, relative, dating partner etc.)
c) Specific relationship (e.g. teacher, babysitter, etc.) or Between friend and acquaintance
d) Acquaintance
e) Stranger
z) Insufficient information available

I4 - Violence towards victim. May need to code by acts rather than degree of injury.
a) Homicide/Murder
b) Severe injury (e.g. lasting impairment or life-threatening injury)
c) Serious injury, requiring substantial hospital treatment (e.g. broken limb, gunshot)
d) Minor injury (e.g. bruises, minor medical treatment)
e) Assault without injury (e.g. pushed victim to ground)
f) Threat but no physical assault
g) No injuries or threats sustained
z) Insufficient information available
I5 - Victim reaction 
a) Compliant / non-reactive (e.g. hands over the money without delay in robbery. Doesn't fight back during assault)

b) Covert reaction (e.g. pushes alarm button, calls for assistance, lying to offender)

c) Some overt action taken by victim (e.g. scream, run away, stalling for time)

d) Strong reaction (e.g. physically fighting back, defending others)

z) Insufficient information available

\section{J - Immediate triggers}

J1 - Types of triggers - circle most significant

a) Conflict with partner (e.g. break-up, arguments, infidelity)

b) Employment problems (e.g. conflict with employer/colleagues, unemployment)

c) Implicit victim provocation (e.g. gang rival)

d) Explicit victim provocation (e.g. assaults offender, cheats with partner)

e) Suggestion of co-offender

f) Conflict with children

g) No apparent trigger

z) Insufficient information available

J2 - Role of alcohol and drugs in offence

a) Alcohol and drugs not linked to offence

b) Compromises inhibition (e.g. too drunk to think clearly)

c) Produces feelings of invincibility (e.g. "I felt ten foot tall and bullet-proof")

d) Produces intense emotional reaction (e.g. rage, depression)

z) Insufficient information available

\section{K - Motives - circle most significant}
a) Thrill
b) Financial/property gain
c) Revenge
d) Harm
e) Acquisition of drugs
f) Gang-related
g) Power
z) Insufficient information available

\section{L - Scene of offence}
a) Offender's own residence
b) Place of business (e.g. Service station, video shop etc.)
c) Victim's residence if different from (a)
d) On the street
e) Bar or club 
f) Other

z) Insufficient information available

\section{M - Co-offenders}

M1 - Number of co-offenders
a) 0
b) 1
c) 2
d) 3
e) 4 or more
z) Insufficient information available

M2 - Co-offenders' relationship with offender - circle as applies to each co-offender
a) Relative/family member
b) Romantic partner
c) Close friend
d) Acquaintance
e) Stranger
f) No co-offender
z) Insufficient information available

\section{N - Offender Reaction}

N1 - Emotional arousal
a) Calm or tense at most
b) Excited, very nervous, anxious, scared
c) Angry, mad, extremely frightened
d) Enraged, furious, described as "out of control" or "irrational” or panicked
z) Insufficient information available

N2 - Clarity of thought during the offence
a) Reports being clear-headed, focussed.
b) Mostly clear-headed, slightly un-focussed (e.g. couldn't think in a moment of panic)
c) Unfocussed, panicky, unable to think clearly
d) Panicked, irrational, blanking out, no thoughts
z) Insufficient information available

N3 - Physiological response

a) No response, calm, feeling “normal” 
b) Feeling a little pumped up (heart beat slightly faster)

c) Somewhat pumped up, sweating, heart-racing

d) Complete adrenalin rush, on a high, "out of it

z) Insufficient information available

\section{O - Cessation of the offence}

O1 - What stopped the offence
a) Victim response (e.g. screaming, crying, fighting back)
b) Extent of victims injuries (e.g. stops when sees blood)
c) Arrival of assistance for victim (e.g. police, other people)
d) Internal blocks (e.g. feeling guilty, remorseful)
e) Goal achieved, motive satisfied (e.g. got the money)
f) Pleas from others to stop (e.g. co-offenders, bystanders, children)
g) Other
z) Insufficient information available

O2 - How offender escaped from scene
a) Motor vehicle
b) Bicycle
c) On foot
d) Does not escape (e.g. arrested at scene, stays at scene)
e) Other
z) Insufficient information available

O3 - Where the offender escaped to
a) Offender's current residence
b) Friend or relative's house
c) Motel
d) Gang base
e) Into hiding (e.g. go bush, on the road etc.)
f) Other
g) Does not escape
z) Insufficient information available

\section{$\underline{\text { Post - Offence Variables }}$}

\section{P - Post-offence reactions}

P1 - Emotional reaction

a) Unemotional, calm, uncaring

b) Feeling slightly nervous or anxious 
c) Worried, frightened, guilty

d) Panicked, extremely frightened, worried about offence

z) Insufficient information available

P2 - Feelings toward victim

a) Denial of harm

b) Admits to harm but believes offence justified or blames others

c) Admits to harm/concerned but minimises

d) Remorseful, guilty, admits harm, seems genuinely regretful

z) Insufficient information available

P3 - Thoughts about the offence

a) No thoughts, unconcerned

b) Slightly preoccupied by offence

c) Preoccupied, unable to concentrate

d) Worried, panicky, thinking only about offence

z) Insufficient information available

\section{Q - Post-offence consequences}

Q1 - Appraisal of consequences

a) Aware of consequences. Fearful of them

b) Aware of consequences. Un-concerned

c) Doesn't consider consequences

d) Foresee only positive outcome

z) Insufficient information available

Q2 - Type of consequences feared
a) Jail time
b) Loss of access to children
c) Loss of partner
d) Injury to / death of victim
e) Psychological harm to victim
f) Other
g) No consequences feared
z) Insufficient information available

\section{R - Capture}
R1 - Means of capture
a) Stays at scene
b) Gives self up immediately (e.g. waits at scene)
c) Escapes but gives self up later 
d) Is caught immediately by police

e) Evades police but is apprehended later

z) Insufficient information available

R2 - Reaction to capture
a) Goes quietly
b) Scuffle/struggle
c) Struggles, uses aggressive force
d) Tries to escape police custody
z) Insufficient information available

\section{S - Feelings toward outcome at time of interview}
a) Satisfied, felt it was worth it
b) Some regret but not overly concerned
c) Remorseful, it wasn't worth it - self-focussed
d) Remorseful, it wasn't worth it - victim focussed
z) No information available 


\section{Appendix B}

Copy of coding sheet

\begin{tabular}{|c|c|c|c|c|c|c|c|}
\hline \multicolumn{8}{|l|}{ LIFESTYLE } \\
\hline Relationship status & single & $\begin{array}{l}\text { in a } \\
\text { relationship }\end{array}$ & married & defacto & $\begin{array}{l}\text { divorced/separate } \\
\text { d }\end{array}$ & $\begin{array}{l}\text { recently } \\
\text { split }\end{array}$ & $\begin{array}{l}\text { insufficient } \\
\text { detail }\end{array}$ \\
\hline $\begin{array}{l}\text { Quality of } \\
\text { relationship }\end{array}$ & strong/stable & $\begin{array}{l}\text { satisfactory, } \\
\text { some conflict }\end{array}$ & $\begin{array}{l}\text { strained, quite } \\
\text { conflictual }\end{array}$ & $\begin{array}{l}\text { significant conflict, } \\
\text { presence of abuse }\end{array}$ & $n / a$ & $\begin{array}{l}\text { insufficien } \\
\text { t detail }\end{array}$ & \\
\hline $\begin{array}{l}\text { Mental health } \\
\text { problems }\end{array}$ & none apparent & some & extensive & insufficient detail & & & \\
\hline $\begin{array}{l}\text { Employment/source } \\
\text { of income }\end{array}$ & $\begin{array}{l}\text { no } \\
\text { employment/on } \\
\text { benefits }\end{array}$ & $\begin{array}{l}\text { illegal income } \\
\text { (material } \\
\text { crimes) }\end{array}$ & $\begin{array}{l}\text { under the } \\
\text { table/cash in } \\
\text { hand }\end{array}$ & legitimate & insufficient detail & & \\
\hline Reliability of income & $\begin{array}{l}\text { no reliable } \\
\text { income }\end{array}$ & $\begin{array}{l}\text { sporadic } \\
\text { income }\end{array}$ & regular income & incarcerated & insufficient detail & & \\
\hline Financial stressors & yes & no & & & & & \\
\hline $\begin{array}{l}\text { Social life/family } \\
\text { support }\end{array}$ & none apparent & some & extensive & insufficient detail & & & \\
\hline $\begin{array}{l}\text { Criminal } \\
\text { lifestyle/associates }\end{array}$ & none & some & extensive & insufficient detail & & & \\
\hline
\end{tabular}




\begin{tabular}{|c|c|c|c|c|c|c|c|}
\hline Substance abuse & does not use & occasional & frequently & excessively \& daily & $\begin{array}{l}\text { uses (no info on } \\
\text { regularity) }\end{array}$ & $\begin{array}{l}\text { insufficien } \\
\text { t detail }\end{array}$ & \\
\hline \multicolumn{8}{|l|}{ Type of drug } \\
\hline Living arrangement & NFA & prison & $\begin{array}{l}\text { flatting/lodgin } \\
\mathrm{g}\end{array}$ & with family & lives alone & $\begin{array}{l}\text { with } \\
\text { partner }\end{array}$ & $\begin{array}{l}\text { insufficient } \\
\text { detail }\end{array}$ \\
\hline $\begin{array}{l}\text { Quality/stability of } \\
\text { living arrangement }\end{array}$ & $\begin{array}{l}\text { poor (NFA, sofa } \\
\text { surfing) }\end{array}$ & $\begin{array}{l}\text { at least } \\
\text { adequate }\end{array}$ & & & & & \\
\hline $\begin{array}{l}\text { Physical health } \\
\text { problems }\end{array}$ & none apparent & some & extensive & insufficient detail & & & \\
\hline Gang activity & yes & no & $\begin{array}{l}\text { insufficient } \\
\text { detail }\end{array}$ & & & & \\
\hline \multicolumn{8}{|l|}{$\begin{array}{l}\text { COPING } \\
\text { STRATEGIES }\end{array}$} \\
\hline $\begin{array}{l}\text { Rumination over } \\
\text { grievances }\end{array}$ & none apparent & some & extensive & & & & \\
\hline Help seeking & yes & no & & & & & \\
\hline
\end{tabular}




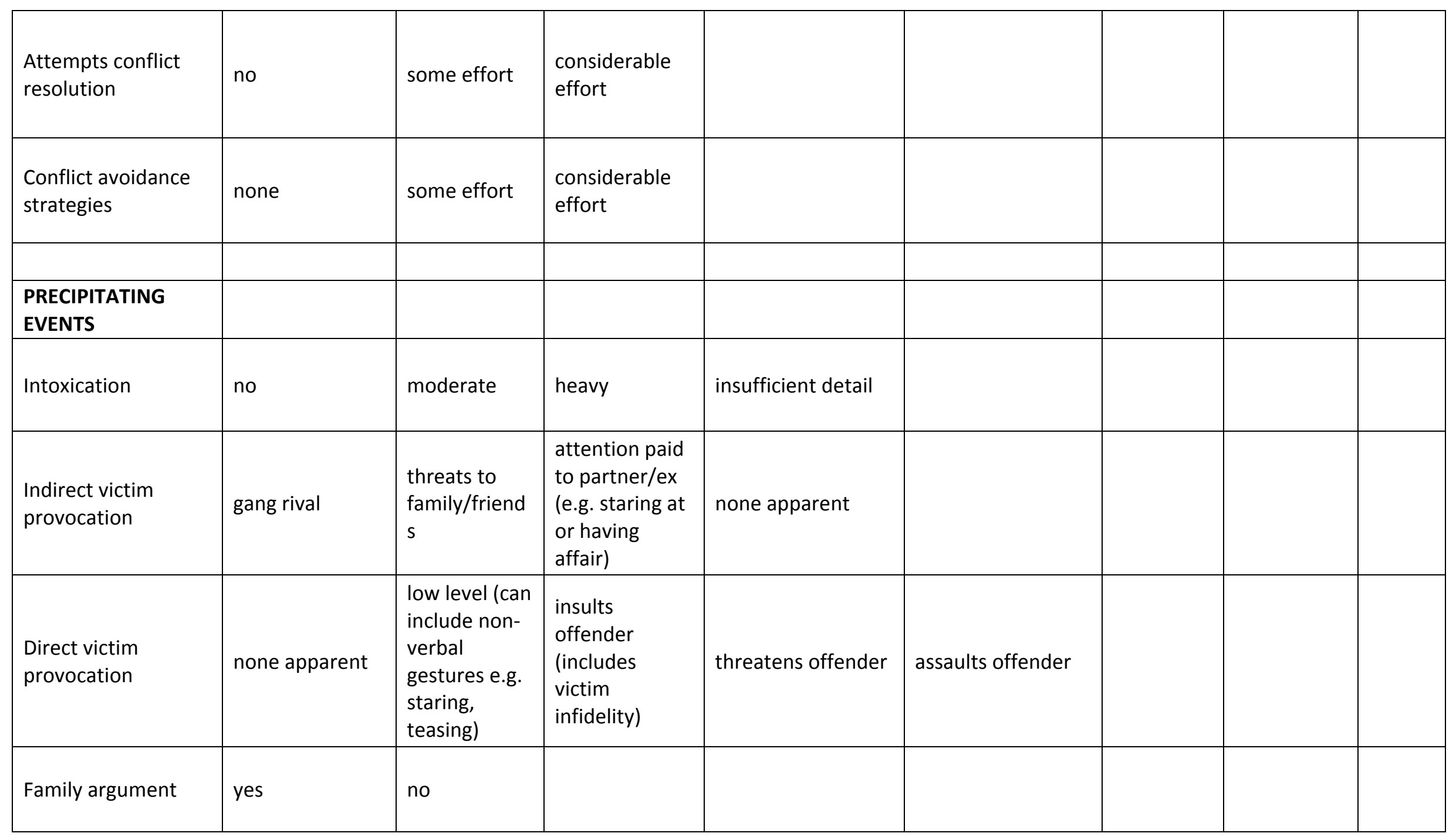




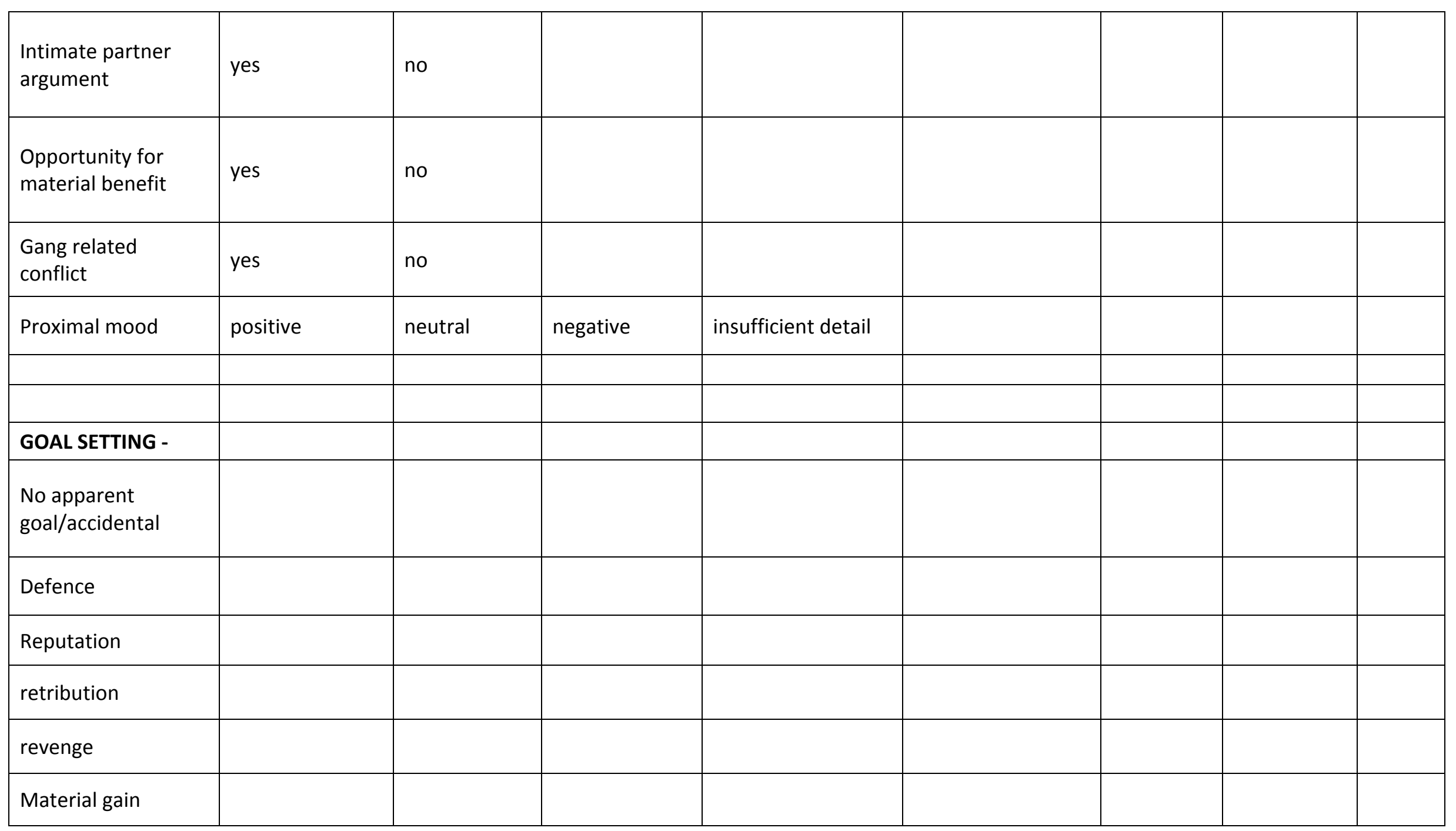




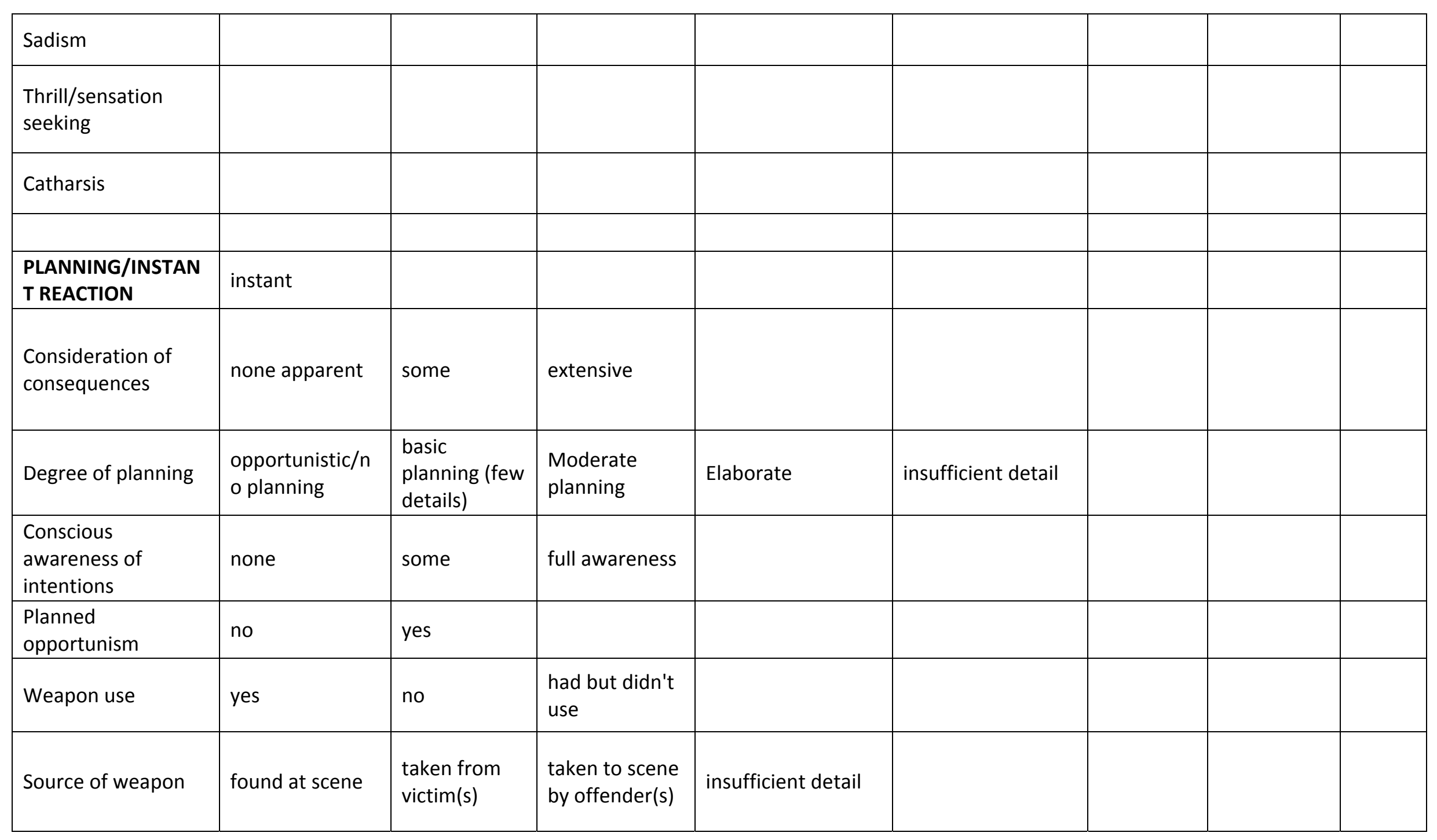




\begin{tabular}{|c|c|c|c|c|c|c|c|c|}
\hline Co-offenders & yes & no & & & & & & \\
\hline Role of offender & main role & $\begin{array}{l}\text { secondary } \\
\text { role }\end{array}$ & & & & & & \\
\hline \multicolumn{9}{|l|}{ Number of victims } \\
\hline Emotional arousal & low & moderate & high & & & & & \\
\hline
\end{tabular}




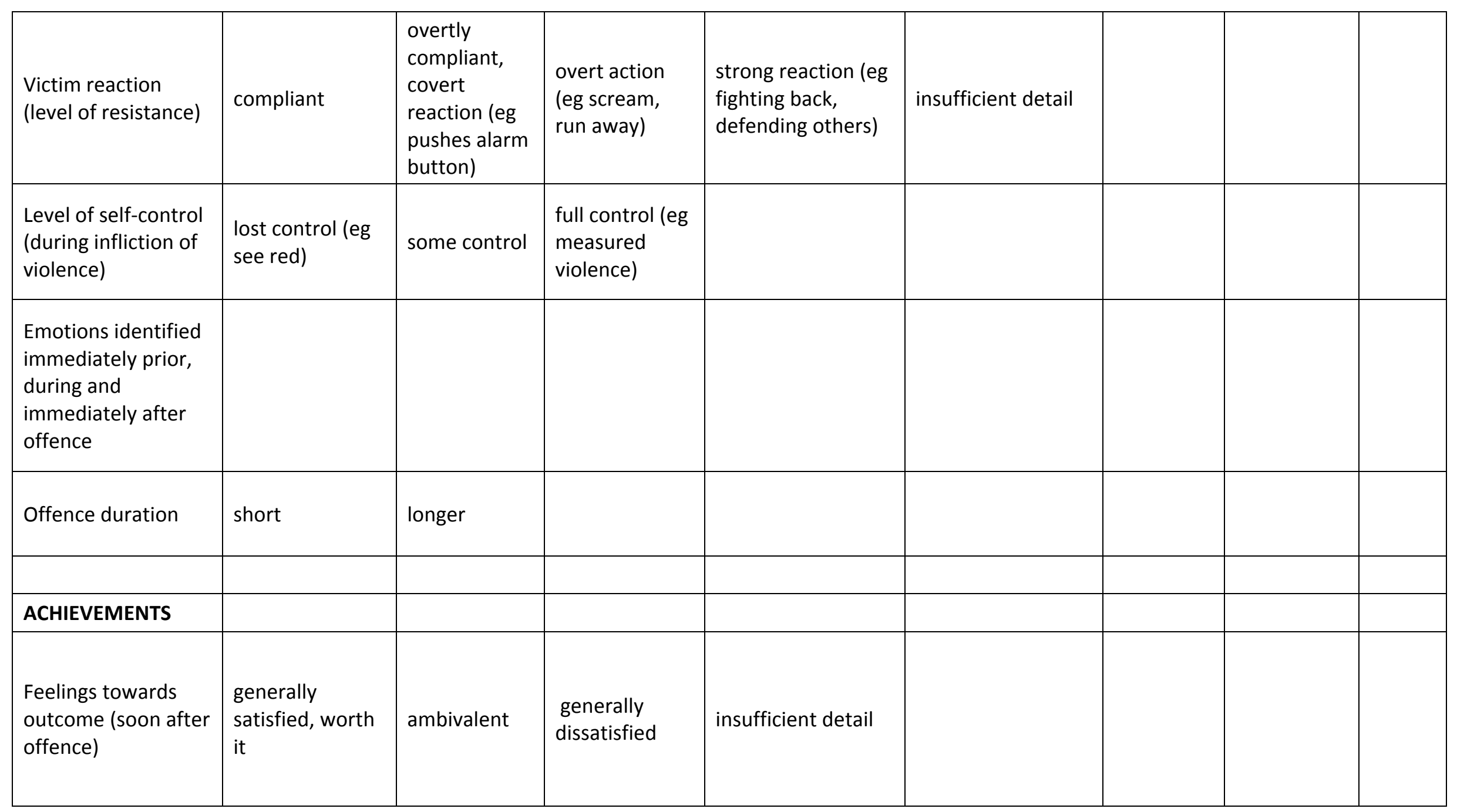




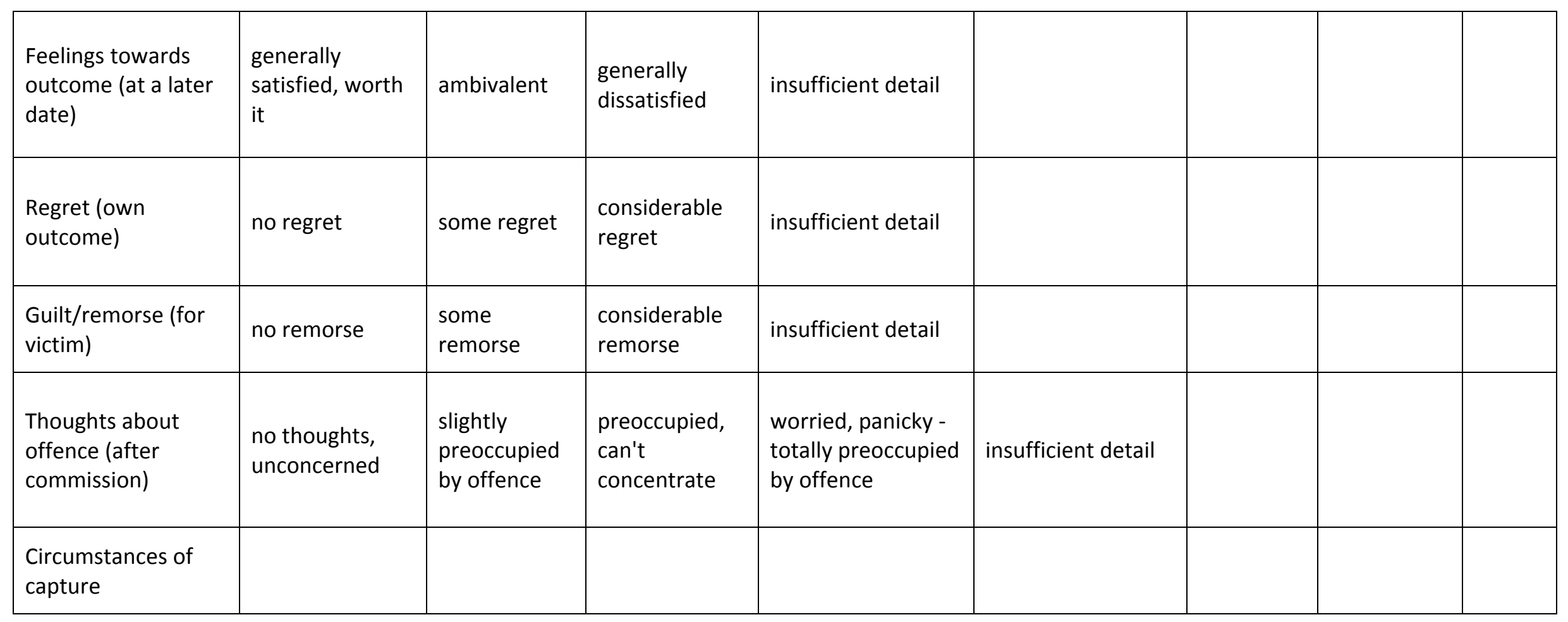


Appendix C

Full definitions of coding variables

\begin{tabular}{|c|c|}
\hline & DEFINITIONS \\
\hline LIFESTYLE & $\begin{array}{l}\text { Chambers - lifestyle before offence - may reflect enduring way of life or recent } \\
\text { life-changing events (Chambers, 2008, p.11). }\end{array}$ \\
\hline Relationship status & $\begin{array}{l}\text { Ross-Oxnam - marital/relationship status of offender. Defacto - co-habiting but } \\
\text { not married. Separated/divorced - may or may/not have been married but have } \\
\text { since split up. }\end{array}$ \\
\hline $\begin{array}{l}\text { Quality of } \\
\text { relationship }\end{array}$ & $\begin{array}{l}\text { Ross-Oxnam - gain understanding of quality of offender's relationship with } \\
\text { partner. Still code this even if they have recently split or separated. }\end{array}$ \\
\hline $\begin{array}{l}\text { Mental health } \\
\text { problems }\end{array}$ & $\begin{array}{l}\text { Chambers - in lead up to offence does offender describe being } \\
\text { emotionally/mentally unwell (also consider any mention of prescribed } \\
\text { medication) }\end{array}$ \\
\hline $\begin{array}{l}\text { Employment/source } \\
\text { of income }\end{array}$ & $\begin{array}{l}\text { Aim is to identify source of income - can have multiple sources, but will need to } \\
\text { correspond each choice with its associated reliability }\end{array}$ \\
\hline Reliability of income & The degree to which the offender has a regular and reliable income \\
\hline Financial stressors & $\begin{array}{l}\text { Indication that offender is under extra financial pressure (e.g. debt, job } \\
\text { uncertainty, got a loan out). May include a specific desire for an item or lifestyle } \\
\text { beyond current financial means if they state info indicating this might be } \\
\text { relevant (make a note if this is the case). }\end{array}$ \\
\hline $\begin{array}{l}\text { Social life/family } \\
\text { support }\end{array}$ & $\begin{array}{l}\text { Spends time with friends and or family. Not socially isolated. Consider both } \\
\text { quality and quantity of family support and/or social life. Eg. None - no evidence } \\
\text { of any family support or friends with which to socialise. Some - perhaps a good } \\
\text { relationship with one or two family members, no friends / ok relationship with } \\
\text { one or two family and a couple of friends / no family but a few friends / spends } \\
\text { time with partner. Extensive - good relationship with number of family and } \\
\text { friends / very good relationship with a family members, no or few friends / no } \\
\text { family relationships but very good or close friends. The family/friends do not } \\
\text { necessarily need to be prosocial - am looking at social isolation aspect. }\end{array}$ \\
\hline $\begin{array}{l}\text { Criminal } \\
\text { lifestyle/associates }\end{array}$ & $\begin{array}{l}\text { Extent to which current lifestyle revolves around crime and/or criminal } \\
\text { associates from no criminal associates or offending to extensive network of } \\
\text { criminal associates or offending behaviour. None= offender not currently into } \\
\text { crime (and hasn't been for some years), and few if any friends are into crime. } \\
\text { Some= e.g. "Was stealing the odd car, and smoking weed". Extensive = "Was } \\
\text { living with gang members and out committing burglaries regularly" }\end{array}$ \\
\hline Substance abuse & $\begin{array}{l}\text { Extent of substance use. Occasional - 1-3 x per week. Frequently - several x per } \\
\text { week. Excessively \& daily - large amounts, multiple times per day. }\end{array}$ \\
\hline Type of drug & $\begin{array}{l}\text { List of drugs offender uses (including alcohol). If it is medication being taken as } \\
\text { prescribed then may be more appropriate to be listed under mental or physical } \\
\text { health items. }\end{array}$ \\
\hline Living arrangement & Where was offender living in lead up to offence? (NFA = no fixed abode) \\
\hline $\begin{array}{l}\text { Quality/stability of } \\
\text { living arrangement }\end{array}$ & $\begin{array}{l}\text { Stability and quality of offenders living arrangement. Poor demonstrated by } \\
\text { instability/uncertainty (e.g., homeless or staying with others due to issues with } \\
\text { regular accommodation. Applies if there is evidence to suggest they have }\end{array}$ \\
\hline
\end{tabular}




\begin{tabular}{|c|c|}
\hline & $\begin{array}{l}\text { stayed the night or spend time elsewhere due to arguments on two occasions } \\
\text { or more). Adequate refers to consistent and at least adequate living } \\
\text { arrangement. }\end{array}$ \\
\hline $\begin{array}{l}\text { Physical health } \\
\text { problems }\end{array}$ & $\begin{array}{l}\text { Is there any evidence of physical health problems (e.g. illness, disability or } \\
\text { prescribed medication). Eg. None apparent - none disclosed or none } \\
\text { mentioned. Some - mentions illness/problem that is not so debilitating they can } \\
\text { function ok generally. Extensive - mentions more than one problem or has a } \\
\text { single problem that appears to interfere with general daily functioning }\end{array}$ \\
\hline Gang activity & $\begin{array}{l}\text { Is offender a gang member, or is he involved with/ or associates with gang } \\
\text { members. This is about lifestyle so it does not necessarily need to relate to the } \\
\text { index offence. Yes - there is mention of gang activity. No - it is stated that there } \\
\text { is no gang involvement/association. Insufficient detail - there is no mention of } \\
\text { gangs so cannot say yes or no. }\end{array}$ \\
\hline \multicolumn{2}{|l|}{ COPING STRATEGIES } \\
\hline $\begin{array}{l}\text { Increased substance } \\
\text { use }\end{array}$ & $\begin{array}{l}\text { Chamber -either evidence of increased substance use in lead up to offence } \\
\text { (more usage than 'normal' for that individual, including heavy substance use on } \\
\text { release from prison if appears prolonged (eg perhaps a few weeks of prolonged } \\
\text { use rather than a few days) / Or clearly seems to be using drugs as a coping } \\
\text { mechanism e.g. "The drink and drugs was the best way for me to blackout so I } \\
\text { didn't have to think" }\end{array}$ \\
\hline $\begin{array}{l}\text { Rumination over } \\
\text { grievances }\end{array}$ & $\begin{array}{l}\text { Chambers - did rumination occur in lead up to offence. Rumination refers to } \\
\text { thinking about anger provoking incidents after they have been suppressed } \\
\text { (Linden et al, } 2003 \text { in Chambers thesis). May involve: angry afterthoughts, angry } \\
\text { memories, or revenge fantasies (Sukhodolsky et al, } 2001 \text { in Chambers thesis). } \\
\text { There should be some element of familiarity with the } \\
\text { thoughts/memories/fantasies - i.e. they should be linked to an event that has } \\
\text { happened not just be angry thoughts in general. Some = short term rumination, } \\
1-3 \text { days. Extensive = longer term rumination, a few days or more. }\end{array}$ \\
\hline Help seeking & $\begin{array}{l}\text { Any indication offender sought prosocial help to cope with stressors (can be } \\
\text { problematic behaviours, or could be debt /child access / marriage problems) in } \\
\text { lead up to offence, or realised he had an issue and was made efforts to address } \\
\text { it (e.g. seeking rehab for substance abuse problems or seeking medical advice } \\
\text { for issues with mood or showed evidence of engaging with therapists - even if it } \\
\text { was a court mandate) }\end{array}$ \\
\hline $\begin{array}{l}\text { Attempts conflict } \\
\text { resolution }\end{array}$ & $\begin{array}{l}\text { Any indication offender attempted to resolve conflict in non-violent manner. } \\
\text { Employs prosocial/constructive problem solving techniques. E.g. asking a family } \\
\text { member of victim to mediate and help resolve differences. (Some effort = 1-2 } \\
\text { attempts. considerable effort = multiple attempts at problem solving) }\end{array}$ \\
\hline $\begin{array}{l}\text { Conflict avoidance } \\
\text { strategies }\end{array}$ & $\begin{array}{l}\text { Evidence to suggest offender attempted to avoid conflict in lead up offence } \\
\text { (e.g. leave area or avoid intoxicants). Considerable effort = multiple attempts } \\
\text { (e.g. changed route to work for a few days to avoid area) or a single major } \\
\text { change (e.g. went teetotal to try to address alcohol related issues - would need } \\
\text { evidence of commitment to the change) }\end{array}$ \\
\hline $\begin{array}{l}\text { PRECIPITATING } \\
\text { EVENTS }\end{array}$ & $\begin{array}{l}\text { Events/incidents/circumstances occurring or present in the lead up to the } \\
\text { offence. Consider information more related to offence (temporally related }\end{array}$ \\
\hline
\end{tabular}




\begin{tabular}{|c|c|}
\hline & $\begin{array}{l}\text { e.g., partner argument is temporally related but partner may not be victim of } \\
\text { index offence; or physically related - as in part of the same theme) when } \\
\text { coding precipitating events. }\end{array}$ \\
\hline Intoxication & $\begin{array}{l}\text { Level of intoxication at time of offence. No = offender is not under influence of } \\
\text { substances. Moderate = under the influence but able to function and maintain } \\
\text { memory of events. Heavy = heavily intoxicated, noticeably impaired } \\
\text { physical/mental function or substance related memory loss. Insufficient detail = } \\
\text { there is insufficient detail to determine whether the offender is under the } \\
\text { influence of substances or not. }\end{array}$ \\
\hline $\begin{array}{l}\text { Indirect victim } \\
\text { provocation }\end{array}$ & $\begin{array}{l}\text { Incidents/events/situations that could be considered provoking but was not } \\
\text { directly addressed/ or happening to the offender himself. Eg. Victim is a gang } \\
\text { rival - even if gang rivalry consciously implicated in the offence. Members of } \\
\text { offender's family or friends have been threatened, assaulted, insulted or } \\
\text { otherwise treated badly. Victim pays some attention to offender's } \\
\text { partner/girlfriend -(can be as little as staring or can be an affair -NOTE - if } \\
\text { victim is offenders girlfriend/partner then an affair should be coded as Direct } \\
\text { victim provocation) }\end{array}$ \\
\hline $\begin{array}{l}\text { Direct victim } \\
\text { provocation }\end{array}$ & $\begin{array}{l}\text { Incidents/events/situations that could be considered provoking and were } \\
\text { directed at/towards the offender himself. None - no apparent direct } \\
\text { provocation. Low-level - mild provocation, can include non-verbal gestures, } \\
\text { staring, teasing; Insult offender - including victim infidelity; Threatens offender- } \\
\text { victim threatens to harm offender, can include hearing about the threat } \\
\text { through a third party; Assaults offender - victim actively assaults or tries to } \\
\text { assault offender (choosing this options means that none of the other } \\
\text { provocation choices occurred first) }\end{array}$ \\
\hline Family argument & $\begin{array}{l}\text { Was the offender involved in any arguments with family members in lead up to } \\
\text { offence? The argument need not be related to index offence - please note if } \\
\text { related or not. }\end{array}$ \\
\hline $\begin{array}{l}\text { Intimate partner } \\
\text { argument }\end{array}$ & $\begin{array}{l}\text { Was the offender involved in any arguments with romantic partner in the lead } \\
\text { up to the offence? The argument need not be related to the index offence - } \\
\text { please note if related or not }\end{array}$ \\
\hline $\begin{array}{l}\text { Opportunity for } \\
\text { material benefit }\end{array}$ & $\begin{array}{l}\text { Crime appears to result from offender taking advantage of recently acquired } \\
\text { knowledge (e.g. passes a shop and sees large sum of money placed in till which } \\
\text { initiates idea for a robbery) }\end{array}$ \\
\hline Gang related conflict & Conflict arising within or between gangs \\
\hline Proximal mood & $\begin{array}{l}\text { In part taken from Polaschek rape model, } 2001 \text { (positive, depressed, angry). In } \\
\text { the few hours preceding the offence was the offenders mood (note this is not } \\
\text { separate emotions) generally positive (happy, chilled, all good) generally } \\
\text { negative (angry, irritated, grumpy, depressed) or appeared neutral - neither } \\
\text { positve nor negative. This is not during the offence itself but in the lead up to } \\
\text { offending. Try to make a global judgement on what was the predominant } \\
\text { mood theme. Don't get too hung up on slight aberrations to the predominant } \\
\text { mood that may occur immediately prior to the offending. }\end{array}$ \\
\hline & \\
\hline GOAL SETTING & \\
\hline
\end{tabular}




\begin{tabular}{|c|c|}
\hline $\begin{array}{l}\text { No apparent } \\
\text { goal/accidental }\end{array}$ & No apparent motivation for the use of violence, or harm was accidental \\
\hline Defence & $\begin{array}{l}\text { Violence viewed as a means of defence either of themselves or of their } \\
\text { family/friends (Chambers thesis, p.109) For these purposes, a goal of defence is } \\
\text { valid if the offender or his family/friends are currently under threat/attack - as } \\
\text { opposed to using it as a preventative measure from as yet unidentified threats }\end{array}$ \\
\hline Reputation & $\begin{array}{l}\text { Violence used for gaining power/respect through development of a reputation - } \\
\text { also for bolstering an existing reputation (place violence to control here too. } \\
\text { Also violence to have people fear you as a pre-emptive form of defence is coded } \\
\text { here - chambers p.109) }\end{array}$ \\
\hline Retribution & $\begin{array}{l}\text { Violence as a punishment for perceived wrongs or norm violations against } \\
\text { others (e.g. assaulting a man for hitting a woman) }\end{array}$ \\
\hline Revenge & $\begin{array}{l}\text { Violence as a punishment for perceived personal wrongs (e.g. assualting partner } \\
\text { upon discovering their infidelity; violence as revenge for attack on a person who } \\
\text { is important/close to the offender) }\end{array}$ \\
\hline Material gain & Violence utilised for material gain, violence as a means to obtain tangible goods \\
\hline Sadism & Inflicting violence for personal pleasure/gratification \\
\hline $\begin{array}{l}\text { Thrill/sensation } \\
\text { seeking }\end{array}$ & $\begin{array}{l}\text { Violence used to counteract feelings of boredom or to provide feelings of } \\
\text { excitement (e.g. I did it just for the hell of it) }\end{array}$ \\
\hline Catharsis & Violence erupts as a means to release a build up of anger or frustration \\
\hline \multicolumn{2}{|l|}{$\begin{array}{l}\text { PLANNING/INSTANT } \\
\text { REACTION }\end{array}$} \\
\hline $\begin{array}{l}\text { Consideration of } \\
\text { consequences }\end{array}$ & $\begin{array}{l}\text { Degree to which offender considered the impact of offence upon } \\
\text { self/victim/family (e.g. losing job, prison recall, child access) }\end{array}$ \\
\hline Degree of planning & $\begin{array}{l}\text { Opportunistic- no planning (e.g. the shop's empty, let rob it - NOTE: would } \\
\text { become Basic planning if offenders then briefly detour to obtain weapons). } \\
\text { Basic planning- vague plan with few details (e.g. let's do a robbery tomorrow - } \\
\text { no role assignments, but may have gathered weapons). Moderate planning- } \\
\text { some evidence of planning beyond basic, but not clearly organised or thought } \\
\text { through. e.g. scene selection/casing, general role assignment. Elaborate - very } \\
\text { well planned, careful scene/victim selection and casing, detailed role } \\
\text { assignment, rehearsals- how we would plan! }\end{array}$ \\
\hline $\begin{array}{l}\text { Conscious } \\
\text { awareness of } \\
\text { intentions }\end{array}$ & $\begin{array}{l}\text { Degree to which offender appeared consciously aware of intention to commit } \\
\text { offence at outset of the offence (not necessarily extent). Aims to capture any } \\
\text { explicit planning. Some = some admission they were going to offend (but not } \\
\text { nec extent e.g. I was annoyed so was heading over to give them a hiding - but } \\
\text { ended up shooting them dead). Full awareness = evidence they knew the full } \\
\text { extent of the offence before it commenced (e.g. I thought I would kill her - and } \\
\text { did so. I intended to smash him cos he threatened me). NOTE: This is not the } \\
\text { same as 'degree of planning' as there need not be any planning of 'how' the } \\
\text { offence was going to be carried out. }\end{array}$ \\
\hline $\begin{array}{l}\text { Planned } \\
\text { opportunism }\end{array}$ & $\begin{array}{l}\text { Evidence to suggest that offender had rehearsed/considered how he might } \\
\text { conduct a similar type of crime prior to this offence (but it seems that this } \\
\text { specific offence was not planned and the offender 'happened upon' the } \\
\text { chance/opportunity to offend). There should be a cognitive element } \\
\text { (awareness) in the rehearsal for this offence. I'm trying to capture a level of }\end{array}$ \\
\hline
\end{tabular}




\begin{tabular}{|c|c|}
\hline & $\begin{array}{l}\text { implicit planning that goes beyond an offender in 'denial' of his true intentions - } \\
\text { this comes from Pithers 'planned impulsivity' with regard sex offending, where } \\
\text { sex offenders may fantasise about committing a sex offence but only commit it } \\
\text { if environmental conditions fall into place and there is little chance of } \\
\text { apprehension - or if they are disinhibted by drugs/emotions etc }\end{array}$ \\
\hline Weapon use & Did offender have a weapon to hand, and was it used in commission of offence \\
\hline Source of weapon & Where did the offender source the weapon \\
\hline Type of weapon & List the type of weapon(s) used \\
\hline Co-offenders & $\begin{array}{l}\text { Were there co-offenders involved in the offence that the offender was } \\
\text { committing i.e. were there a number of offenders committing the offence to try } \\
\text { to attain some shared goal. }\end{array}$ \\
\hline Role of offender & $\begin{array}{l}\text { Did the offender undertake a 'main' role or a 'secondary' role during the offence } \\
\text { (e.g. main - had gun and demanded money from bank teller vs. secondary - was } \\
\text { look out stood outside bank) }\end{array}$ \\
\hline Number of victims & How many victims were involved in the index offence \\
\hline $\begin{array}{l}\text { Victim/offender } \\
\text { relationship }\end{array}$ & $\begin{array}{l}\text { Very close relationship - immediate family, romantic partner. Close relationship } \\
\text { - friend, relative, dating partner. Specific relationship - teacher, employer, } \\
\text { babysitter. Acquaintance/other. Stranger }\end{array}$ \\
\hline Emotional arousal & $\begin{array}{l}\text { Judgement based on how offender was feeling immediately before and during } \\
\text { the offence. E.g. low - I felt cool about it, calm. Moderate - I was pretty } \\
\text { annoyed, feeling excited, nervous. High - I was very angry/adrenalines } \\
\text { rush/panicky }\end{array}$ \\
\hline $\begin{array}{l}\text { VIOLENCE } \\
\text { ENACTMENTS }\end{array}$ & $\begin{array}{l}\text { Extent to which the violence enacted was disinhibited (out of control, 'seeing } \\
\text { red') vs. strategic (offender used strategic level of violence in order to achieve } \\
\text { their goal - did not become completely disinhibited). Coding - make judgement } \\
\text { on info that is specific to the offence. }\end{array}$ \\
\hline Level of violence & $\begin{array}{l}\text { As per Ross-oxnam, based on Cornell. No injuries along a scale resulting in fatal } \\
\text { level of violence. }\end{array}$ \\
\hline $\begin{array}{l}\text { Victim reaction } \\
\text { (level of resistance) }\end{array}$ & $\begin{array}{l}\text { As per Ross-Oxnam. Aim is to ascertain how victim reacted during the offence - } \\
\text { from compliant to strong reaction along a scale. }\end{array}$ \\
\hline $\begin{array}{l}\text { Level of self-control } \\
\text { (during infliction of } \\
\text { violence) }\end{array}$ & $\begin{array}{l}\text { To what extent could the offender control himself during the infliction of } \\
\text { violence? Lost control= seeing red, unable to stop. Some control= violence has } \\
\text { elements of disinhibition but offender demonstrates some control and is able to } \\
\text { stop. Full control = violence inflicted is measured and offender remains } \\
\text { controlled throughout }\end{array}$ \\
\hline $\begin{array}{l}\text { Emotions identified } \\
\text { immediately prior, } \\
\text { during and } \\
\text { immediately after } \\
\text { offence }\end{array}$ & List any emotions - where possible separate to before/during/after \\
\hline Offence duration & $\begin{array}{l}\text { Short = anything less than } 30 \text { mins. Longer = over } 30 \text { mins. If a duration can } \\
\text { deduced then please include that detail. }\end{array}$ \\
\hline Evaluations later & $\begin{array}{l}\text { Satisfied with the outcome even if that was not their original goal. Dissatisfied - } \\
\text {-ve feelings about the violent offence- violence has no utility }\end{array}$ \\
\hline
\end{tabular}




\begin{tabular}{|c|c|}
\hline $\begin{array}{l}\text { Feelings towards } \\
\text { outcome (soon after } \\
\text { offence) }\end{array}$ & $\begin{array}{l}\text { How did offender appear to feel about the offence soon after it occurred and } \\
\text { what was achieved or not achieved by the offence. Generally satisfied = it was } \\
\text { worth it / or I feel better / or they deserved it. Ambivalent = not bothered } \\
\text { either way / don't feel any different/ not really sure why I did it. Generally } \\
\text { dissatisfied = not worth it, wish I hadn't done it / or generally feel bad/worse. } \\
\text { Trying to get a general feel for what the offender felt had been achieved/not } \\
\text { achieved by the offence, not too specific as that should be covered by 'thoughts } \\
\text { about the offence' }\end{array}$ \\
\hline $\begin{array}{l}\text { Feelings towards } \\
\text { outcome (at a later } \\
\text { date) }\end{array}$ & As above apart from these are feeling at some (unspecified) later date \\
\hline $\begin{array}{l}\text { Regret (own } \\
\text { outcome) }\end{array}$ & $\begin{array}{l}\text { Does offender regret how his circumstances have turned out (including how his } \\
\text { family may have been affected). Some = it's not great but could have been } \\
\text { worse. Considerable regret = can't believe I have been so stupid/I've let my } \\
\text { family down. }\end{array}$ \\
\hline $\begin{array}{l}\text { Guilt/remorse (for } \\
\text { victim) }\end{array}$ & $\begin{array}{l}\text { Level of remorse the offender demonstrates for victim (and/or victims family). } \\
\text { Some = I feel a bit sorry about what I did to him. Considerable = I'm very sorry } \\
\text { that I did that to her. Note: Code for any mention of remorse even if it is mixed } \\
\text { in with other thoughts/emotions e.g." he deserved it, I'm pleased I did it and } \\
\text { wouldn't change anything, but I have felt a bit bad about it at times" - this } \\
\text { would be coded as some remorse. }\end{array}$ \\
\hline $\begin{array}{l}\text { Thoughts about } \\
\text { offence (after } \\
\text { commission) }\end{array}$ & $\begin{array}{l}\text { Trying to ascertain the offenders processing of the event and how it is affecting } \\
\text { their functioning. Useful to think of this in terms of thoughts between offence } \\
\text { and apprehension where that info is available (so in the immediate hours - } \\
\text { week between commission and apprehension). No thoughts/unconcerned - } \\
\text { offender unconcerned and life continues as normal. Slightly preoccupied - } \\
\text { offender continuing as normal but it is a bit of an effort or they are mildly } \\
\text { concerned about things. Preoccupied, can't concentrate - it is an effort to } \\
\text { continue/function as normal, may include being on the run if they are still } \\
\text { functioning e.g. "it took me a few days to return to myself". Worried, panicky, } \\
\text { totally preoccupied - offender not functioning well, is highly } \\
\text { anxious/depressed. May have blacked out the days surrounding the offence. }\end{array}$ \\
\hline $\begin{array}{l}\text { Circumstances of } \\
\text { capture }\end{array}$ & $\begin{array}{l}\text { How was offender apprehended for the offence? E.g. arrested at scene. } \\
\text { Arrested a week later. Did he go quietly or resist? May not be any detail but } \\
\text { note it if there is. }\end{array}$ \\
\hline
\end{tabular}


Appendix D

Breakdown of qualitative emotion data

Watson and Tellegen's (1985, p.221) Two-Factor Structure of Affect

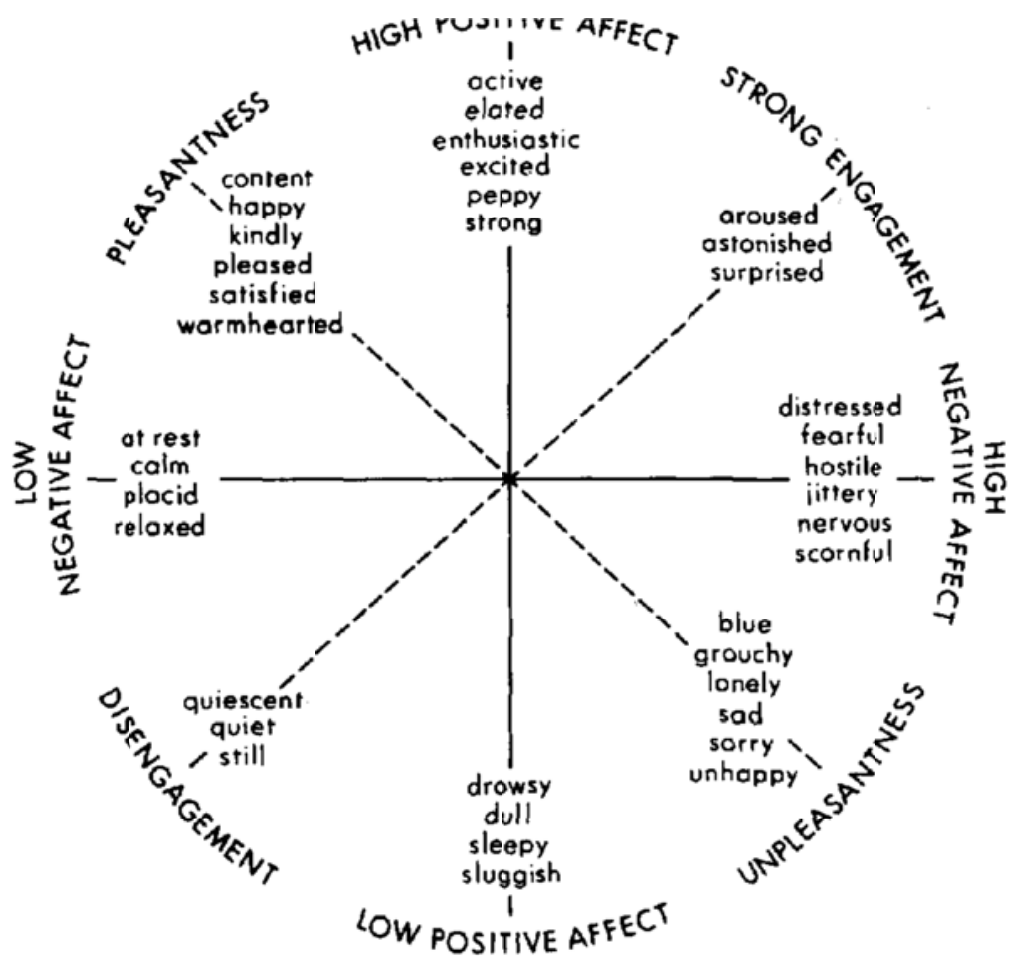

Figure 1. The two-factor structure of affect.

Watson and Tellegen propose a two dimensional configuration of self-reported mood - their results strongly attest to the stability and robustness of positive and negative affect in self-report (p.219).

According to Watson and Tellegen (1985) the high affect end of the continuum reflects a level of emotional arousal, and the low affect end of the continuum reflects a lack of arousal. Each end of the pleasantness and engagement dimensions reflects a mixture of the affect style it is sandwiched between (e.g., pleasantness reflects a mixture of high positive affect and low negative affect) (Watson \& Tellegen, 1985). 
A summary of the qualitative emotion data reported in the offence narratives and how that data was categorized in the present study

\begin{tabular}{|c|c|c|c|c|c|c|c|}
\hline $\begin{array}{l}\text { High positive } \\
\text { affect } \\
1\end{array}$ & $\begin{array}{l}\text { Low } \\
\text { positive } \\
\text { affect } \\
2\end{array}$ & $\begin{array}{l}\text { High negative } \\
\text { affect } \\
3\end{array}$ & $\begin{array}{l}\text { Low } \\
\text { negative } \\
\text { affect } \\
4\end{array}$ & $\begin{array}{l}\text { Pleasantness } \\
5\end{array}$ & $\begin{array}{l}\text { Unpleasantness } \\
6\end{array}$ & $\begin{array}{l}\text { Strong } \\
\text { engagement } \\
7\end{array}$ & $\begin{array}{l}\text { Disengagement } \\
8\end{array}$ \\
\hline $\begin{array}{l}\text { Amused/funny } \\
\text { Adrenaline } \\
\text { excited } \\
\text { hyped } \\
\text { jubilant } \\
\text { thrilled } \\
\text { joy }\end{array}$ & tired & $\begin{array}{l}\text { Nervous } \\
\text { Anxious } \\
\text { tense } \\
\text { worried } \\
\text { agitated } \\
\text { Angry } \\
\text { Rage } \\
\text { Fearful/scared } \\
\text { Freaked out/ } \\
\text { shock } \\
\text { panic } \\
\text { annoyed } \\
\text { paranoid } \\
\text { confused } \\
\text { frustrated } \\
\text { stressed } \\
\text { hatred } \\
\text { resentment } \\
\text { devastated }\end{array}$ & $\begin{array}{l}\text { relaxed } \\
\text { calm }\end{array}$ & $\begin{array}{l}\text { satisfied } \\
\text { Feeling good } \\
\text { happy } \\
\text { relief } \\
\text { pleased } \\
\text { pleasure }\end{array}$ & $\begin{array}{l}\text { Felt bad } \\
\text { crappy } \\
\text { Bummed out } \\
\text { guilt } \\
\text { desperate } \\
\text { hunger } \\
\text { disappointed } \\
\text { shame } \\
\text { dejected } \\
\text { misery } \\
\text { remorse } \\
\text { hurt } \\
\text { jealous } \\
\text { betrayed } \\
\text { disgusted } \\
\text { pain } \\
\text { sad } \\
\text { lonely } \\
\text { gutted } \\
\text { sick } \\
\text { withdrawn }\end{array}$ & surprise & quiet \\
\hline
\end{tabular}




\section{Appendix E}

Cluster analysis re-coding sheet

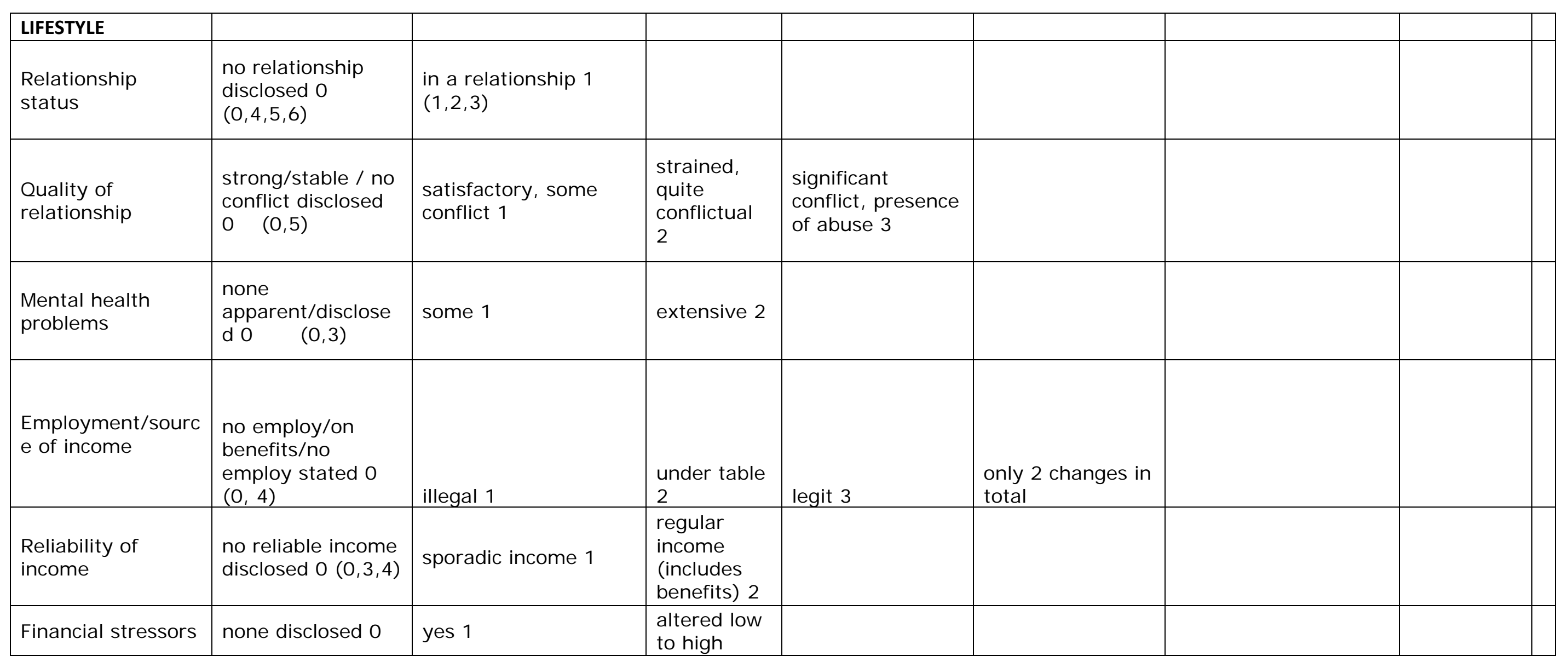




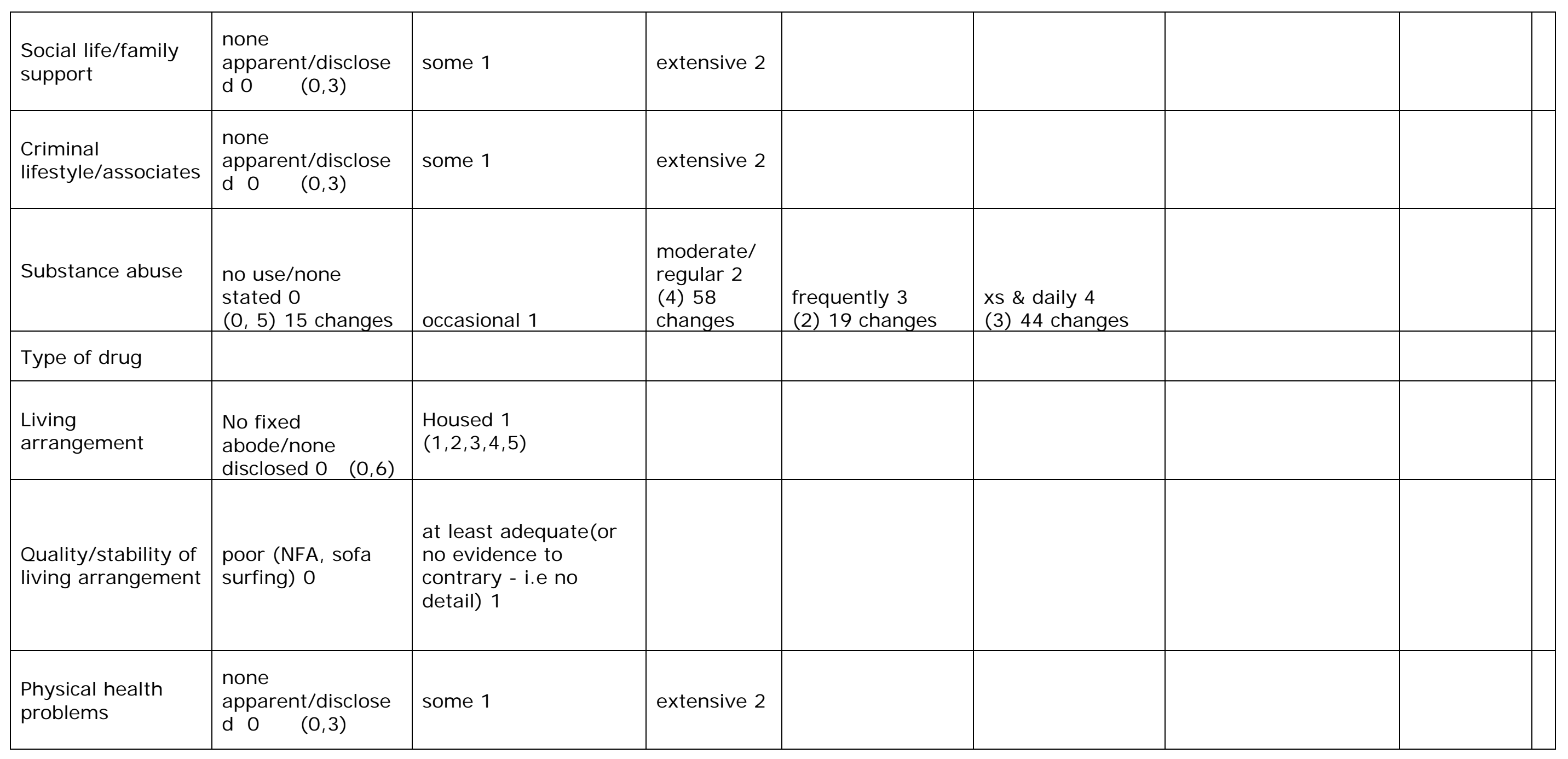




\begin{tabular}{|c|c|c|c|c|c|c|c|}
\hline Gang activity & yes 0 & $\begin{array}{l}\text { none } \\
\text { disclosed/apparent } 1 \\
(1,2)\end{array}$ & & $\begin{array}{l}\text { none } \\
\text { disclosed/appare } \\
\text { nt } 0\end{array}$ & yes 1 & altered low to high & \\
\hline \multicolumn{8}{|l|}{ COPING STRATEGIES } \\
\hline $\begin{array}{l}\text { Increased } \\
\text { substance use }\end{array}$ & yes 0 & $\begin{array}{l}\text { none apparent } 1 \\
(1,2)\end{array}$ & & $\begin{array}{l}\text { none apparent } 0 \\
(1,2)\end{array}$ & yes 1 & altered low to high & \\
\hline $\begin{array}{l}\text { Rumination over } \\
\text { grievances }\end{array}$ & none apparent 0 & some 1 & extensive 2 & & & & \\
\hline Help seeking & yes 0 & none apparent 1 & & none apparent 0 & yes 1 & altered low to high & \\
\hline $\begin{array}{l}\text { Attempts conflict } \\
\text { resolution }\end{array}$ & $\begin{array}{l}\text { none } \\
\text { apparent/disclose } \\
\text { d } 0\end{array}$ & some effort 1 & $\begin{array}{l}\text { considerabl } \\
\text { e effort } 2\end{array}$ & & & & \\
\hline $\begin{array}{l}\text { Conflict avoidance } \\
\text { strategies }\end{array}$ & $\begin{array}{l}\text { none } \\
\text { apparent/disclose } \\
\text { d } 0\end{array}$ & some effort 1 & $\begin{array}{l}\text { considerabl } \\
\text { e effort } 2\end{array}$ & & & & \\
\hline \multicolumn{8}{|l|}{$\begin{array}{l}\text { PRECIPITATING } \\
\text { EVENTS }\end{array}$} \\
\hline Intoxication & $\begin{array}{l}\text { none } \\
\text { apparent/disclose } \\
\text { d } 0 \quad(0,3)\end{array}$ & moderate 1 & heavy 2 & & $\begin{array}{l}\text { none } \\
\text { apparent/disclose } \\
\text { d } 0\end{array}$ & yes 0 & \\
\hline $\begin{array}{l}\text { Indirect victim } \\
\text { provocation }\end{array}$ & $\begin{array}{l}\text { yes } 0 \\
(0,1,2)\end{array}$ & no 1 & & $\begin{array}{l}\text { no } 0 \\
\text { (3) }\end{array}$ & $\begin{array}{l}\text { yes } 1 \\
(0,1,2)\end{array}$ & altered low to high & \\
\hline
\end{tabular}




\begin{tabular}{|c|c|c|c|c|c|c|c|}
\hline $\begin{array}{l}\text { Direct victim } \\
\text { provocation }\end{array}$ & none apparent 0 & $\begin{array}{l}\text { low level (can include } \\
\text { non-verbal gestures } \\
\text { e.g. staring, teasing) } \\
1\end{array}$ & $\begin{array}{l}\text { insults } \\
\text { offender } \\
\text { (includes } \\
\text { victim } \\
\text { infidelity) } 2\end{array}$ & $\begin{array}{l}\text { threatens } \\
\text { offender } 3\end{array}$ & $\begin{array}{l}\text { assaults offender } \\
4\end{array}$ & & \\
\hline Family argument & yes 0 & no 1 & & no 0 & yes 1 & altered low to high & \\
\hline $\begin{array}{l}\text { Intimate partner } \\
\text { argument }\end{array}$ & yes 0 & no 1 & & no 0 & yes 1 & altered low to high & \\
\hline $\begin{array}{l}\text { Opportunity for } \\
\text { material benefit }\end{array}$ & yes 0 & no 1 & & no 0 & yes 1 & altered low to high & \\
\hline $\begin{array}{l}\text { Gang related } \\
\text { conflict }\end{array}$ & yes 0 & no 1 & & no 0 & yes 1 & altered low to high & \\
\hline Proximal mood & positive 0 & $\begin{array}{l}\text { neutral/none } \\
\text { apparent } 1 \\
(1,3)\end{array}$ & negative 2 & & negative 0 & $\begin{array}{l}\text { neutral/none } \\
\text { apparent } 1 \\
(1,3)\end{array}$ & positive 2 \\
\hline & & & 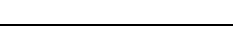 & & & & \\
\hline GOAL SETTING - & & & & & & & \\
\hline $\begin{array}{l}\text { No apparent } \\
\text { goal/accidental }\end{array}$ & not present 0 & present 1 & & & & & \\
\hline Defence & not present 0 & present 1 & & & & & \\
\hline
\end{tabular}




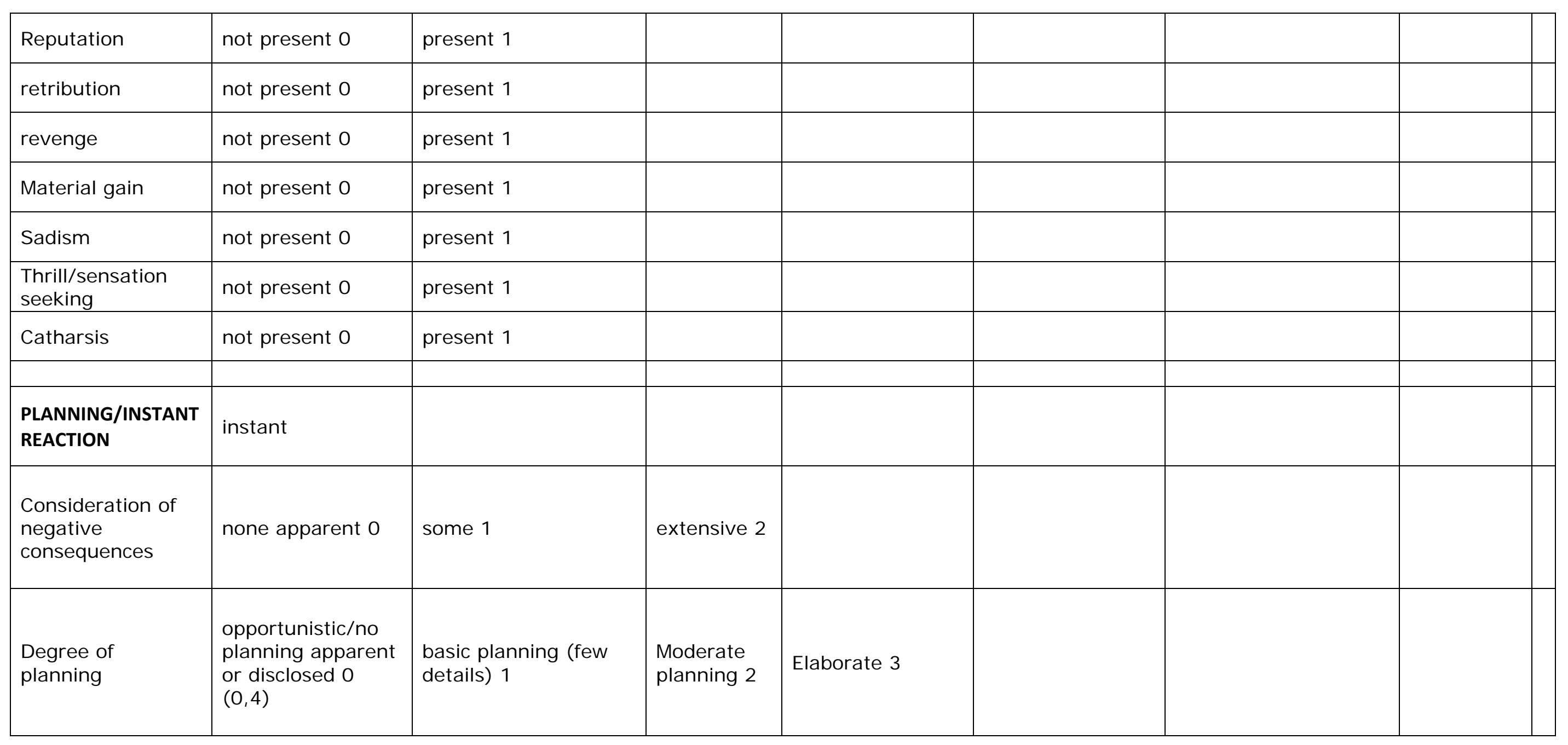




\begin{tabular}{|c|c|c|c|c|c|c|c|}
\hline $\begin{array}{l}\text { Conscious } \\
\text { awareness of } \\
\text { intentions }\end{array}$ & $\begin{array}{l}\text { none } \\
\text { apparent/disclose } \\
\text { d } 0\end{array}$ & some 1 & $\begin{array}{l}\text { full } \\
\text { awareness } \\
2\end{array}$ & & & & \\
\hline $\begin{array}{l}\text { Planned } \\
\text { opportunism }\end{array}$ & no 0 & yes 1 & & & & & \\
\hline Weapon use & yes 0 & $\begin{array}{l}\text { none } \\
\text { apparent/disclosed } 1 \\
(1,2)\end{array}$ & & $\begin{array}{l}\text { none } \\
\text { apparent/disclose } \\
\text { d } 0 \quad(1,2)\end{array}$ & yes1 & altered low to high & \\
\hline Source of weapon & found at scene & taken from victim(s) & $\begin{array}{l}\text { taken to } \\
\text { scene by } \\
\text { offender(s) }\end{array}$ & insufficient detail & & $\begin{array}{l}\text { found at scene/not } \\
\text { disclosed } 0 \\
(0,1,3)\end{array}$ & $\begin{array}{l}\text { taken to } \\
\text { scene } 1 \\
\text { (2) }\end{array}$ \\
\hline \multicolumn{8}{|l|}{ Type of weapon } \\
\hline Co-offenders & yes 0 & $\begin{array}{l}\text { none } \\
\text { apparent/disclosed } 1\end{array}$ & & $\begin{array}{l}\text { none } \\
\text { apparent/disclose } \\
\text { d } 0\end{array}$ & yes1 & altered low to high & \\
\hline \multicolumn{8}{|l|}{ Number of victims } \\
\hline $\begin{array}{l}\text { Victim/offender } \\
\text { relationship }\end{array}$ & $\begin{array}{l}\text { close } 0 \\
(0,1)\end{array}$ & known $1 \quad(2,3)$ & $\begin{array}{l}\text { unknown } 2 \\
\text { (4) }\end{array}$ & & unknown 0 & known 1 & $\begin{array}{l}\text { close } 2 \\
(0,1)\end{array}$ \\
\hline Emotional arousal & $\begin{array}{l}\text { low (none } \\
\text { apparent/disclose } \\
\text { d) } 0\end{array}$ & moderate 1 & high 2 & & & & \\
\hline & & & & & & & \\
\hline
\end{tabular}




\begin{tabular}{|c|c|c|c|c|c|c|c|}
\hline $\begin{array}{l}\text { VIOLENCE } \\
\text { ENACTMENTS }\end{array}$ & & & & & & & \\
\hline Level of violence & $\begin{array}{l}\text { no injuries or } \\
\text { threats } 0\end{array}$ & $\begin{array}{l}\text { threat but no physical } \\
\text { assault } 1\end{array}$ & $\begin{array}{l}\text { assault, no } \\
\text { injury } 2\end{array}$ & $\begin{array}{l}\text { minor injury (eg } \\
\text { bruises, small } \\
\text { cuts) } 3\end{array}$ & $\begin{array}{l}\text { moderate injury } \\
\text { (larger cuts \& } \\
\text { wounds, severe } \\
\text { bruising) } 4\end{array}$ & $\begin{array}{l}\text { serious injury (eg } \\
\text { broken limb, gunshot } \\
\text { wound) } 5\end{array}$ & $\begin{array}{l}\text { severe } \\
\text { injury (eg } \\
\text { life- } \\
\text { threatening } \\
\text { injury or } \\
\text { lasting } \\
\text { impairment } \\
\text { ) } 6\end{array}$ \\
\hline $\begin{array}{l}\text { Victim reaction } \\
\text { (level of } \\
\text { resistance) }\end{array}$ & $\begin{array}{l}\text { compliant/no } \\
\text { resistance } \\
\text { disclosed } 0 \quad(0,4)\end{array}$ & $\begin{array}{l}\text { overtly compliant, } \\
\text { covert reaction (eg } \\
\text { pushes alarm button) } \\
1\end{array}$ & $\begin{array}{l}\text { overt action } \\
\text { (eg scream, } \\
\text { run away) } \\
2\end{array}$ & $\begin{array}{l}\text { strong reaction } \\
\text { (eg fighting back, } \\
\text { defending others) } \\
3\end{array}$ & & & \\
\hline
\end{tabular}




\begin{tabular}{|c|c|c|c|c|c|c|}
\hline $\begin{array}{l}\text { Emotions } \\
\text { identified } \\
\text { immediately prior, } \\
\text { during and } \\
\text { immediately after } \\
\text { offence }\end{array}$ & & & & & & \\
\hline Offence duration & short 0 & longer 1 & & & & \\
\hline \multicolumn{7}{|l|}{ ACHIEVEMENTS } \\
\hline $\begin{array}{l}\text { Feelings towards } \\
\text { outcome (soon } \\
\text { after offence) }\end{array}$ & $\begin{array}{l}\text { generally } \\
\text { satisfied, worth it } \\
0\end{array}$ & $\begin{array}{l}\text { ambivalent/undisclose } \\
\text { d } 1 \\
(1,3)\end{array}$ & $\begin{array}{l}\text { generally } \\
\text { dissatisfied } \\
2\end{array}$ & $\begin{array}{l}\text { generally } \\
\text { dissatisfied } 0 \\
\text { (2) }\end{array}$ & $\begin{array}{l}\text { ambivalent/undisclose } \\
\text { d } 1 \\
(1,3)\end{array}$ & $\begin{array}{l}\text { generally } \\
\text { satisfied, } \\
\text { worth it } 2 \\
\text { (0) }\end{array}$ \\
\hline $\begin{array}{l}\text { Feelings towards } \\
\text { outcome (at a } \\
\text { later date) }\end{array}$ & $\begin{array}{l}\text { generally } \\
\text { satisfied, worth it } \\
0\end{array}$ & $\begin{array}{l}\text { ambivalent/undisclose } \\
\text { d } 1 \\
(1,3)\end{array}$ & $\begin{array}{l}\text { generally } \\
\text { dissatisfied } \\
2\end{array}$ & $\begin{array}{l}\text { generally } \\
\text { dissatisfied } 0 \\
\text { (2) }\end{array}$ & $\begin{array}{l}\text { ambivalent/undisclose } \\
\text { d } 1 \\
(1,3)\end{array}$ & $\begin{array}{l}\text { generally } \\
\text { satisfied, } \\
\text { worth it } 2 \\
\text { (0) }\end{array}$ \\
\hline $\begin{array}{l}\text { Regret (own } \\
\text { outcome) }\end{array}$ & $\begin{array}{l}\text { no regret/no } \\
\text { regret disclosed } 0 \\
(0,3)\end{array}$ & some regret 1 & $\begin{array}{l}\text { considerabl } \\
\text { e regret } 2\end{array}$ & & & \\
\hline
\end{tabular}




\begin{tabular}{|l|l|l|l|l|l|l|}
\hline $\begin{array}{l}\text { Guilt/remorse (for } \\
\text { victim) }\end{array}$ & $\begin{array}{l}\text { no remorse/none } \\
\text { disclosed 0 } \\
(0,3)\end{array}$ & some remorse 1 & $\begin{array}{l}\text { considerabl } \\
\text { e remorse } \\
2\end{array}$ & & & \\
\hline $\begin{array}{l}\text { Thoughts about } \\
\text { offence (after } \\
\text { commission) }\end{array}$ & $\begin{array}{l}\text { no thoughts, } \\
\text { unconcerned/none } \\
\text { disclosed 0 (0,4) }\end{array}$ & $\begin{array}{l}\text { slightly preoccupied } \\
\text { by offence 1 }\end{array}$ & $\begin{array}{l}\text { preoccupied } \\
\text { can't } \\
\text { concentrate } \\
2\end{array}$ & $\begin{array}{l}\text { worried, panicky } \\
\text { - totally } \\
\text { preoccupied by } \\
\text { offence 3 }\end{array}$ & & \\
\hline $\begin{array}{l}\text { Circumstances of } \\
\text { capture }\end{array}$ & & & & \\
\hline
\end{tabular}


Appendix F

Cluster analysis SPSS solutions of each phase showing differences between characteristics

Lifestyle and coping

ANOVA

\begin{tabular}{|c|c|c|c|c|c|c|}
\hline & \multicolumn{2}{|c|}{ Cluster } & \multicolumn{2}{|c|}{ Error } & \multirow[b]{2}{*}{$\mathrm{F}$} & \multirow[b]{2}{*}{ Sig. } \\
\hline & $\begin{array}{l}\text { Mean } \\
\text { Square }\end{array}$ & df & $\begin{array}{l}\text { Mean } \\
\text { Square }\end{array}$ & df & & \\
\hline $\begin{array}{l}\text { Zscore: Relship } \\
\text { status }\end{array}$ & 4.761 & 1 & .990 & 148 & 4.810 & .030 \\
\hline $\begin{array}{l}\text { Zscore: mental } \\
\text { health }\end{array}$ & 2.175 & 1 & 1.021 & 148 & 2.130 & .147 \\
\hline $\begin{array}{l}\text { Zscore: employ } \\
\text { source }\end{array}$ & 65.843 & 1 & .574 & 148 & 114.662 & .000 \\
\hline $\begin{array}{l}\text { Zscore: reliability } \\
\text { income }\end{array}$ & 17.887 & 1 & .878 & 148 & 20.366 & .000 \\
\hline $\begin{array}{l}\text { Zscore: Financial } \\
\text { stress }\end{array}$ & .713 & 1 & 1.006 & 148 & .708 & .401 \\
\hline Zscore(support) & 10.587 & 1 & .951 & 148 & 11.134 & .001 \\
\hline Zscore: crim lifestyle & 58.411 & 1 & .625 & 148 & 93.500 & .000 \\
\hline Zscore: sub abuse & 15.327 & 1 & .919 & 148 & 16.673 & .000 \\
\hline $\begin{array}{l}\text { Zscore: liv } \\
\text { arrangement }\end{array}$ & 2.529 & 1 & 1.016 & 148 & 2.489 & .117 \\
\hline $\begin{array}{l}\text { Zscore: qual/stability } \\
\text { of liv }\end{array}$ & 14.223 & 1 & .938 & 148 & 15.156 & .000 \\
\hline Zscore: gang activity & 4.948 & 1 & .970 & 148 & 5.102 & .025 \\
\hline $\begin{array}{l}\text { Zscore: increased } \\
\text { sub use }\end{array}$ & .650 & 1 & .999 & 148 & .651 & .421 \\
\hline Zscore(rumination) & 22.582 & 1 & .843 & 148 & 26.784 & .000 \\
\hline Zscore: help seeking & .005 & 1 & 1.037 & 148 & .004 & .947 \\
\hline Zscore: conflict avoid & 4.442 & 1 & .941 & 148 & 4.722 & .031 \\
\hline
\end{tabular}


Precipitating events and goals

ANOVA

\begin{tabular}{|c|c|c|c|c|c|c|}
\hline & \multicolumn{2}{|c|}{ Cluster } & \multicolumn{2}{|c|}{ Error } & \multirow[b]{2}{*}{$\mathrm{F}$} & \multirow[b]{2}{*}{ Sig. } \\
\hline & $\begin{array}{l}\text { Mean } \\
\text { Square }\end{array}$ & df & $\begin{array}{l}\text { Mean } \\
\text { Square }\end{array}$ & df & & \\
\hline Zscore(intoxication) & .018 & 1 & 1.017 & 148 & .018 & .893 \\
\hline $\begin{array}{l}\text { Zscore: collapsed } \\
\text { indirect prov }\end{array}$ & 48.195 & 1 & .706 & 148 & 68.244 & .000 \\
\hline Zscore: direct prov & 42.878 & 1 & .733 & 148 & 58.475 & .000 \\
\hline $\begin{array}{l}\text { Zscore: fam } \\
\text { argument }\end{array}$ & 1.032 & 1 & 1.032 & 148 & 1.000 & .319 \\
\hline $\begin{array}{l}\text { Zscore: partner } \\
\text { argument }\end{array}$ & 4.931 & 1 & .946 & 148 & 5.212 & .024 \\
\hline $\begin{array}{l}\text { Zscore: gang } \\
\text { related }\end{array}$ & 22.269 & 1 & .888 & 148 & 25.073 & .000 \\
\hline $\begin{array}{l}\text { Zscore: proximal } \\
\text { mood }\end{array}$ & 14.270 & 1 & .926 & 148 & 15.405 & .000 \\
\hline Zscore(defence) & 65.266 & 1 & .591 & 148 & 110.522 & .000 \\
\hline Zscore(reputation) & 6.444 & 1 & .967 & 148 & 6.665 & .011 \\
\hline Zscore(retribution) & 7.658 & 1 & .986 & 148 & 7.765 & .006 \\
\hline Zscore(revenge) & .613 & 1 & .995 & 148 & .616 & .434 \\
\hline $\begin{array}{l}\text { Zscore: material } \\
\text { gain }\end{array}$ & 39.730 & 1 & .739 & 148 & 53.784 & .000 \\
\hline $\begin{array}{l}\text { Zscore: thrill } \\
\text { seeking }\end{array}$ & 4.268 & 1 & 1.009 & 148 & 4.229 & .042 \\
\hline Zscore(catharsis) & 11.786 & 1 & .918 & 148 & 12.837 & .000 \\
\hline
\end{tabular}


Planning

Initial Cluster Centers

\begin{tabular}{|l|r|r|}
\hline \multirow{2}{*}{} & \multicolumn{2}{|c|}{ Cluster } \\
\cline { 2 - 3 } & \multicolumn{1}{|c|}{1} & \multicolumn{1}{c|}{2} \\
\hline Zscore: consequences & 3.87361 & -.47718 \\
consider & & \\
Zscore: planning degree & 1.41387 & -.90517 \\
Zscore: aware of & .68105 & -1.92544 \\
intentions & & \\
Zscore: weapon use & .77475 & -1.28235 \\
Zscore: co-offenders & 1.14235 & 1.14235 \\
Zscore: offender role & -.26176 & 3.79558 \\
Zscore: vic/off relship & -.98501 & -.98501 \\
Zscore(arousal) & 1.01774 & -1.65599 \\
\hline
\end{tabular}

Violence enactments

ANOVA

\begin{tabular}{|l|r|r|r|r|r|r|}
\hline & \multicolumn{2}{|c|}{ Cluster } & \multicolumn{2}{c|}{ Error } & \\
\cline { 2 - 6 } & \multicolumn{1}{|c|}{$\begin{array}{c}\text { Mean } \\
\text { Square }\end{array}$} & df & \multicolumn{1}{c|}{$\begin{array}{c}\text { Mean } \\
\text { Square }\end{array}$} & \multicolumn{1}{c|}{ df } & \multicolumn{1}{c|}{$\mathrm{F}$} & Sig. \\
\hline $\begin{array}{l}\text { Zscore: level } \\
\text { violence }\end{array}$ & 25.432 & 1 & .792 & 148 & 32.116 & .000 \\
$\begin{array}{l}\text { Zscore: victim } \\
\text { reaction }\end{array}$ & 1.784 & 1 & .996 & 148 & 1.792 & .183 \\
$\begin{array}{l}\text { Zscore: self- } \\
\text { control }\end{array}$ & 94.592 & 1 & .338 & 148 & 280.21 & .000 \\
$\begin{array}{l}\text { Zscore: offence } \\
\text { duration }\end{array}$ & 23.701 & 1 & .877 & 148 & 27.026 & .000 \\
\hline
\end{tabular}


Evaluations

ANOVA

\begin{tabular}{|l|r|r|r|r|r|r|}
\hline & \multicolumn{2}{|c|}{ Cluster } & \multicolumn{2}{c|}{ Error } & \\
\cline { 2 - 6 } & $\begin{array}{c}\text { Mean } \\
\text { Square }\end{array}$ & df & $\begin{array}{c}\text { Mean } \\
\text { Square }\end{array}$ & \multicolumn{1}{c|}{$\mathrm{df}$} & \multicolumn{1}{c|}{$\mathrm{F}$} & Sig. \\
\hline $\begin{array}{l}\text { Zscore: feeling } \\
\text { outcome }\end{array}$ & 58.289 & 1 & .635 & 148 & 91.80 & .000 \\
$\begin{array}{l}\text { Zscore: feeling } \\
\text { later date }\end{array}$ & 24.715 & 1 & .849 & 148 & 29.10 & .000 \\
$\begin{array}{l}\text { Zscore: regret } \\
\text { (own o/c) }\end{array}$ & 11.796 & 1 & .909 & 148 & 12.97 & .000 \\
$\begin{array}{l}\text { Zscore: remorse } \\
\text { (for vic) }\end{array}$ & 54.217 & 1 & .651 & 148 & 83.31 & .000 \\
Zscore: thoughts & 49.570 & 1 & .668 & 148 & 74.17 & .000 \\
\hline
\end{tabular}

